\title{
Direct Determination of the Dynamic Elastic Modulus and Poisson's Ratio of Timoshenko Prisms and Rods
}

\author{
Guadalupe Leon \\ West Virginia University, gleon@mix.wvu.edu
}

Follow this and additional works at: https://researchrepository.wvu.edu/etd

Part of the Civil Engineering Commons, and the Structural Engineering Commons

\section{Recommended Citation \\ Leon, Guadalupe, "Direct Determination of the Dynamic Elastic Modulus and Poisson's Ratio of Timoshenko Prisms and Rods" (2019). Graduate Theses, Dissertations, and Problem Reports. 7482. https://researchrepository.wvu.edu/etd/7482}

This Thesis is protected by copyright and/or related rights. It has been brought to you by the The Research Repository @ WVU with permission from the rights-holder(s). You are free to use this Thesis in any way that is permitted by the copyright and related rights legislation that applies to your use. For other uses you must obtain permission from the rights-holder(s) directly, unless additional rights are indicated by a Creative Commons license in the record and/ or on the work itself. This Thesis has been accepted for inclusion in WVU Graduate Theses, Dissertations, and Problem Reports collection by an authorized administrator of The Research Repository @ WVU. For more information, please contact researchrepository@mail.wvu.edu. 
Direct Determination of the Dynamic Elastic Modulus and Poisson's Ratio of Timoshenko Prisms and Rods

Guadalupe Leon

Thesis submitted

to the Benjamin M. Statler College of Engineering and Mineral Resources at West Virginia University

in partial fulfillment of the requirements for the degree of

Master of Science

in

Civil and Environmental Engineering

Roger H.L. Chen, Ph.D., Chair

P.V. Vijay, Ph.D.

Karl E. Barth, Ph.D.

Department of Civil and Environmental Engineering

Morgantown, West Virginia

2019

Keywords: Timoshenko beam; Elastic Modulus; Poisson's Ratio; Non-Destructive Testing 


\begin{abstract}
Direct Determination of the Dynamic Elastic Modulus and Poisson's Ratio of Timoshenko Prisms and Rods
\end{abstract}

\title{
Guadalupe Leon
}

In this study, the exact solution of the Timoshenko beam vibration frequency equation under freefree boundary conditions was determined with an accurate shear shape factor. The exact solution was compared with a 3-D finite element calculation using ABAQUS program, and the difference between the exact solution and the 3-D FEM was within $0.15 \%$ for both the transverse and torsional modes. Furthermore, relationships between the resonance frequencies and Poisson's ratio were proposed that can directly determine the elastic constants, unlike the equations provided by ASTM C215. The frequency ratio between the $1^{\text {st }}$ bending mode and the $1^{\text {st }}$ torsional mode, or the frequency ratio between the $1^{\text {st }}$ bending mode and the $2^{\text {nd }}$ bending mode for any rectangular prism or rod can be directly estimated. Likewise, the bending and torsional modes can be used to determine the elastic constants of any rectangular prism or rod. The proposed equations were used to verify the elastic constants of a steel rod and prism with less than $0.36 \%$ error. The transverse and torsional frequencies of concrete, aluminum and steel rods were tested. Rectangular concrete beam specimens with three different mix designs were produced, and the transverse and torsional frequencies of these beams were tested. Results show that using the equations proposed in this study, the Young's modulus and Poisson's ratio of a Timoshenko prism and rod can be determined more directly than those obtained from ASTM C215 and with excellent accuracy. 


\section{ACKNOWLEDGEMENTS}

First, I would like to express my gratitude to my advisor Dr. Roger Chen for his unwavering support during my graduate study and research. I am grateful for all the opportunities and knowledge he has imparted to me since the beginning of my research career. He has my sincerest thanks for giving me the opportunity of joining his research group immediately after earning my undergraduate degree. Besides my advisor, I would like to thank the rest of my thesis committee: Dr. Vijay and Dr. Barth, for their constructive comments and encouragement. Their time and effort in making this thesis possible is greatly appreciated. I would also like to acknowledge the West Virginia Department of Transportation (WVDOT) for their continuous support during RP-312. Secondly, I thank Seyednavid Mardmomen, Zhanxiao Ma, Tadamon Mohammed and Yun Lin. They were all instrumental in my growth as a researcher. In particular, Seyednavid has been of immense help through discussions and assistance during experiments in the lab. Finally, I would like to thank my family: my parents, sister and brother for supporting me throughout my graduate studies. I would have not made it this far without them. Lastly, I would like to thank my fiancée, Zahira. Your encouragement and reassurance over the last several years will not be forgotten. Without your constant support during late nights and stressful days, this thesis would not be possible. 


\section{TABLE OF CONTENTS}

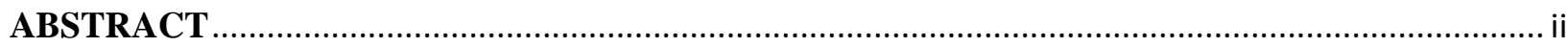

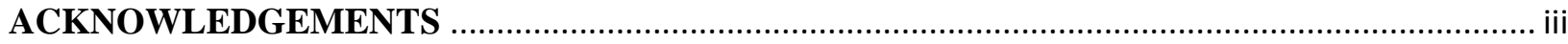

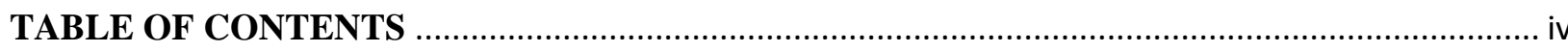

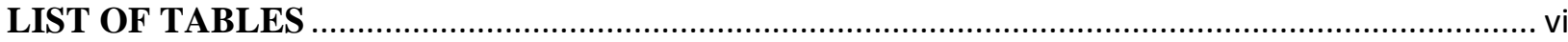

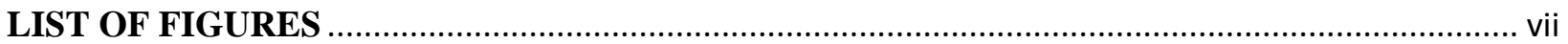

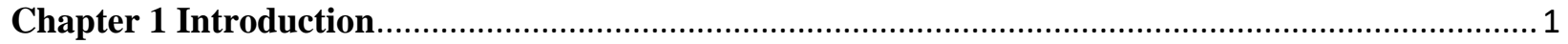

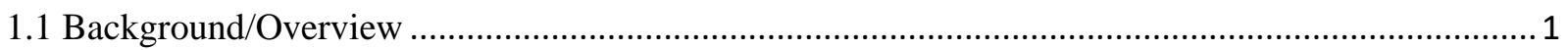

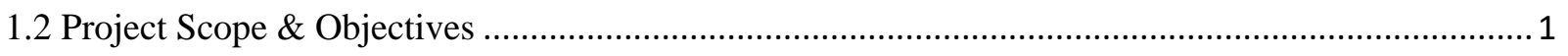

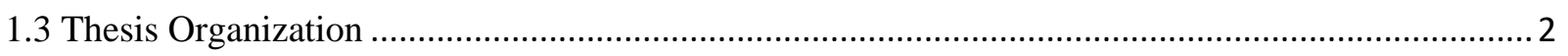

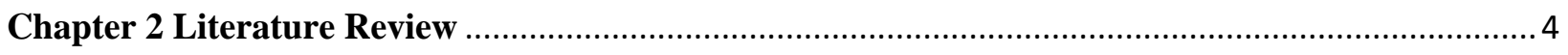

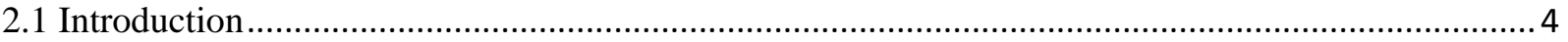

2.2 Literature

2.2.1 Wave Propagation Techniques......................................................................................... 5

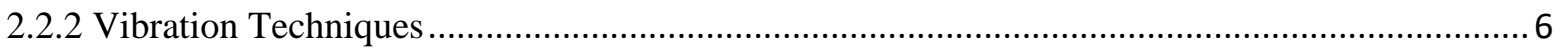

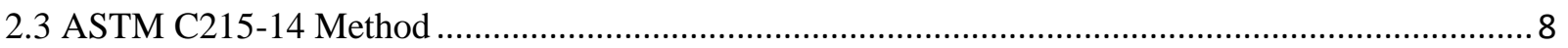

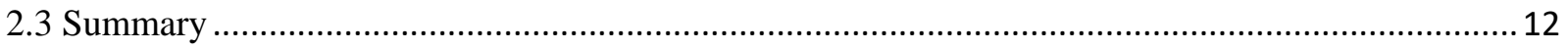

Chapter 3 Vibration of a Timoshenko Beam............................................................................. 13

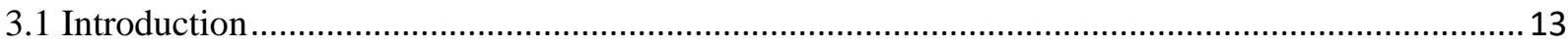

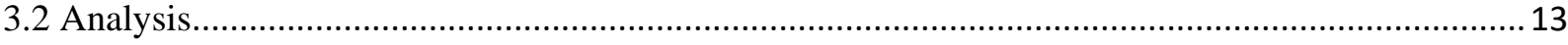

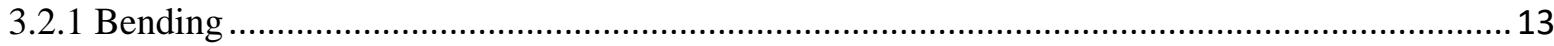

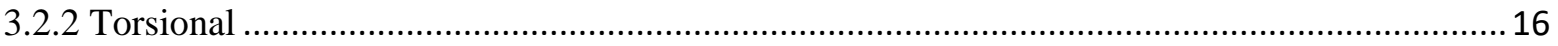

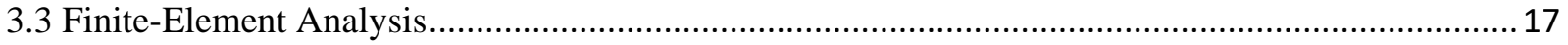

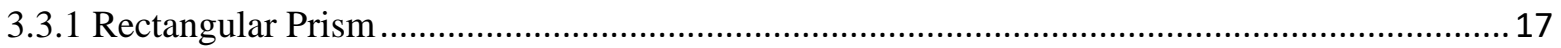

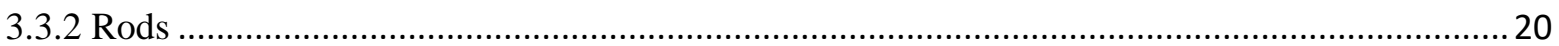

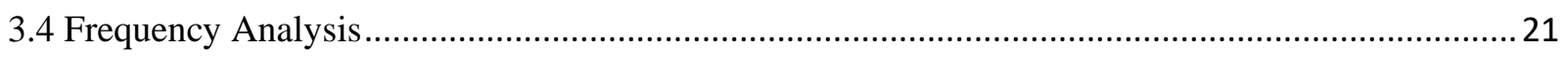

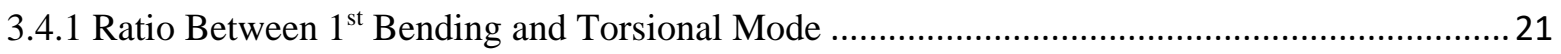

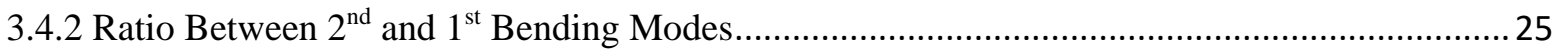

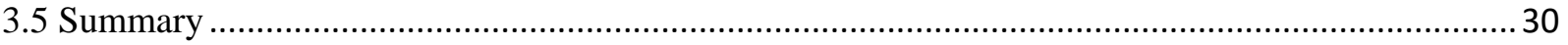

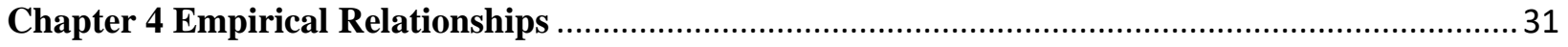

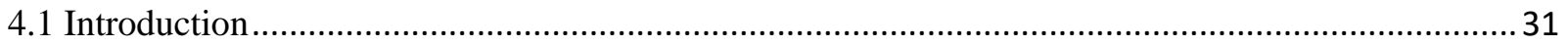




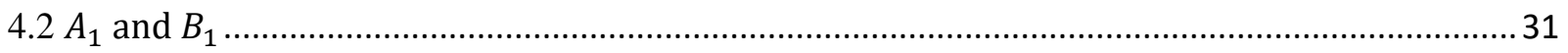

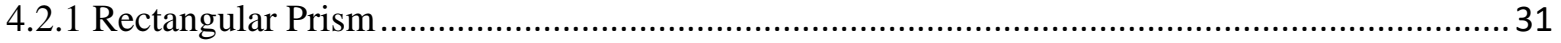

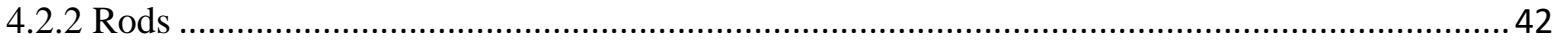

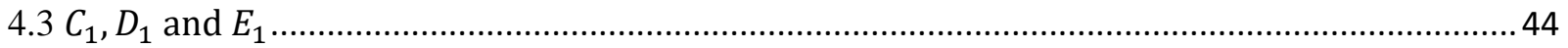

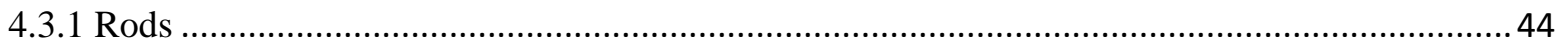

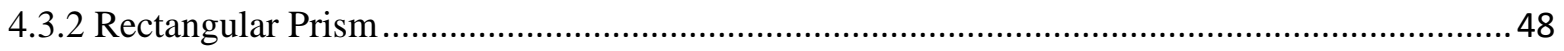

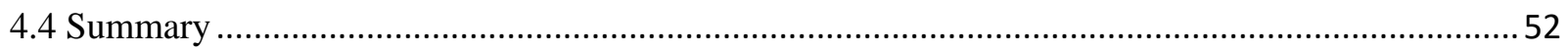

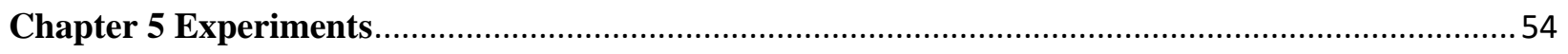

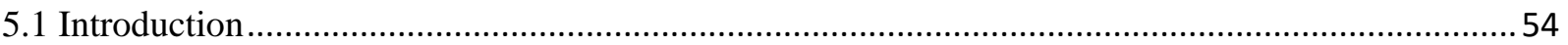

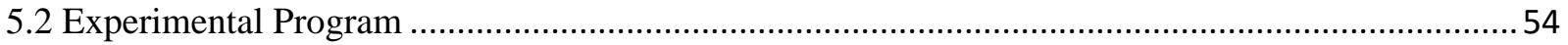

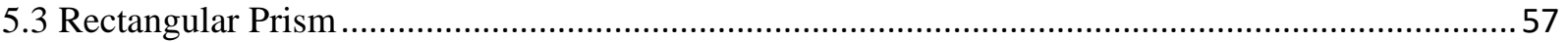

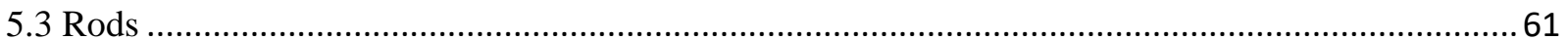

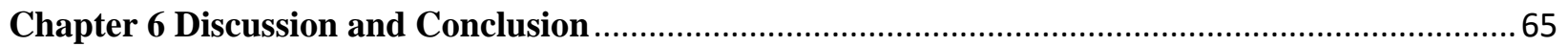

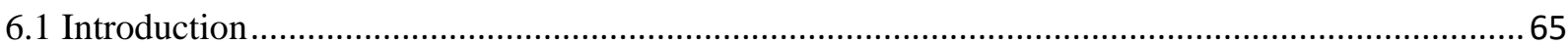

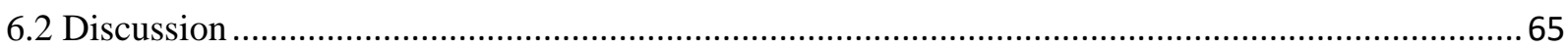

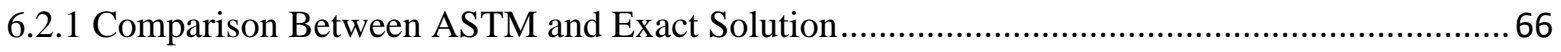

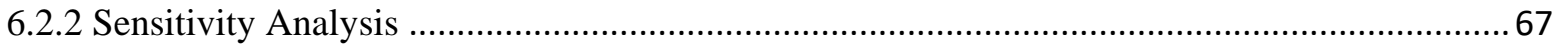

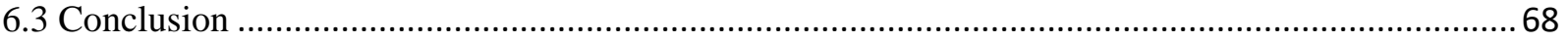

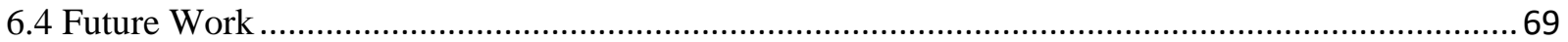

REFERENCES

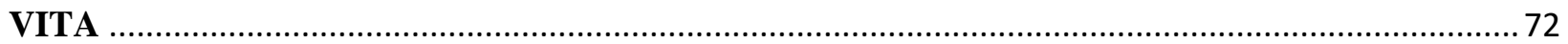




\section{LIST OF TABLES}

Table 3-1. Elastic modulus and Poisson' s ratio assumed in FEM ....................................................... 17

Table 3-2. Comparison of FEM and the analytical solutions ............................................................ 19

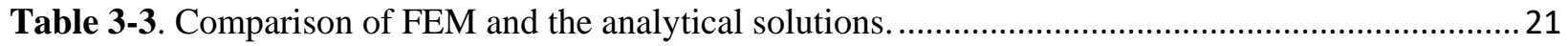

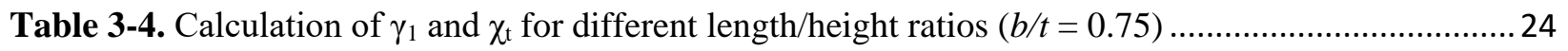

Table 3-5. Calculation of $\gamma_{1}, \gamma_{2}$ and $\chi_{b}$ for different length/diameter ratios .........................................29

Table 4-1. The values of $B_{1}$ for different length/height and width/height ratios.................................... 32

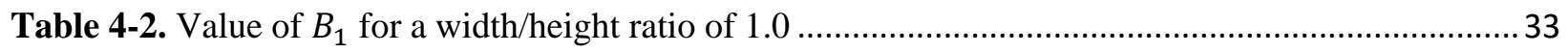

Table 4-3. The value of $A_{1}$ for different width/height and length/height ratios ..................................... 34

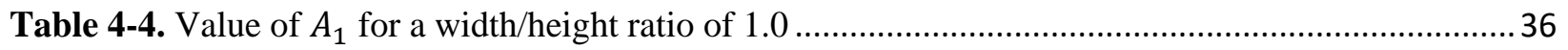

Table 4-5. Steel prism with different length/height ratio .................................................................... 37

Table 4-6. Experimental data from Spinner et.al (1960)................................................................. 40

Table 4-7. Analytical calculations and comparison with Spinner et.al. experimental data....................... 41

Table 4-8. The values of $B_{1}$ and $A_{1}$ for different length/diameter ratios ............................................... 42

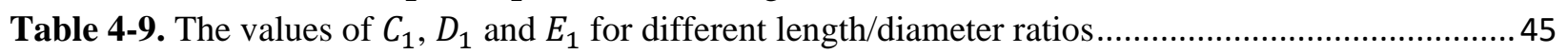

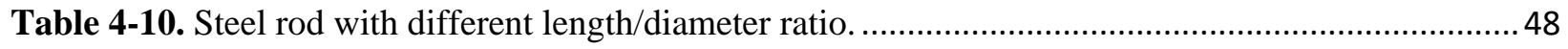

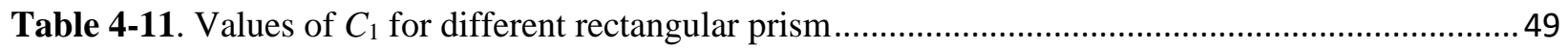

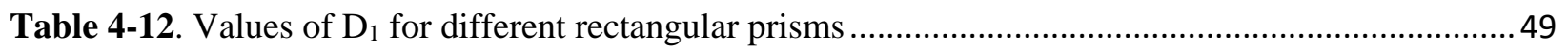

Table 4-13. Values of $E_{1}$ for different rectangular prisms ............................................................5 50

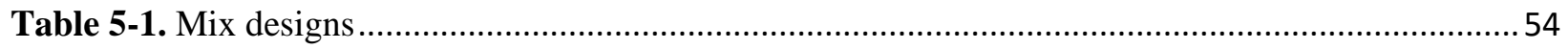

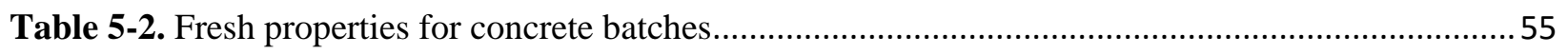

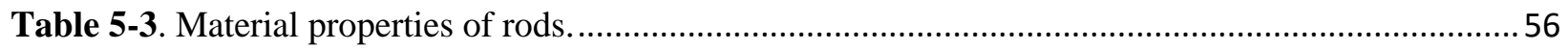

Table 5-4.Calculated properties of three different mix designs ...........................................................61

Table 5-5. Calculated properties of an aluminum, steel and concrete rod. ...........................................6 64

Table 6-1.Sensitivity analysis of the aluminum, steel, and concrete specimens...................................67 


\section{LIST OF FIGURES}

Figure 2-1. Poisson's ratio vs. longitudinal resonance frequency ratio (Kolluru, Popovics, and Shah 2000)

Figure 2-2. Empirical constants: (a) quadratic term, (b) linear term, and (c) constant term (Kolluru,

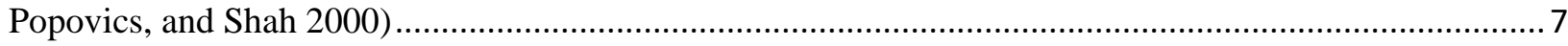

Figure 2-3. Schematic of transverse mode (ASTM C215) .................................................................... 9

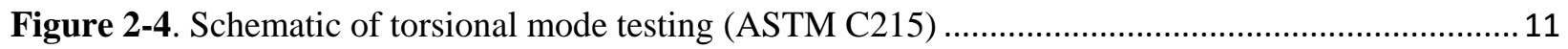

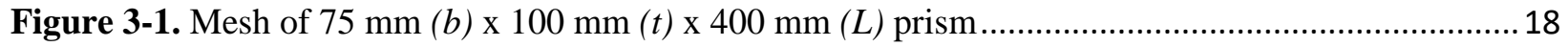

Figure 3-2. (a) $1^{\text {st }}$ bending mode, (b) $2^{\text {nd }}$ bending mode, and (c) $1^{\text {st }}$ torsional mode................................. 19

Figure 3-3. Mesh of $75 \mathrm{~mm}(D)$ x $300 \mathrm{~mm}(L)$ rod: (a) $1^{\text {st }}$ bending mode: $2101.5 \mathrm{~Hz}$, (b) $2^{\text {nd }}$ bending

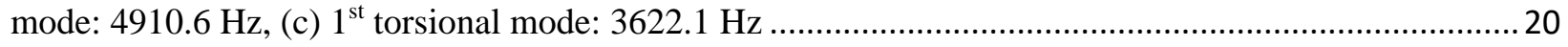

Figure 3-4. Relationship between $\chi_{t}$ and Poisson's ratio with different prism dimensions (width $\mathrm{x}$ height $\mathrm{x}$ length): (a) $75 \mathrm{~mm} \times 100 \mathrm{~mm} \times 400 \mathrm{~mm}$, (b) $10 \mathrm{~mm} \times 20 \mathrm{~mm} \times 160 \mathrm{~mm}$ and (c) $50 \mathrm{~mm} \times 50 \mathrm{~mm} \times 100$

$\mathrm{mm}$

Figure 3-5. Relationship between $\chi_{t}$ and Poisson's ratio with different rod dimensions (diameter $\mathrm{x}$ length): (a) $100 \mathrm{~mm} \times 400 \mathrm{~mm}$, (b) $20 \mathrm{~mm} \times 160 \mathrm{~mm}$ and (c) normalized $\chi t$ for different $L / D$ ratios $(L / D$ $=2,4,8$ and 10)

Figure 3-6. Relationship between $\chi_{b}$ and Poisson's ratio with different prism dimensions (width $\mathrm{x}$ height x length): (a) $75 \mathrm{~mm}$ x $100 \mathrm{~mm}$ x $400 \mathrm{~mm}$, (b) $10 \mathrm{~mm}$ x $20 \mathrm{~mm}$ x $160 \mathrm{~mm}$ and (c) $50 \mathrm{~mm}$ x $50 \mathrm{~mm}$ x 100 $\mathrm{mm}$

Figure 3-7. Relationship between $\chi_{b}$ and Poisson's ratio with different rod dimensions (diameter $\mathrm{x}$ length): (a) $100 \mathrm{~mm}$ x $400 \mathrm{~mm}$, (b) $20 \mathrm{~mm} \times 160 \mathrm{~mm}$ and (c) normalized $\chi_{b}$ for different $L / D$ ratios $(L / D$ $=2,4,8$ and 10)

Figure 4-1. (a) $B_{1}$ versus width/height ( $b / t$ ) ratio for the cases with different length/height ratios (b) Normalized $B_{1}$ by $B_{1}$ at $(b / t=1.0)$ for all the cases with different width/height ratios..... 34

Figure 4-2. (a) $A_{1}$ versus width/height ( $\left.b / t\right)$ ratio for the cases with different length/height ratios (b) Normalized $A_{1}$ by $A_{1}$ at $(b / t=1.0)$ for all the cases with different width/height ratios............................36

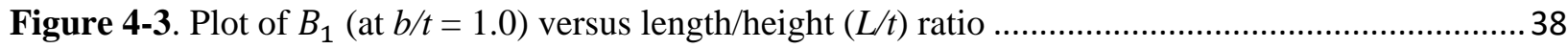

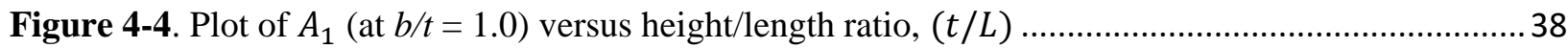

Figure 4-5. Plot of $\mathrm{B}_{1}$ versus the length/diameter ratio: (a) $L / D \leq 10$ and (b) $L / D>10 \ldots \ldots \ldots \ldots \ldots \ldots . . . .43$

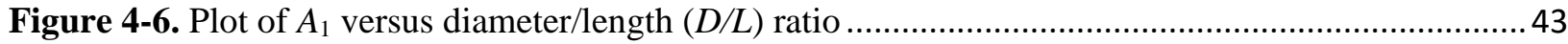

Figure 4-7. Plot of $C_{1}$ versus the diameter/length $(D / L)$ ratio........................................................... 46

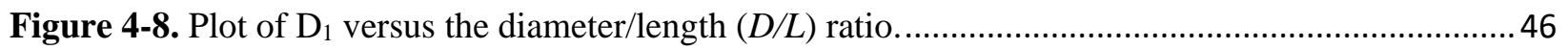

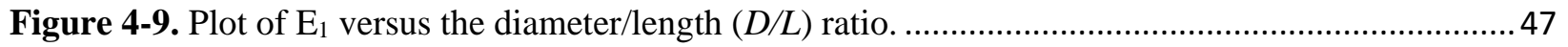

Figure 4-10. Normalized $C_{1}$ for rectangular prisms ..................................................................... 51

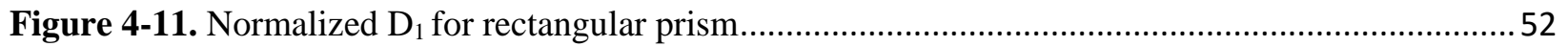

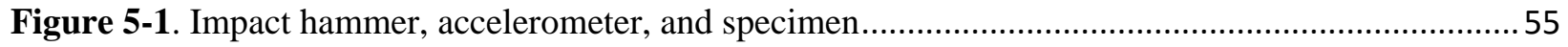

Figure 5-2. Typical setup of torsional mode testing ........................................................................5 56

Figure 5-3. Picture of experiment (a) Impact hammer, accelerometer, and specimens (b) Experimental

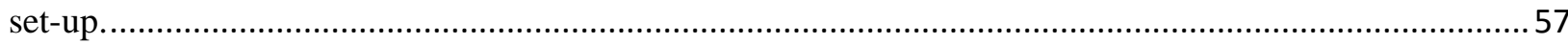

Figure 5-4. (a) Typical acceleration time history and (b) Typical response power spectrum (transverse mode)

Figure 5-5. (a) Typical impact loading time history and (b) Typical impact power spectrum (transverse mode) 
Figure 5-6. Example of amplitude vs. frequency (transverse mode)

Figure 5-7. (a) Typical acceleration time history and (b) Typical response power spectrum density (torsional mode). 59

Figure 5-8. (a) Typical impact loading time history and (b) Typical impact power spectrum (torsional

mode) .60

Figure 5-9. Example of amplitude vs. frequency (torsional mode).....................................................60

Figure 5-10. (a) Typical acceleration time history and (b) Typical response power spectrum (Transverse

Mode).

Figure 5-11. (a) Typical impact loading time history and (b) Typical impact power spectrum (Transverse

Mode). 62

Figure 5-12. (a) Typical acceleration time history and (b) Typical response power spectrum density (Torsional Mode). 63

Figure 5-13. (a) Typical impact loading time history and (b) Typical impact power spectrum (Torsional Mode). 63 


\section{Chapter 1 Introduction}

\subsection{Background/Overview}

Non-destructive testing (NDT) methods are often used to estimate the elastic properties of a material such as the dynamic elastic modulus and Poisson's ratio. There are several types of non-destructive testing (NDT) methods available. These include ultrasonic pulse velocity methods, resonance frequency methods, and other wave propagation techniques. Material properties measured with these methods are called dynamic elastic constants. ASTM C215 (2014) and ASTM E1876 (2015) standards are widely used to determine the dynamic elastic modulus using the fundamental resonance frequency. The equations provided in these standards were formulated by simplifying the free-free vibration solution of a Timoshenko beam with the effects of shear and rotational inertia reduced to a simple correction constant. However, the value of the elastic modulus cannot be directly calculated without knowing the material's Poisson's ratio. Therefore, to calculate the dynamic modulus and Poisson's ratio a lengthy iteration process is needed. To develop a direct method to determine the elastic constants, the frequency ratios between the bending modes and torsional mode were studied.

\subsection{Project Scope \& Objectives}

The scope of this thesis was to develop a method to directly determine the dynamic elastic modulus and Poisson's ratio of a rectangular prism and rod without the need for iterations. Additionally, the method should employ the resonance frequencies and be 
applicable to any homogenous material. These objectives were completed using the following steps:

- A brief discussion of prior research and available methods such as ASTM C215 and ASTM E1876.

- A detailed analysis of the free-free vibration of Timoshenko beams with rectangular or circular cross-sections.

- A study of the frequency ratios between the bending modes and $1^{\text {st }}$ torsional mode.

- Propose empirical equations that allow an accurate and simple method to determine the elastic constants.

- An explanation of the experimental methods used to verify the proposed method.

- A summary of the results and conclusions with a comparison with ASTM C215 and ASTM E1876.

\subsection{Thesis Organization}

A brief overview of the organization of this thesis is as follows:

- Chapter 2:

- This chapter will provide a brief overview of non-destructive techniques available to measure the dynamic modulus and Poisson's ratio of rectangular and circular Timoshenko beams, specifically techniques that use vibration methods.

- Chapter 3: 
- This chapter contains the derivation of the vibration of a free-free Timoshenko beam including an accurate shear shape factor. Finite-element analysis using a commercial software was compared to the derived exact solution. This chapter also contains an investigation of the frequency ratios of the $2^{\text {nd }}$ and $1^{\text {st }}$ bending modes, and the $1^{\text {st }}$ bending and $1^{\text {st }}$ torsional modes.

\section{- $\quad$ Chapter 4:}

- This chapter presents empirical equations to estimate the coefficients presented in Chapter 3. These equations allow for a direct calculation of the dynamic elastic modulus and Poisson's ratio of rectangular prisms and rods of any dimension. The proposed equations were used to calculate the frequency ratio of a steel prism and rod.

\section{- Chapter 5:}

- This chapter discusses the experimental program employed during this study. A detailed explanation of the experiments and results is provided. The proposed methods were compared to ASTM C215 for the rectangular prism case.

\section{- Chapter 6:}

- This chapter discusses the results obtained during the experimental program and limitations of the proposed methods. A sensitivity analysis of the methods is included in this chapter. This chapter provides a summary of the research study and recommendations for future work. 


\section{Chapter 2 Literature Review}

\subsection{Introduction}

Concrete specifications usually require a specific value for the modulus of elasticity (Popovics 2008). Formwork removal time and pre-stressing of concrete members are often determined from this property at early-age (Zhou et al. 2015). Young's modulus is also an indicator of the degradation of concrete, hence it is used frequently to determine the damage due to freeze-thaw or fire (Lee et al. 2015; Gucunski 2013). An empirical relationship between the compressive strength and the modulus of elasticity of the concrete is given in ACI 318-14, however, the ACI formula usually provides overly conservative results. An alternative technique is to use a non-destructive testing (NDT) method to estimate the concrete properties. There are several types of non-destructive testing (NDT) methods available for measurements of concrete Young's modulus. Material properties measured with these methods are called dynamic elastic constants. Many researchers have found that the dynamic modulus, $E_{d}$, is often higher than that of the static modulus, $E_{S}$ and proposed relationships to correlate the static and dynamic modulus (Zhou et al. 2015; Chavhan and Vyawahare 2015; Lee et al. 2017; Lydon and Balendran 1986; Y1ldırım and Sengul 2011; Weiss 2006). In this chapter an overview of the current research regarding the measurement of the Young's elastic modulus and Poisson's ratio using NDT methods is presented. 


\subsection{Literature}

\subsubsection{Wave Propagation Techniques}

Most wave propagation techniques are based on the propagation of either longitudinal waves (P-wave), Rayleigh waves or transverse waves ( $\mathrm{S}$-wave). In a typical experiment, a piezoelectric transducer is used to generate a wave at one end of a specimen while another transducer captures the arrival at the opposite end. The wave speed is then calculated by dividing the length of the specimen by the time it took for the wave to be received by the piezoelectric transducer. Since the longitudinal wave is the fastest it will arrive before the other wave propagations, so the calculated wave speed corresponds to the longitudinal wave speed. For an isotropic and homogenous material, the longitudinal wave speed can be used to calculate the dynamic elastic modulus if the Poisson's ratio is known. Similarly, the S-wave and Rayleigh wave speed can also be used.

Lee et al. found the dynamic elastic modulus using both the P-wave and S-wave. Based on their experimental measurements, they stated that the wave propagation techniques produced slightly higher values for the dynamic modulus compared to the vibration techniques (Lee et al. 2017). Similarly, another research also concluded that the wave propagation method produced a concrete dynamic modulus approximately $10 \%$ higher than those obtained through vibration methods (Logan 2017). However, in their analysis a Poisson's ratio of 0.2 was assumed since it was not measured independently. Herein lies a disadvantage of using a single wave propagation method because the Poisson's ratio must be known in advance. However, it should be noted, that since the Pwave and S-wave both depend on the elastic modulus and Poisson's ratio a simultaneous measurement of each will allow the determination of the elastic constant. 


\subsubsection{Vibration Techniques}

Researchers have used forced vibration and impulse vibration to measure the dynamic elastic constants of steel plates (Alfano and Pagnotta 2007) as well as impactecho resonance and Rayleigh wave velocity (Medina and Bayón 2010). Kolluru et al. proposed a technique to determine the elastic material constants of a standard test cylinder using the longitudinal resonance frequencies of concrete, steel, and aluminum (Kolluru, Popovics, and Shah 2000). The ratio between the $2^{\text {nd }}$ and $1^{\text {st }}$ longitudinal resonance frequencies was used to determine the Poisson's ratio for a variety of length-to-diameter ratios $(L / D)$ and afterward the elastic modulus was estimated. They observed a parabolic relationship between the longitudinal resonance as shown in Figure 2-1. Kolluru et al. proposed Eq. (1) to determine the Poisson's ratio.

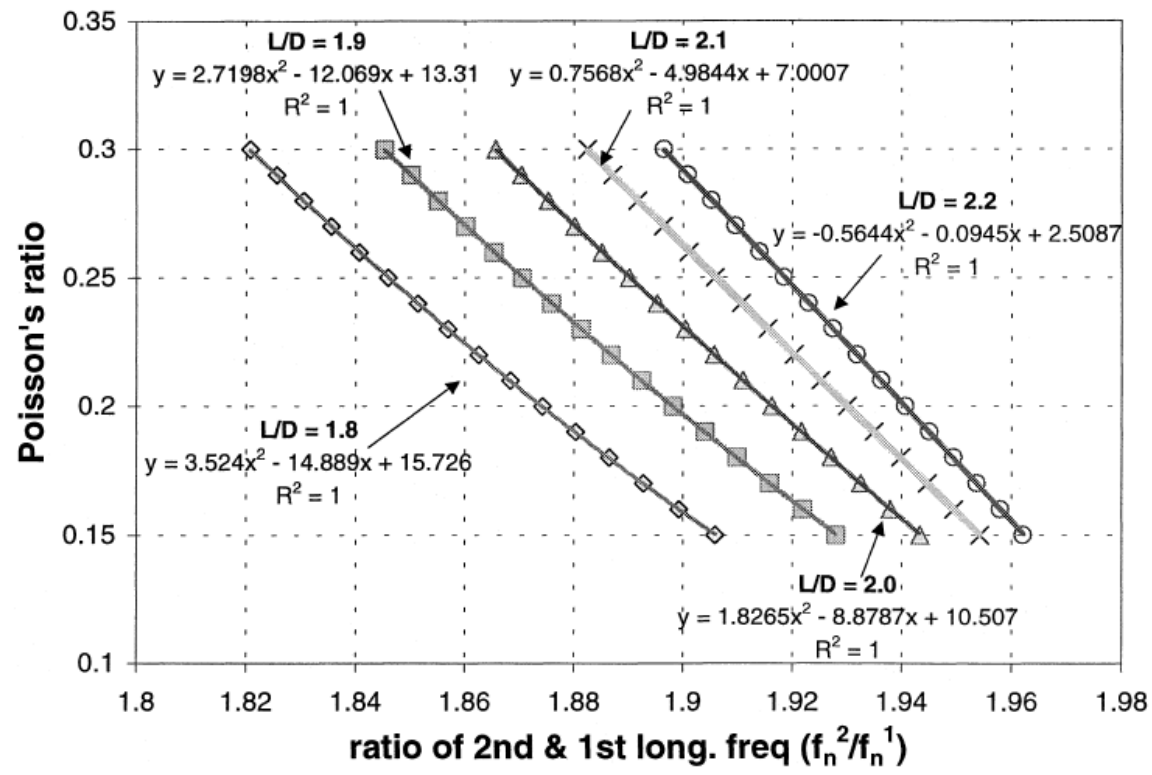

Figure 2-1. Poisson's ratio vs. longitudinal resonance frequency ratio (Kolluru, Popovics, and Shah 2000) 


$$
v=A_{1}\left(\frac{f_{2}}{f_{1}}\right)^{2}+B_{1}\left(\frac{f_{2}}{f_{1}}\right)+C_{1}
$$

where $f_{2}$ and $f_{1}$ are the measured $1^{\text {st }}$ and $2^{\text {nd }}$ longitudinal resonance frequency; $A_{1}, B_{1}$ and $C_{1}$ are empirical constants that depend on the length to diameter, $L / D$, ratio. These empirical constants were found using the best-fit parabolic curve shown in Figure 2-2. It should be noted that only a small range of $L / D$ ratios were included since their focus was on cored cylinders of intermediate lengths. Therefore, its applicability on shorter or longer cylinders is uncertain. Additionally, in longer cylinders it may be difficult to accurately excite the longitudinal mode due to concrete's high attenuation.

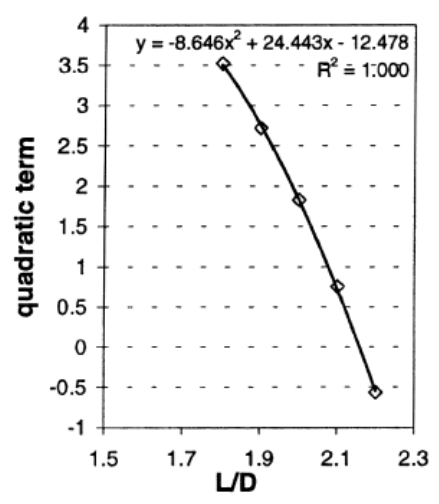

(a)

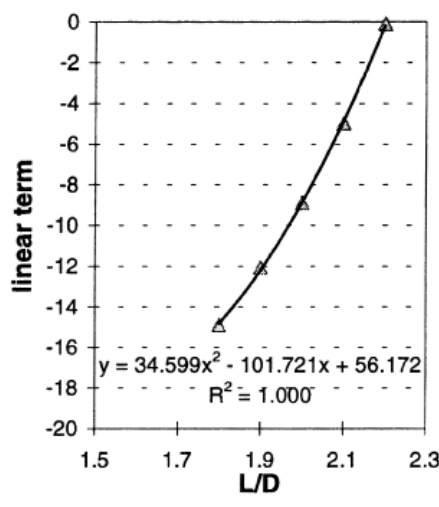

(b)

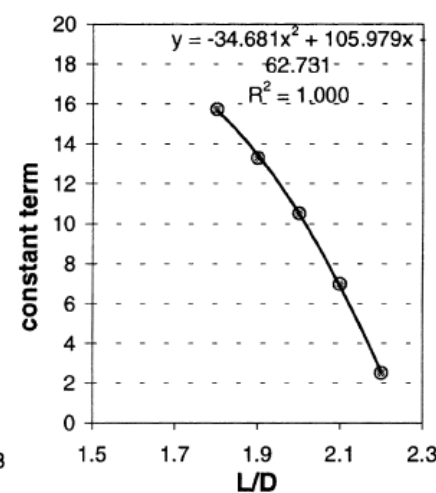

(c)

Figure 2-2. Empirical constants: (a) quadratic term, (b) linear term, and (c) constant term (Kolluru, Popovics, and Shah 2000)

Nieves et al. estimated the shear modulus and Poisson's ratio for short cylinders using the two lowest axisymmetric natural frequencies (Nieves, Gascón, and Bayón 1998). Verification of their methods was made using various cylindrical specimens with an $L / D$ less than 3. Wang et al. proposed a method to evaluate Poisson's ratio of a rod with only two experimental impact-echo values (fundamental longitudinal and cross-sectional 
resonant frequencies). However, their methods require an $L / D \geq 25 v$ for the dynamic Poisson's ratio to be valid (Wang et al. 2012).

ASTM C215 (2014) and ASTM E1876 (2015) are widely used to determine the dynamic elastic modulus using the fundamental resonance frequency. The equations provided in these standards were formulated by simplifying the free-free vibration solution of a Timoshenko beam with the effects of shear and rotational inertia reduced to a simple correction constant. However, the value of the elastic modulus cannot be directly calculated without knowing the material's Poisson's ratio. Therefore, in order to calculate the dynamic modulus and Poisson's ratio, a lengthy iteration process is needed.

In this study, the exact solution of the Timoshenko beam vibration frequency equation under free-free boundary conditions was determined. The fundamental transverse and torsional frequencies were used to determine the dynamic elastic modulus and Poisson's ratio of rods with an $L / D \geq 2$. Then, relationships between the resonance frequencies and Poisson's ratio were proposed that can directly determine the elastic modulus and the Poisson's ratio, simultaneously without the need for iteration, using the frequency ratio between the $1^{\text {st }}$ bending mode and the $1^{\text {st }}$ torsional mode, or the frequency ratio between the $2^{\text {nd }}$ bending mode and the $1^{\text {st }}$ bending mode.

\subsection{ASTM C215-14 Method}

Following the ASTM Standard Test Method for Fundamental Transverse, Longitudinal, and Torsional Resonant Frequencies of Concrete Specimens (ASTM C215- 
14), the dynamic modulus of elasticity can be obtained. The equations presented in ASTM C215-14 can be derived using the Timoshenko beam vibration. However, the solution shown in ASTM C215-14 was simplified by Goens (Goens 1931), and Pickett (Pickett 1945) later using numerical solutions for a correction factor, $T$, for different values of Poisson's ratio and $K / L$ (the ratio of the radius of gyration, $K$, and the length, $L$ ), assuming only one-dimensional motion (Pickett 1945).

Using the impact resonance frequency method, the fundamental resonant frequency was used to calculate the dynamic modulus. This method was first applied on concrete samples by Powers (Powers 1938). Figure 2-3 shows the schematic drawing of the test setup for a rectangular concrete prism with $b=$ width, and $t=$ height, and $L=$ length. The location of the boundary conditions, accelerometer and impact can be found in ASTM C215. It should be noted, ASTM C215 specifies that the supports should be placed at the nodal locations to allow free vibration in the fundamental transverse mode with free-free boundary condition.

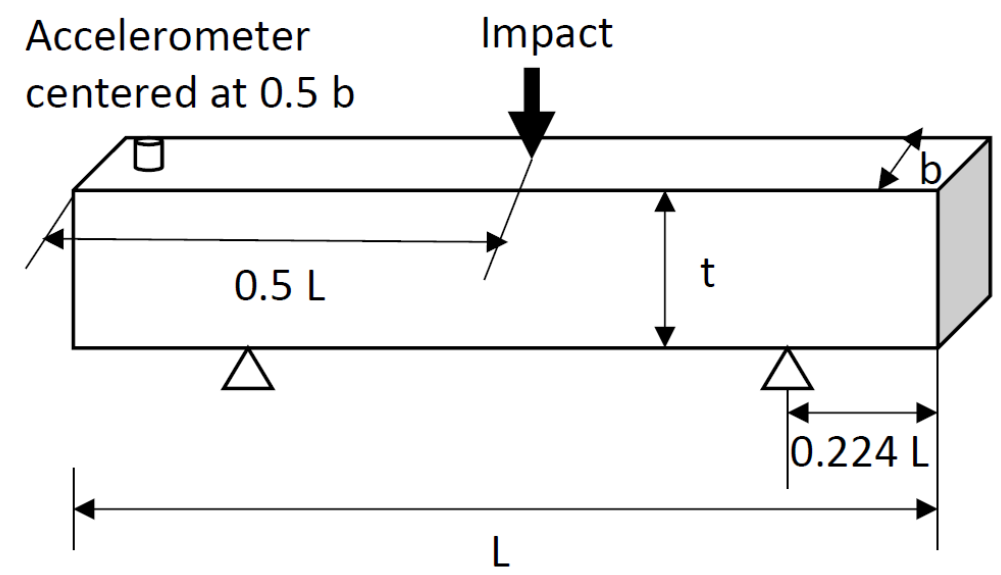

Figure 2-3. Schematic of transverse mode (Adopted from ASTM C215) 
ASTM C215-14 provides the following equation to calculate the dynamic modulus:

$$
E=C M n^{2}
$$

where, $E$ is the dynamic modulus of elasticity $(\mathrm{Pa}) ; C=0.9464\left(L^{3} T / b t^{3}\right)\left(\mathrm{m}^{-1}\right) ; M$ is the mass of the specimen $(\mathrm{kg}) ; n$ is the fundamental transverse frequency $(\mathrm{Hz}) ; L$ is the length of the specimen $(\mathrm{m}) ; t, b$ are the height and the width of the cross section of the prism (m); and $T$ is a correction factor that depends on the ratio of the radius of gyration, $K$, and the length, $L$, of the specimen. The parameter $T$ in $C$ was developed by Pickett (Pickett 1945) to account for shear and rotational inertia, and numerical values for $T$ at different Poisson's ratio and $K / L$ values can be found in a table shown in ASTM C215.

The torsional frequency can also be obtained. A schematic drawing of the test setup can be found in Figure 2-4. The support is placed at the center of the specimen which corresponds to the nodal point of the specimen. Details of the testing set-up and procedures will be explained in Chapter 4. 


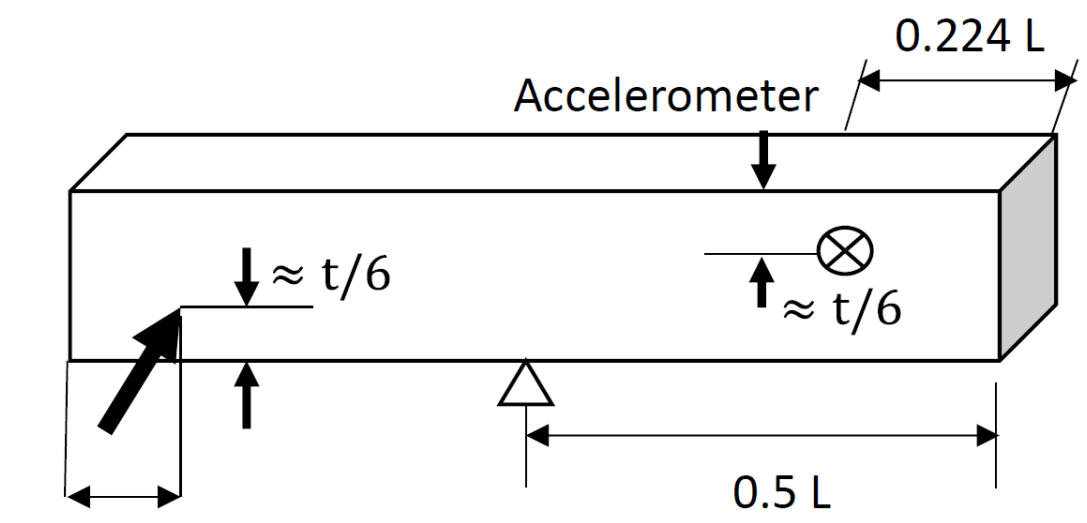

\section{$0.13 \pm 0.01 \mathrm{~L}$}

Figure 2-4. Schematic of torsional mode testing (Adopted from ASTM C215)

The fundamental torsional frequency was used to calculate the dynamic modulus of rigidity (shear modulus). ASTM C215 provides the equation below to calculate the dynamic modulus of rigidity:

$$
G=B M\left(n^{\prime \prime}\right)^{2}
$$

where $G$ is the dynamic modulus of rigidity $(\mathrm{Pa}) ; B=4 L R / A\left(\mathrm{~m}^{-1}\right) ; M$ is the mass of the specimen $(\mathrm{kg}) ; n$ " is the fundamental torsional frequency $(\mathrm{Hz}) ; R$ is the ratio between the polar moment of inertia and the equivalent moment of inertia.

The solution for the modulus of rigidity was derived using a Euler-Bernoulli beam in torsion (Augustyn and Kozien 2015; Pickett 1945; Vet 1962). Poisson's ratio can be calculated using the ratio between the modulus of elasticity and modulus of rigidity if the concrete specimen is assumed to be a homogeneous linear-elastic isotropic solid. The equation below can be used to calculate Poisson's ratio: 


$$
v=\left(\frac{E}{2 G}\right)-1
$$

where $v$ is Poisson's ratio; $E$ is the elastic modulus; and $G$ is the shear modulus. Concrete Poisson's ratio typically ranges from 0.1 for dry specimens to 0.25 for saturated specimens (ASTM C215 2014).

\subsection{Summary}

In this chapter a brief overview of NDT methods was presented. Two of the most common non-destructive techniques were discussed, wave propagation and vibration methods. From literature it was found that the wave propagation method produces slightly larger values of the dynamic elastic modulus than the vibration methods. It was also found that researchers have successfully used the ratio between the resonance frequencies to directly determine the elastic constants. Therefore, in this study the ratio between the bending and torsional modes will be utilized. 


\section{Chapter 3 Vibration of a Timoshenko Beam}

\subsection{Introduction}

The vibration of a beam can be simplified using a Euler-Bernoulli beam. For the vibration of a Euler-Bernoulli beam the effects from shear are assumed neglectable. This simplification is only true when the beam is considered slender and produces large errors for shorter beams. In the early $20^{\text {th }}$ century, Timoshenko developed a fourth-order differential equation to consider shear and rotary effects. Using this beam vibration equation, the vibration of thick beams could be predicted with more accuracy. Since it is not feasible to always test slender beams the effect of shear must be considered. Therefore, in this study the Timoshenko beam formulation will be used to determine the bending modes. Furthermore, it will be shown that the Euler-Bernoulli torsional mode is accurate and therefore applicable in this study.

\subsection{Analysis}

\subsubsection{Bending}

For a homogenous and isotropic material, the Timoshenko beam vibration equation can be expressed as:

$$
E I \frac{\partial^{4} y}{\partial x^{4}}+m \frac{\partial^{2} y}{\partial t^{2}}-\rho I\left(1+\frac{E}{k^{\prime} G}\right) \frac{\partial^{4} y}{\partial x^{2} \partial t^{2}}+\frac{\rho^{2} I}{k^{\prime} G} \frac{\partial^{4} y}{\partial t^{4}}=0
$$

The third and fourth terms were added by Timoshenko to consider the shear and rotary effects in the beam (Timoshenko 1937). In the equation, $y$ is the transverse displacement; $t$ is time; $k^{\prime}$ is a shape factor; $G$ is the shear modulus; $E$ is the Young's 
modulus; $I$ is the moment of inertia of the cross section; $\rho$ is the mass density and $m$ is the mass per unit length. In Timoshenko's publication (Timoshenko 1937), a shape factor of $\frac{3}{4}$ was assumed for a circular cross-section and $\frac{2}{3}$ was assumed for a rectangular cross-section. In 1966, Cowper also derived the shape factor for different geometries (Cowper 1966). However, Hutchinson derived more accurate shape factors for a variety of geometries which match more closely with experimental results (Hutchinson 2000). In this study, Hutchinson's shape factor, Eq. (6) and Eq. (7), were used to calculate the shape factor for a circular and rectangular cross-section respectively. The shape factor for a rod is solely dependent on Poisson's ratio while for a rectangular prism it depends on the dimensions. In Eq. (7), $t$ is the height of the beam and $b$ is the width.

$$
\begin{gathered}
k^{\prime}=\frac{6(1+v)^{2}}{7+12 v+4 v^{2}} \\
k^{\prime}=-\frac{2(1+v)}{\left[\frac{144}{t^{5} b} C_{4}+v\left(1-\frac{b^{2}}{t^{2}}\right)\right]}
\end{gathered}
$$

where:

$$
C_{4}=\frac{1}{720} t^{3} b\left(-12 t^{2}-15 v t^{2}+5 v b^{2}\right)+\sum_{n=1}^{\infty} \frac{v^{2} b^{5}\left(n \pi t-b \tanh \left(\frac{n \pi t}{b}\right)\right)}{4(n \pi)^{5}(1+v)}
$$

For a Timoshenko beam with free-free boundary conditions, the following can be applied:

$$
\left.y^{\prime \prime}(x)\right|_{x=0}=0 ;\left.\quad y^{\prime \prime}(x)\right|_{x=L}=0 ;\left.\quad y^{\prime \prime \prime}(x)\right|_{x=0}=0 ;\left.\quad y^{\prime \prime \prime}(x)\right|_{x=L}=0
$$


Using these boundary conditions for a nontrivial solution, the frequency equation can be written as (Goens E 1931; Chen and Kiriakidis 2005):

$$
2-2 \cosh (\alpha) \cos (\beta)+\frac{\gamma^{2}\left(\gamma^{4} r^{2}\left(r^{2}-s^{2}\right)^{2}+\left(3 r^{2}-s^{2}\right)\right)}{\sqrt{1-\gamma^{4} r^{2} s^{2}}} \sinh (\alpha) \sin (\beta)=0
$$

where $r^{2}=\frac{I}{A L^{2}}, s^{2}=\frac{E I}{k^{\prime} G A L^{2}}, \gamma^{4}=\frac{\rho A L^{4}}{E I} \omega^{2}$ and $A$ is the cross-sectional area; $\alpha$ and $\beta$ represent the eigenvalues of the frequency equation. The eigenvalues $\alpha$ and $\beta$ can be expressed as:

$$
\alpha_{i}=\frac{\gamma_{i}^{2}}{\sqrt{2}} \sqrt{-\left(r^{2}+s^{2}\right)+\sqrt{\left(r^{2}-s^{2}\right)^{2}+\frac{4}{\gamma_{i}^{4}}}}
$$

and

$$
\beta_{i}=\frac{\gamma_{i}^{2}}{\sqrt{2}} \sqrt{\left(r^{2}+s^{2}\right)+\sqrt{\left(r^{2}-s^{2}\right)^{2}+\frac{4}{\gamma_{i}^{4}}}}
$$

A MATLAB program was used to solve for the eigenvalues of the frequency equation. The natural frequencies $(\mathrm{Hz})$ can be expressed using the eigenvalues (Huang 1961):

$$
n_{i}=\frac{\gamma_{i}^{2}}{2 \pi} \sqrt{\frac{E I}{\rho A L^{4}}}
$$

Let $i=1$ to obtain the $1^{\text {st }}$ bending mode and $i=2$ for the $2^{\text {nd }}$ bending mode. 


\subsubsection{Torsional}

In this study, the torsional mode obtained from the free-free Euler-Bernoulli beam solution was employed. If the cross-section of the beam has two axes of symmetry, the torsional vibration of the beam can be expressed with Eq. (12) and is independent of the bending modes (Augustyn and Marek Kozien 2015):

$$
\rho J_{0} \frac{\partial^{2} \varphi}{\partial t^{2}}-G J_{s} \frac{\partial^{2} \varphi}{\partial x^{2}}=0
$$

In the equation, $\varphi$ is the angle of twist; $J_{0}$ is the polar moment of inertia and $J_{S}$ is the equivalent moment of inertia due to torsion. For a Euler-Bernoulli beam with free-free conditions, the following can be applied:

$$
\left.\varphi^{\prime}(x)\right|_{x=0}=0 ;\left.\quad \varphi^{\prime}(x)\right|_{x=L}=0 ;
$$

Using these boundary conditions for a nontrivial solution, the torsional frequency equation can be written as:

$$
\sin (k L)=0
$$

where

$$
k_{i}^{2}=\frac{\rho J_{0} \omega_{i}^{2}}{G J_{s}}
$$

The solutions of the torsional frequency equation can be expressed as $k_{i} L=N_{i} \pi$, where $N_{i}$ can be any positive integer. Finally, the $1^{\text {st }}$ free-free torsional mode of a beam can be calculated as: 


$$
n^{\prime \prime}=\frac{1}{2 L} \sqrt{\frac{G J_{s}}{\rho J_{0}}}=\frac{1}{2 L} \sqrt{\frac{G}{\rho R}}
$$

where $R$ is the ratio between the polar moment of inertia and the equivalent moment of inertia. For a rectangular prism whose cross-sectional dimensions are $b$ and $t$ with $b<t$, $R$ can be calculated with Eq. (16). For a rod, the equivalent moment of inertia is equal to the polar moment of inertia therefore $R=1$.

$$
R=(b / t+t / b) /\left[\left(4 b / t-2.52(b / t)^{2}+0.21(b / t)^{6}\right]\right.
$$

\subsection{Finite-Element Analysis}

\subsubsection{Rectangular Prism}

Frequency analysis using 3-D finite element method (FEM) was carried out and compared to the exact solution for the transverse and torsional modes of the rectangular prism. The density of the specimen was assumed to be $2,400 \mathrm{~kg} \mathrm{~m}^{-3}$. Six different sets of elastic modulus and Poisson's ratio were used in the FEM as shown in Table 3-1.

Table 3-1. Elastic modulus and Poisson's ratio assumed in FEM

\begin{tabular}{ccc}
\hline Test & Elastic Modulus (GPa) & Poisson's ratio \\
\hline 1 & 25.0 & 0.1 \\
2 & 25.0 & 0.15 \\
3 & 25.0 & 0.2 \\
4 & 10.0 & 0.2 \\
5 & 20.0 & 0.2 \\
6 & 30.0 & 0.2 \\
\hline
\end{tabular}

A total of 192,000 elements of $2.5 \mathrm{~mm}(0.1$-in) cubes, 8-node linear brick with reduced integration and hourglass control elements (C3D8R) from ABAQUS program 
were utilized. The $75 \mathrm{~mm} \times 100 \mathrm{~mm} \times 400 \mathrm{~mm}$ concrete prism was modeled as a free-free beam shown in Figure 3-1.

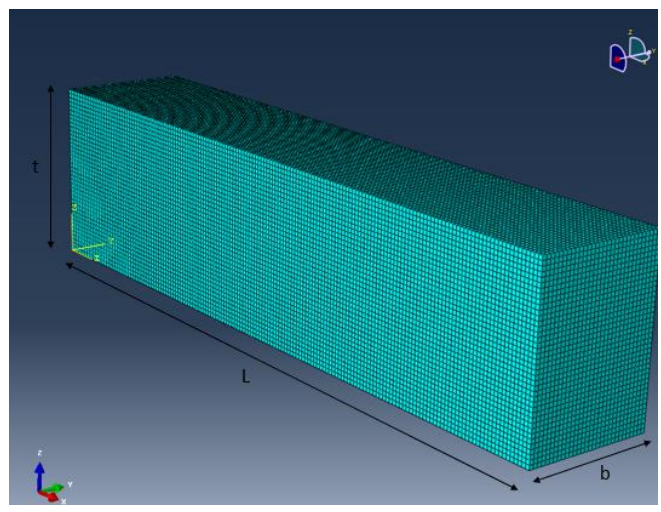

Figure 3-1. Mesh of $75 \mathrm{~mm}(b)$ x $100 \mathrm{~mm}(t)$ x $400 \mathrm{~mm}(L)$ prism

Figure 3-2 shows the $1^{\text {st }}$ and $2^{\text {nd }}$ bending modes as well as the torsional mode. In the prism experimental testing, the $2^{\text {nd }}$ bending mode was not observed, however with a longer specimen it should be possible to experimentally measure the $2^{\text {nd }}$ mode. Additionally, the experimental set-up can be modified to capture the $2^{\text {nd }}$ mode (i.e. placement of the accelerometer). 


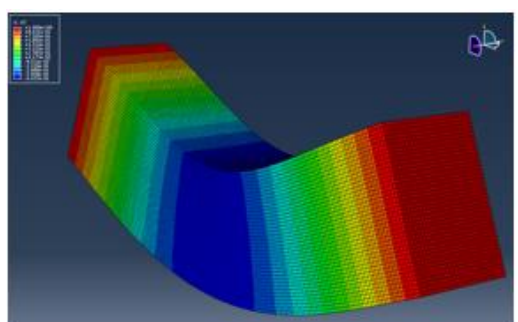

(a)

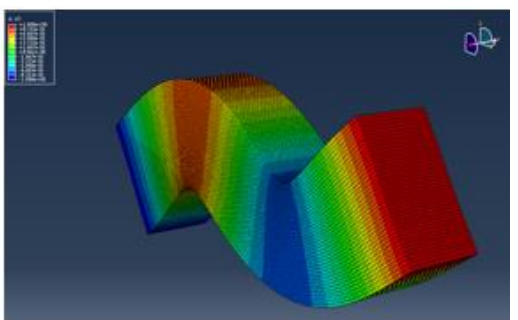

(b)

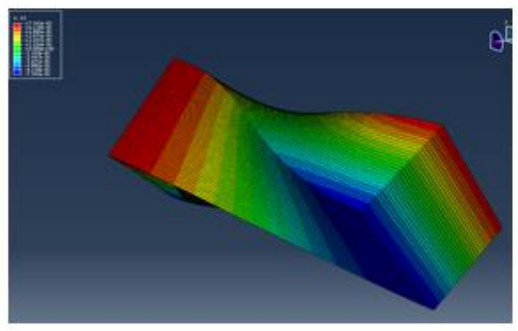

(c)

Figure 3-2. (a) $1^{\text {st }}$ bending mode, (b) $2^{\text {nd }}$ bending mode, and (c) $1^{\text {st }}$ torsional mode

A comparison between the FEM and the analytical solutions is shown in Table 3-2.

Results show that the percent error for all the cases is less than $0.05 \%$. This indicates that the elastic modulus and Poisson's ratio obtained from the roots of the Timoshenko beam frequency equation in the analysis section above is accurate and the $1^{\text {st }}$ free-free torsional mode from the Euler-Bernoulli beam solution is also close to exact.

Table 3-2. Comparison of FEM and the analytical solutions

\begin{tabular}{|c|c|c|c|c|c|c|c|c|c|}
\hline \multirow{3}{*}{ Test } & \multicolumn{6}{|c|}{ Transverse Mode (Hz) } & \multirow{2}{*}{\multicolumn{3}{|c|}{ Torsional Mode (Hz) }} \\
\hline & \multicolumn{3}{|c|}{$1^{\text {st }}$} & \multicolumn{3}{|c|}{$2^{\text {nd }}$} & & & \\
\hline & Exact & FEM & Error $(\%)$ & Exact & FEM & Error $(\%)$ & Exact & FEM & Error $(\%)$ \\
\hline 1 & 1728.8 & 1728.1 & $0.041 \%$ & 3899.5 & 3898.1 & $0.036 \%$ & 2361.6 & 2360.5 & $0.047 \%$ \\
\hline 2 & 1722.3 & 1721.7 & $0.033 \%$ & 3860.3 & 3859.4 & $0.023 \%$ & 2261.1 & 2260.3 & $0.033 \%$ \\
\hline 3 & 1719.0 & 1718.5 & $0.031 \%$ & 3841.0 & 3840.0 & $0.027 \%$ & 2215.4 & 2214.7 & $0.031 \%$ \\
\hline 4 & 1089.3 & 1088.9 & $0.033 \%$ & 2441.5 & 2440.9 & $0.023 \%$ & 1430.0 & 1429.5 & $0.036 \%$ \\
\hline 5 & 1540.4 & 1539.9 & $0.035 \%$ & 3452.7 & 3451.9 & $0.024 \%$ & 2022.4 & 2021.6 & $0.037 \%$ \\
\hline 6 & 1886.7 & 1886.0 & $0.035 \%$ & 4228.7 & 4227.8 & $0.020 \%$ & 2476.9 & 2479 & $0.035 \%$ \\
\hline
\end{tabular}




\subsubsection{Rods}

Similarly, a frequency analysis using 3-D finite element method (FEM) was carried out and compared to the exact solution for the transverse and torsional modes of a rod. A similar methodology was applied by other researches for circular cylinders (Gladwell and Vijay 1975). The same sets, shown in Table 3-1, of elastic modulus and Poisson's ratio were used in the FEM simulations.

A total of 199,950 elements of 2.0-mm (0.08-in) cubes, 8-node linear brick with reduced integration and hourglass control elements (C3D8R) from ABAQUS program were utilized. A $75 \mathrm{~mm}$ (diameter) x $300 \mathrm{~mm}$ rod was modeled as a free-free beam. The $1^{\text {st }}$ and $2^{\text {nd }}$ bending modes as well as the $1^{\text {st }}$ torsional mode are shown in Figure 3-3. A comparison between the FEM and the analytical solutions is shown in Table 3-3. Results show that the percent error for all the cases is less than $0.15 \%$.

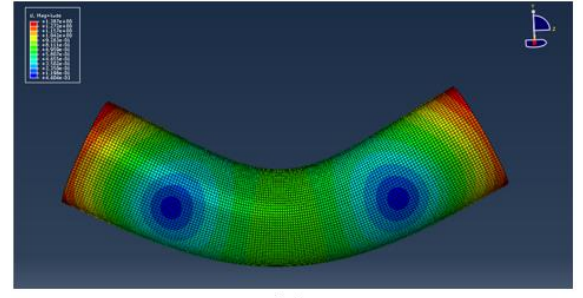

(a)

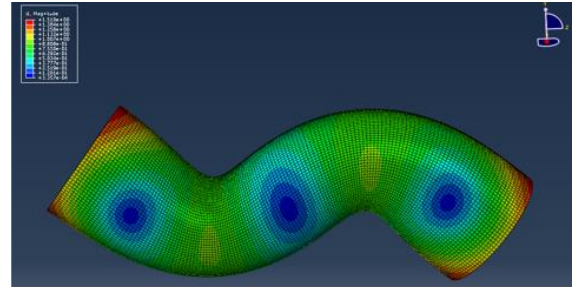

(b)

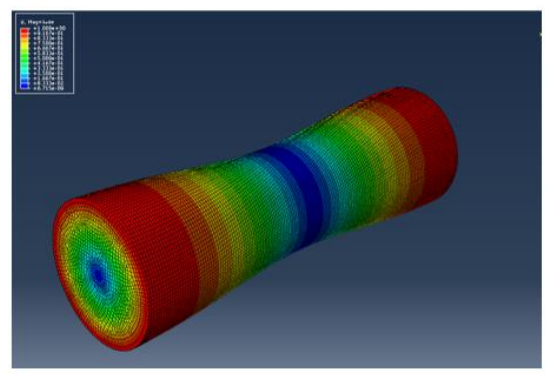

(c)

Figure 3-3. Mesh of $75 \mathrm{~mm}(D)$ x $300 \mathrm{~mm}(L)$ rod: (a) $1^{\text {st }}$ bending mode: $2101.5 \mathrm{~Hz}$, (b) $2^{\text {nd }}$ bending mode: $4910.6 \mathrm{~Hz}$, (c) $1^{\text {st }}$ torsional mode: $3622.1 \mathrm{~Hz}$ 
Table 3-3. Comparison of FEM and the analytical solutions.

\begin{tabular}{c|ccc|ccc|ccc}
\hline \multirow{2}{*}{ Test } & \multicolumn{5}{|c|}{ Transverse Mode (Hz) } & \multicolumn{3}{c}{ Torsional Mode (Hz) } \\
\cline { 2 - 9 } & Exact & FEM & Error (\%) & Exact & FEM & Error (\%) & Exact & FEM & Error (\%) \\
\hline 1 & 2103.083 & 2101.5 & $0.08 \%$ & 4914.196 & 4910.6 & $0.07 \%$ & 3626.66 & 3622.1 & $0.13 \%$ \\
2 & 2100.394 & 2098.9 & $0.07 \%$ & 4896.9 & 4894 & $0.06 \%$ & 3546.943 & 3542.4 & $0.13 \%$ \\
3 & 2097.75 & 2096.3 & $0.07 \%$ & 4879.969 & 4877.4 & $0.05 \%$ & 3472.262 & 3467.8 & $0.13 \%$ \\
4 & 1326.551 & 1325.6 & $0.07 \%$ & 3085.938 & 3084.3 & $0.05 \%$ & 2195.749 & 2193 & $0.13 \%$ \\
5 & 1876.349 & 1875 & $0.07 \%$ & 4364.927 & 4362.6 & $0.05 \%$ & 3105.793 & 3101.8 & $0.13 \%$ \\
6 & 2297.917 & 2296.3 & $0.07 \%$ & 5345.615 & 5342.8 & $0.05 \%$ & 3803.585 & 3798.8 & $0.13 \%$ \\
\hline
\end{tabular}

The percent error is slightly higher for the rod than the rectangular prism. This might be caused by the non-uniformity of the mesh used in the rod FEM analysis. Since FEM usually requires large amounts of computations using commercial software, it would be more efficient to use the analytical solutions to determine the transverse and torsional vibration frequencies.

\subsection{Frequency Analysis}

\subsubsection{Ratio Between $1^{\text {st }}$ Bending and Torsional Mode}

The ratio between the fundamental torsional frequency and the fundamental transverse frequency, $\chi_{t}$ can be expressed as the following relationship:

$$
\chi_{t}=2\left(\frac{n^{\prime \prime}}{n_{1}}\right)^{2}(v+1)
$$

where, $n^{\prime \prime}$ is the fundamental torsional frequency $(\mathrm{Hz})$ and $n_{1}$ is the fundamental transverse frequency $(\mathrm{Hz})$. For a Euler-Bernoulli beam, it can be shown that, $\chi_{t}$ approaches a constant value which only depends on the dimensions of the beam and its boundary conditions 
(Augustyn and Marek Kozien 2015). Using the first torsional mode and the first bending mode, the relationship shown in Eq. (18) and Eq. (19) can be derived to express the ratio, $\chi_{t}$ for a rectangular and circular Euler-Bernoulli beam with free-free boundary conditions, which only depends on the dimensions of the beam and is independent of the Poisson's ratio.

$$
\begin{gathered}
\chi_{t}=\frac{12 \pi^{2} L^{2}}{(4.73)^{4} R t^{2}} \\
\chi_{t}=\frac{16 \pi^{2}\left(\frac{L}{D}\right)^{2}}{(4.73)^{4}}
\end{gathered}
$$

However, that is not the case for the vibration of a Timoshenko Beam. Using the roots of the Timoshenko frequency equation, Eq. (9), and the solution for the torsional mode, Eq. (15), the frequency ratio, $\chi_{t}$ is expressed as Eq. (20).

$$
\chi_{t}=\pi^{2} A L^{2} / R I \gamma_{1}^{4}
$$

Eq. (20) was evaluated for a variety of Poisson's ratios and beam dimensions as shown in Figure 3-4 and Figure 3-5. From these figures, a linear relationship between the Poisson's ratio, $v$, and the ratio, $\chi_{t}$ can be observed. The y-intercept, $B_{1}$, corresponds to the value of $\chi_{t}$ when $v=0.0$. A clear linear trend can be seen after normalizing the frequency ratio, $\chi_{t}$, with $\chi_{t}$ at $v=0$ as shown in Figure 3-5c. It was found that the slope of the line and the y-intercept are independent of the elastic modulus and the mass density. The frequency ratio, $\chi_{t}$ only depends on the dimensions of the prism and rod as shown in Eq. (20). Hence, the ratio, $\chi_{t}$ can be expressed as Eq. (21). 


$$
\chi_{t}=2\left(\frac{n^{\prime \prime}}{n_{1}}\right)^{2}(v+1)=A_{1} v+B_{1}
$$

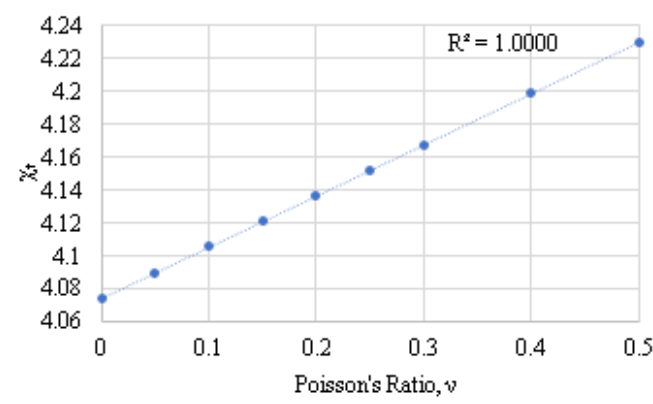

(a)

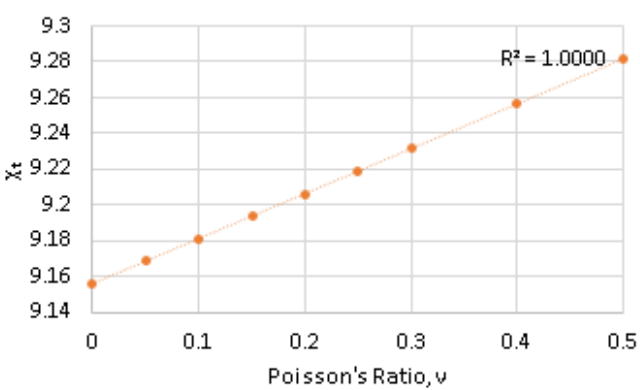

(b)

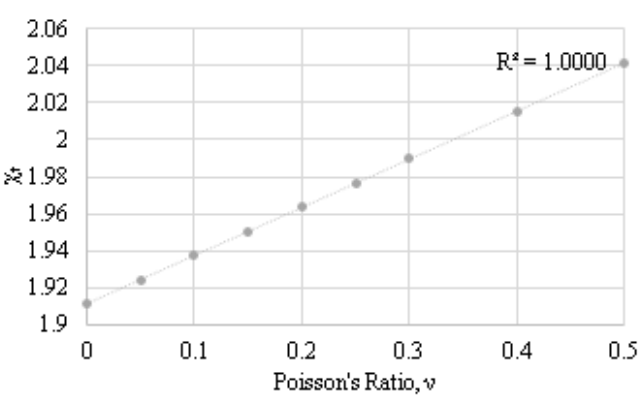

(c)

Figure 3-4. Relationship between $\chi_{t}$ and Poisson's ratio with different prism dimensions (width $\mathrm{x}$ height x length): (a) $75 \mathrm{~mm} \times 100 \mathrm{~mm} \times 400 \mathrm{~mm}$, (b) $10 \mathrm{~mm} \times 20 \mathrm{~mm} \times 160 \mathrm{~mm}$ and (c) $50 \mathrm{~mm}$ x $50 \mathrm{~mm} \times 100 \mathrm{~mm}$

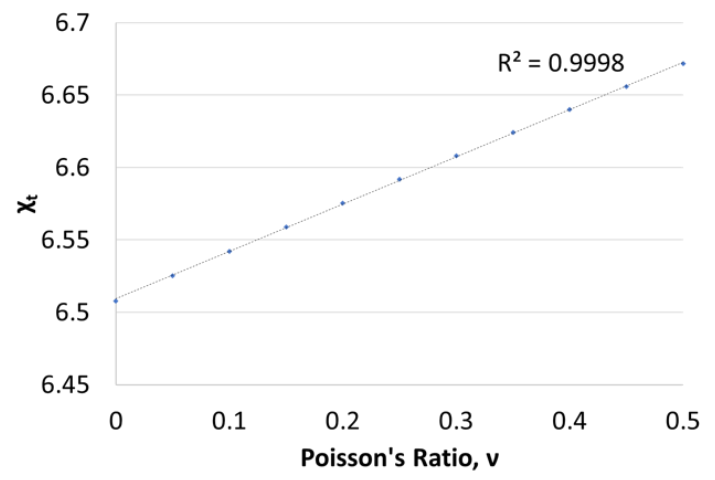

(a)

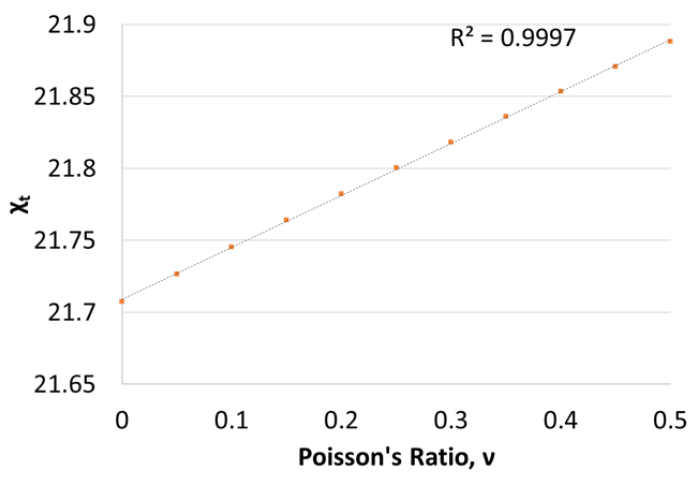

(b) 


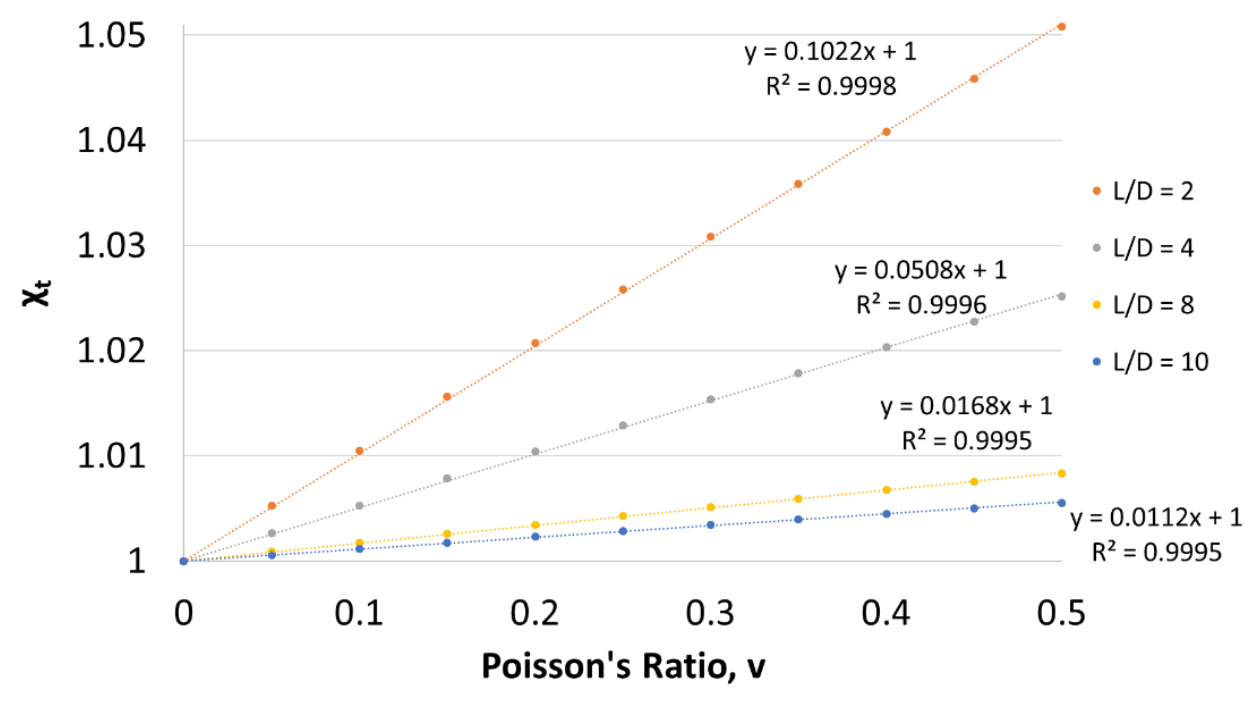

(c)

Figure 3-5. Relationship between $\chi_{t}$ and Poisson's ratio with different rod dimensions (diameter x length): (a) $100 \mathrm{~mm}$ x $400 \mathrm{~mm}$, (b) $20 \mathrm{~mm}$ x $160 \mathrm{~mm}$ and (c) normalized $\chi_{t}$ for different $L / D$ $\operatorname{ratios}(L / D=2,4,8$ and 10$)$

Table 3-4 shows the calculated values of $\gamma_{1}$ and $\chi_{t}$ due to different Poisson's ratio and prism length/depth $(L / t)$ ratio while maintaining a constant width/height ratio $(b / t)$ of 0.75. As expected, Table 3-4 shows that as the length/depth ratio becomes large the value of $\gamma_{1}$ approaches 4.73 which is the same value shown in Eq. (18) for a Euler-Bernoulli beam, and in this case, $\chi_{t}$ is no longer dependent of Poisson's ratio and approaches a constant value.

Table 3-4. Calculation of $\gamma_{1}$ and $\chi_{t}$ for different length/height ratios $(b / t=0.75)$

\begin{tabular}{ccccccccccccc}
\hline \multirow{2}{*}{$\begin{array}{c}\text { Poisson's Ratio, } \\
v\end{array}$} & \multirow{2}{*}{$\mathrm{k}^{\prime}$} & \multicolumn{2}{c}{$L / t=4$} & \multicolumn{2}{c}{$L / t=20$} & \multicolumn{2}{c}{$L / t=50$} & \multicolumn{2}{c}{$L / t=100$} & \multicolumn{2}{c}{$L / t=200$} \\
\cline { 3 - 13 } & & $\gamma_{1}$ & $X_{t}$ & $\gamma_{1}$ & $X_{t}$ & $\gamma_{1}$ & $X_{t}$ & $\gamma_{1}$ & $X_{t}$ & $\gamma_{1}$ & $X_{t}$ \\
\hline 0.0 & 0.8333 & 4.3609 & 4.0739 & 4.7108 & 74.7944 & 4.7269 & 461.1327 & 4.7293 & 1840.8997 & 4.729846 & 7359.966 \\
0.1 & 0.8464 & 4.3526 & 4.1053 & 4.7103 & 74.8316 & 4.7268 & 461.1702 & 4.7292 & 1840.9374 & 4.72984 & 7360.003 \\
0.2 & 0.8581 & 4.3443 & 4.1365 & 4.7097 & 74.8685 & 4.7267 & 461.2075 & 4.7292 & 1840.9746 & 4.729834 & 7360.041 \\
0.3 & 0.8686 & 4.3362 & 4.1676 & 4.7091 & 74.9053 & 4.7266 & 461.2445 & 4.7292 & 1841.0117 & 4.729828 & 7360.078
\end{tabular}




\begin{tabular}{llllllllllll}
0.4 & 0.8781 & 4.3281 & 4.1988 & 4.7085 & 74.9419 & 4.7266 & 461.2814 & 4.7292 & 1841.0486 & 4.729822 & 7360.115 \\
0.5 & 0.8866 & 4.3202 & 4.2299 & 4.7080 & 74.9781 & 4.7265 & 461.3179 & 4.7291 & 1841.0852 & 4.729816 & 7360.151 \\
\hline
\end{tabular}

The Poisson's ratio can then be calculated using the equation below:

$$
v=\frac{2\left(\frac{n^{\prime \prime}}{n_{1}}\right)^{2}-B_{1}}{A_{1}-2\left(\frac{n^{\prime \prime}}{n_{1}}\right)^{2}}
$$

Therefore, the Poisson's ratio can be readily calculated using the experimentally measured torsional vibration frequency, $n^{\prime \prime}$, and the transverse vibration frequency, $n_{1}$. Furthermore, after knowing the Poisson's ratio, the elastic modulus can be determined using the experimental torsional frequency with Eq. (23):

$$
E=8 \rho R L^{2} n^{\prime 2}(1+v)
$$

\subsubsection{Ratio Between $2^{\text {nd }}$ and $1^{\text {st }}$ Bending Modes}

Although the method presented above can be used to determine the dynamic elastic constants easily and quickly, it has two disadvantages. First, it requires a precise measurement of the torsional mode which is difficult to excite in a cylindrical specimen (ASTM C215 2014; Wang et al. 2012). Additionally, it requires two separate experimental tests. Therefore, it would be beneficial to develop a method based on only the transverse bending modes which can be measured simultaneously and accurately. Similar to $\chi_{t}$, the ratio between the $2^{\text {nd }}$ bending mode and the $1^{\text {st }}$ bending mode was used to directly calculate Poisson's ratio and the dynamic elastic modulus. 
The ratio between the $2^{\text {nd }}$ and $1^{\text {st }}$ fundamental transverse frequency, $\chi_{b}$ can be expressed with the following relationship:

$$
\chi_{b}=\left(\frac{n_{2}}{n_{1}}\right)^{2}=\frac{\gamma_{2}^{4}}{\gamma_{1}^{4}}
$$

where, $n_{2}$ is the $2^{\text {nd }}$ fundamental transverse frequency $(\mathrm{Hz}) \cdot \gamma_{1}$ and $\gamma_{2}$ are the roots from the frequency equation, shown in Eq. (5), for the $1^{\text {st }}$ and the $2^{\text {nd }}$ bending mode. For a very slender beam, the relationship shown in Eq. (25) can be derived to express $\chi_{b}$ for a EulerBernoulli beam with free-free boundary conditions.

$$
\chi_{b}=\frac{(7.853)^{4}}{(4.73)^{4}}=7.598
$$

However, for the vibration of a non-slender beam, $\chi_{b}$ can only be expressed with the roots of the Timoshenko frequency equation using Eq. (5). Hence, Eq. (24) was evaluated for a variety of Poisson's ratios and beam dimensions as shown in Figure 3-6 and Figure 3-7. From the figures, a slightly parabolic relationship between the Poisson's ratio, $v$, and the ratio, $\chi_{b}$ can be observed. A clear trend can be seen after normalizing the frequency ratio, $\chi_{b}$, with $\chi_{b}$ at $v=0$ as shown in Figure 3-7c. The y-intercept, $E_{1}$, corresponds to the value of $\chi_{b}$ when $v=0$. It was found that the frequency ratio, $\chi_{b}$ is independent of the elastic modulus and the mass density, and $\chi_{b}$ only depends on the roots of Eq. (5). Hence, the ratio, $\chi_{b}$ can be expressed as Eq. (26)

$$
\chi_{b}=\left(\frac{n_{2}}{n_{1}}\right)^{2}=C_{1} v^{2}+D_{1} v+E_{1}
$$

$C_{1}, D_{1}$ and $E_{1}$ are the coefficients of the $2^{\text {nd }}$ order polynomial describing the relationship between $\chi_{b}$ and Poisson's ratio. Table 3-5 shows the calculated values of $\gamma_{1}$, 
$\gamma_{2}$ and $\chi_{b}$ due to different Poisson's ratio and length/diameter $(L / D)$ for a rod. As expected, as the $L / D$ ratio becomes very large, the values of $\gamma_{1}$ and $\gamma_{2}$ approach 4.73 and 7.853 . They are the same values shown in Eq. (25) and correspond to a Euler-Bernoulli beam. For a very slender rod $(L / D=200), \chi_{b}$ is no longer dependent on Poisson's ratio and approaches a constant value.

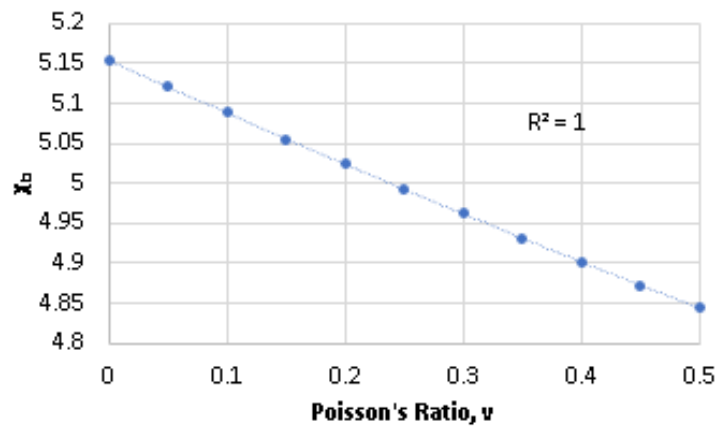

(a)

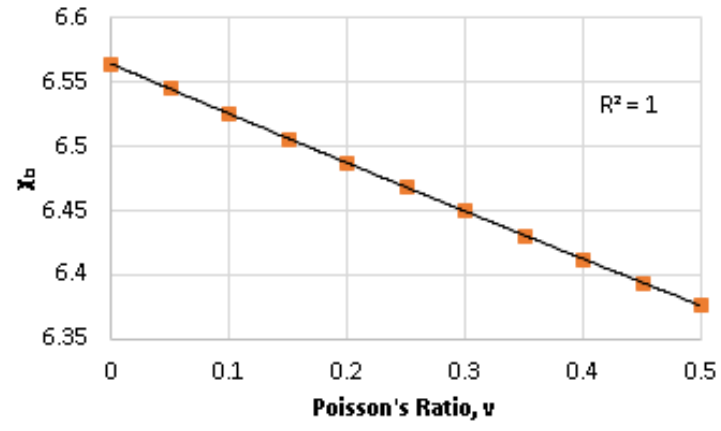

(b)

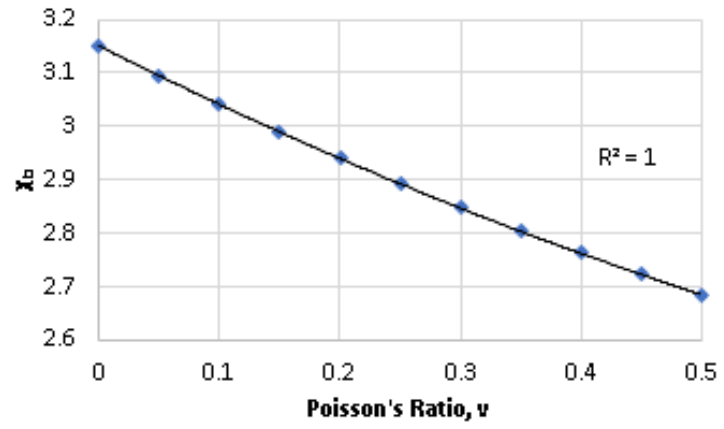

(c)

Figure 3-6. Relationship between $\chi_{b}$ and Poisson's ratio with different prism dimensions (width $\mathrm{x}$ height x length): (a) $75 \mathrm{~mm} \times 100 \mathrm{~mm} \times 400 \mathrm{~mm}$, (b) $10 \mathrm{~mm} \times 20 \mathrm{~mm} \times 160 \mathrm{~mm}$ and (c) $50 \mathrm{~mm}$ x $50 \mathrm{~mm} \times 100 \mathrm{~mm}$ 


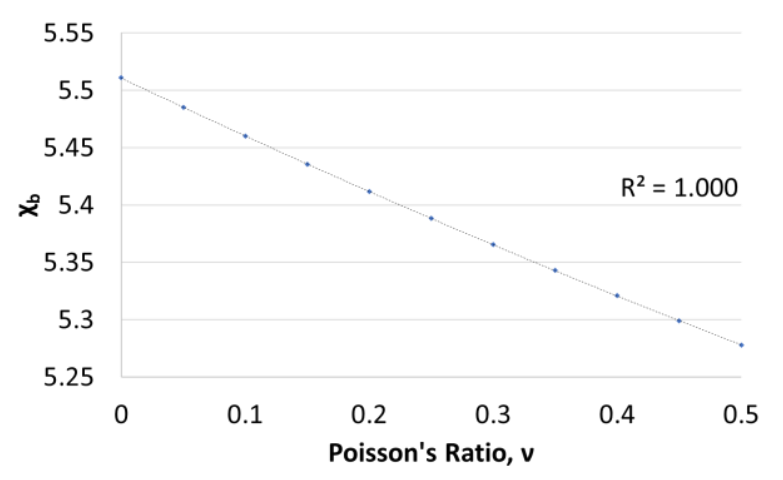

(a)

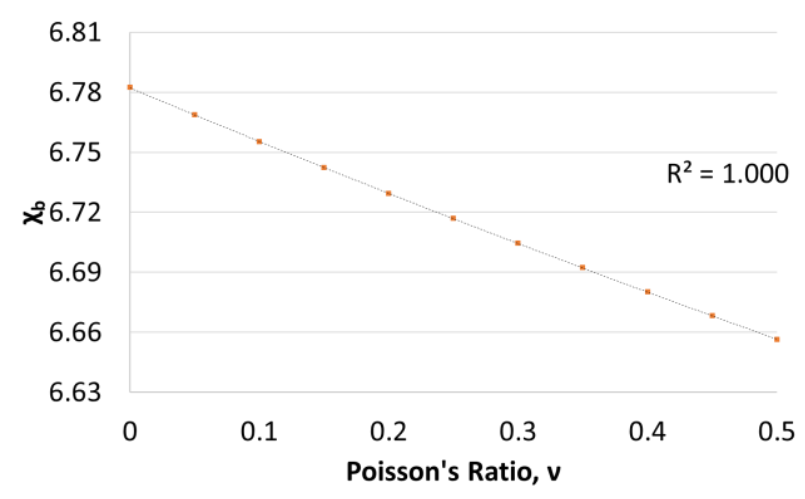

(b)

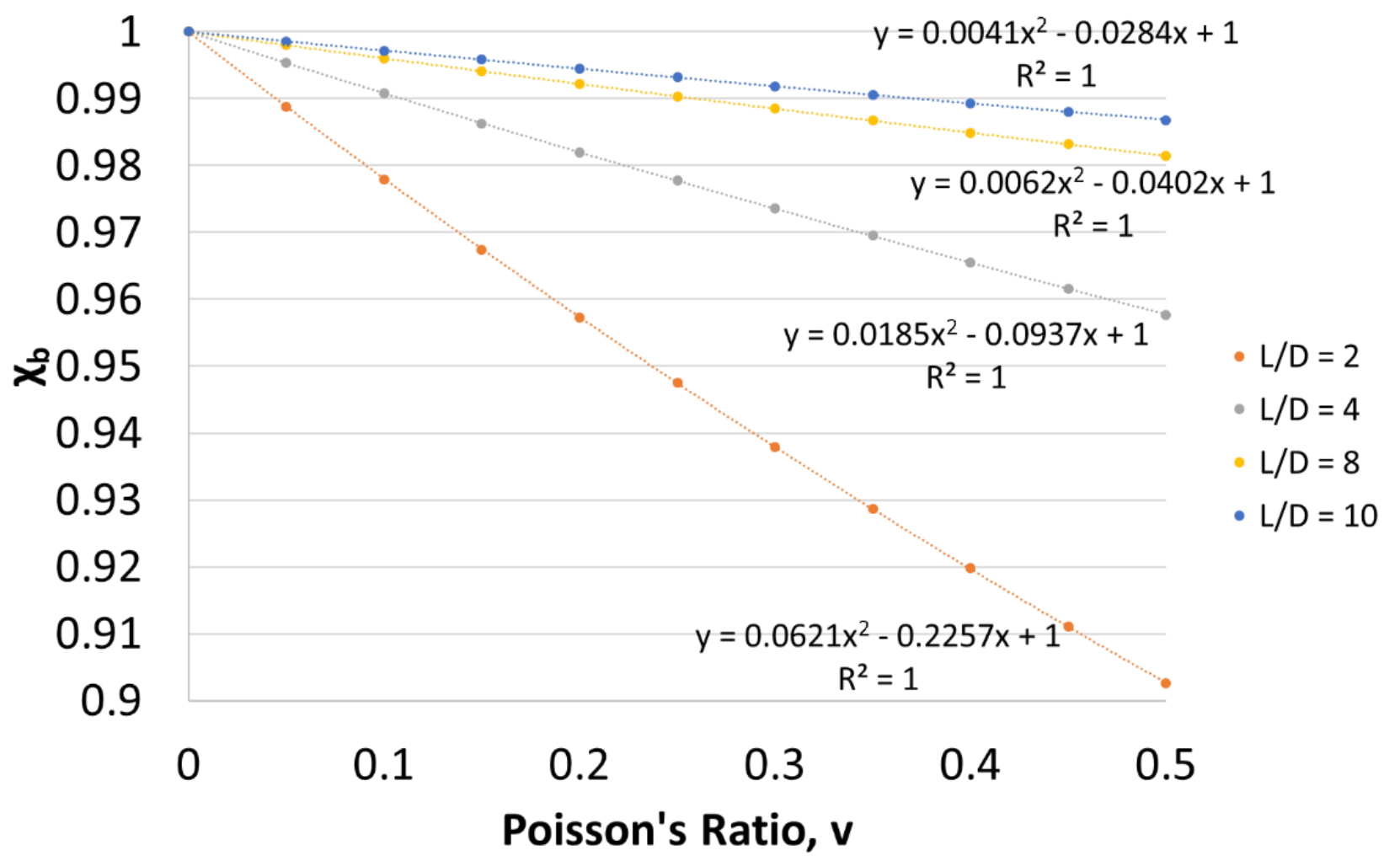

(c)

Figure 3-7. Relationship between $\chi_{b}$ and Poisson's ratio with different rod dimensions (diameter x length): (a) $100 \mathrm{~mm} \times 400 \mathrm{~mm}$, (b) $20 \mathrm{~mm} \times 160 \mathrm{~mm}$ and (c) normalized $\chi_{b}$ for different $L / D$ ratios $(L / D=2,4,8$ and 10$)$ 
Table 3-5. Calculation of $\gamma_{1}, \gamma_{2}$ and $\chi_{b}$ for different length/diameter ratios

\begin{tabular}{|c|c|c|c|c|c|c|c|c|c|c|c|c|c|c|c|}
\hline \multirow{2}{*}{$\begin{array}{c}\text { Poisson's } \\
\text { Ratio, } v\end{array}$} & \multicolumn{3}{|c|}{$L / D=4$} & \multicolumn{3}{|c|}{$L / D=20$} & \multicolumn{3}{|c|}{$\mathbf{L} / \mathbf{D}=\mathbf{5 0}$} & \multicolumn{3}{|c|}{$\mathrm{L} / \mathrm{D}=100$} & \multicolumn{3}{|c|}{$\mathrm{L} / \mathrm{D}=\mathbf{2 0 0}$} \\
\hline & $\gamma_{1}$ & $\gamma_{2}$ & $\chi_{b}$ & $\gamma_{1}$ & $\gamma_{2}$ & $\chi_{b}$ & $\gamma_{1}$ & $\gamma_{2}$ & $\chi_{b}$ & $\gamma_{1}$ & $\gamma_{2}$ & $\chi_{b}$ & $\gamma_{1}$ & $\gamma_{2}$ & $\chi_{b}$ \\
\hline 0 & 4.4389 & 6.801 & 5.511 & 4.7157 & 7.789 & 7.441 & 4.7277 & 7.843 & 7.572 & 4.7295 & 7.851 & 7.592 & 4.7299 & 7.853 & 7.597 \\
\hline 0.1 & 4.4331 & 6.776 & 5.460 & 4.7154 & 7.786 & 7.435 & 4.7277 & 7.842 & 7.571 & 4.7294 & 7.850 & 7.592 & 4.7299 & 7.853 & 7.597 \\
\hline 0.2 & 4.4274 & 6.753 & 5.412 & 4.7150 & 7.784 & 7.429 & 4.7276 & 7.842 & 7.570 & 4.7294 & 7.850 & 7.591 & 4.7299 & 7.852 & 7.597 \\
\hline 0.3 & 4.4220 & 6.730 & 5.365 & 4.7147 & 7.782 & 7.423 & 4.7276 & 7.842 & 7.569 & 4.7294 & 7.850 & 7.591 & 4.7299 & 7.852 & 7.597 \\
\hline 0.4 & 4.4166 & 6.708 & 5.321 & 4.7143 & 7.780 & 7.418 & 4.7275 & 7.841 & 7.568 & 4.7294 & 7.850 & 7.591 & 4.7299 & 7.852 & 7.597 \\
\hline 0.5 & 4.4114 & 6.686 & 5.278 & 4.7140 & 7.778 & 7.412 & 4.7275 & 7.841 & 7.568 & 4.7294 & 7.850 & 7.591 & 4.7299 & 7.852 & 7.597 \\
\hline
\end{tabular}

The Poisson's ratio can then be calculated using the equation below:

$$
v=\frac{-D_{1}-\sqrt{D_{1}^{2}-4 C_{1}\left(E_{1}-\left(\frac{n_{2}}{n_{1}}\right)^{2}\right)}}{2 C_{1}}
$$

Therefore, Poisson's ratio can be readily calculated using the experimentally measured transverse vibration frequencies, $n_{2}$ and $n_{1}$. Furthermore, after knowing Poisson's ratio, the elastic modulus can be determined using the $1^{\text {st }}$ bending mode as shown in Eq. (28). To find $\gamma_{1}$, one can use Eq. (22) and Eq. (23) and the calculated Poisson's ratio from Eq. (27). Hence, the elastic modulus can be calculated directly as:

$$
E=4 \rho L^{2} n_{1}^{2} R\left(A_{1} v+B_{1}\right)
$$

The equation can also be used to determine the $1^{\text {st }}$ bending mode solely from the dimensions of the beam and assumed elastic constants without solving the Timoshenko frequency equation. Using the equations presented above the dynamic elastic modulus and Poisson's ratio can be calculated using the experimental resonance frequencies if the coefficients $A_{1}, B_{1}, C_{1}, D_{1}$ and $E_{1}$ are known beforehand. 


\subsection{Summary}

This chapter discusses the derivation of the bending modes using the Timoshenko beam vibration equation and the torsional mode using the Euler-Bernoulli beam simplification. The equation of motion was solved using the boundary conditions of a freefree beam. In the case of the Timoshenko beam vibration a closed form solution cannot be obtained therefore the natural frequencies are expressed in terms of the eigenvalues which can be solved with numerical methods. It was shown that the exact solution matches closely with a commercial FEM software. After solving the bending and torsional modes, the ratio between the $1^{\text {st }}$ bending mode and $1^{\text {st }}$ torsional mode was investigated. Likewise, an examination of the ratio between the $1^{\text {st }}$ and $2^{\text {nd }}$ bending modes is described. Furthermore, equations are presented to allow a direct determination of the dynamic elastic modulus and Poisson's ratio. 


\section{Chapter 4 Empirical Relationships}

\subsection{Introduction}

In order to determine the elastic constants, the coefficients $A_{1}, B_{1}, C_{1}, D_{1}$ and $E_{1}$ are needed. In this chapter, the coefficients were tabulated for a variety of dimensions. For the rectangular prism the width/height $(b / t)$ and the length/height $(L / t)$ ratios were considered. For the rod, only the length/diameter $(L / D)$ ratio must be considered. Based on the tabulated values, empirical equations will be proposed to determine the coefficients based on the stated ratios. This chapter contains two separate sections. The first describes the empirical equations for $A_{1}$ and $B_{1}$ which are used with $\chi_{\mathrm{t}}$. Likewise the second section describes the empirical equations to obtain $C_{1}, D_{1}$ and $E_{1}$.

\section{2 $A_{1}$ and $B_{1}$}

\subsubsection{Rectangular Prism}

The values of $A_{1}$ and $B_{1}$ for different specimen dimensions were found by calculating $\chi_{\mathrm{t}}$ for different width/height and length/height ratios as well as varying Poisson's ratio. It is noted from Eq. (20) that the frequency ratio $\chi_{t}$ is only dependent on the dimensional properties of the beam and is independent of the elastic modulus, Poisson's ratio and mass density of the beam, therefore, any set of material proprieties would produce the same values of $A_{1}$ and $B_{1}$. Note, that the values of $\chi_{t}$ and its derived $A_{1}$ and $B_{1}$ shown in this study are only applicable to the $1^{\text {st }}$ bending and $1^{\text {st }}$ torsional mode of a Timoshenko beam with free-free boundary conditions. The constant $B_{1}$ was found by calculating $\chi_{t}$ when Poisson's ratio is equal to zero. The calculated values for $\chi_{t}$ are shown in Table 4-1; 
$B_{1}=\chi_{t}($ when $v=0) . B_{1}$ increases when either the width/height or length/height ratio increases.

Table 4-1. The values of $B_{1}$ for different length/height and width/height ratios

\begin{tabular}{cccccccc}
\hline \multicolumn{7}{c}{ Length/height } \\
$\begin{array}{c}\text { Width/ } \\
\text { height }\end{array}$ & 2 & 4 & 8 & 10 & 20 & 50 & 100 \\
\hline 0.100 & 0.08393 & 0.19443 & 0.61853 & 0.93502 & 3.56964 & 22.00805 & 87.85889 \\
0.200 & 0.30414 & 0.70452 & 2.24123 & 3.38804 & 12.93459 & 79.74610 & 318.35648 \\
0.300 & 0.60594 & 1.40364 & 4.46524 & 6.75005 & 25.76982 & 158.87963 & 634.26746 \\
0.400 & 0.93411 & 2.16384 & 6.88359 & 10.40585 & 39.72664 & 244.92812 & 977.78387 \\
0.500 & 1.24246 & 2.87812 & 9.15585 & 13.84081 & 52.84035 & 325.77858 & 1300.54908 \\
0.600 & 1.49940 & 3.47332 & 11.04929 & 16.70310 & 63.76778 & 393.14986 & 1569.50370 \\
0.700 & 1.68946 & 3.91356 & 12.44981 & 18.82025 & 71.85045 & 442.98227 & 1768.44095 \\
0.750 & 1.75868 & 4.07392 & 12.95992 & 19.59138 & 74.79440 & 461.13270 & 1840.89974 \\
0.800 & 1.81196 & 4.19735 & 13.35257 & 20.18494 & 77.06048 & 475.10382 & 1896.67420 \\
0.900 & 1.87866 & 4.35185 & 13.84409 & 20.92797 & 79.89715 & 492.59289 & 1966.49279 \\
1.000 & 1.91126 & 4.42737 & 14.08433 & 21.29113 & 81.28360 & 501.14079 & 2000.61709 \\
\hline \hline
\end{tabular}

It is found from Table 4-1 that when $B_{1}$ values are normalized, it becomes independent of length/height ratio. In this case, $B_{1}$ was normalized using the value at a width/height ratio of 1.0, representing a square cross-section. Figure 4-1 shows the relationship between the normalized $B_{1}$, called $\overline{B_{1}}$, and the width/height, $b / t$, ratio which is independent of length/height ratios. A sixth order polynomial can be used to express the normalized $B_{1}$ with an $R^{2}=1.000$. The equation is shown below: 


$$
\begin{gathered}
\overline{B_{1}}=-1.430658\left(\frac{b}{t}\right)^{6}+4.569006\left(\frac{b}{t}\right)^{5}-2.577872\left(\frac{b}{t}\right)^{4} \\
-4.773641\left(\frac{b}{t}\right)^{3}+5.283568\left(\frac{b}{t}\right)^{2}-0.073874\left(\frac{b}{t}\right) \\
+0.003463 \\
B_{1}=\overline{B_{1}} * B_{1} \text { at }\left(\frac{b}{t}\right)=1.0
\end{gathered}
$$

After calculating $\overline{B_{1}}, B_{1}$ can be found by multiplying its respective normalization value. For example, $B_{1}$ for a width/height ratio of 0.75 and length/height ratio of 20 can be calculated as follows:

1. Calculate $\overline{B_{1}}$ using Eq. (29); $(b / t=0.75)$ to obtain $\overline{B_{1}}=0.92015$

2. Using Table 4-2 obtain $B_{1}$ for a square specimen of the same length/height ratio $(L / t=20)$ : $B_{1}=81.2836$

3. Multiply the values from steps 1 and 2 to get $B_{1}=74.7931$

Table 4-2. Value of $B_{1}$ for a width/height ratio of 1.0

\begin{tabular}{lccccccc}
\hline \multicolumn{8}{c}{ Length/height } \\
Width/ & \multicolumn{8}{c}{. } & & & & \\
height & 2 & 4 & 8 & 10 & 20 & 50 & 100 \\
1.000 & 1.91126 & 4.42737 & 14.08433 & 21.29113 & 81.28360 & 501.14079 & 2000.61709 \\
\hline \hline
\end{tabular}




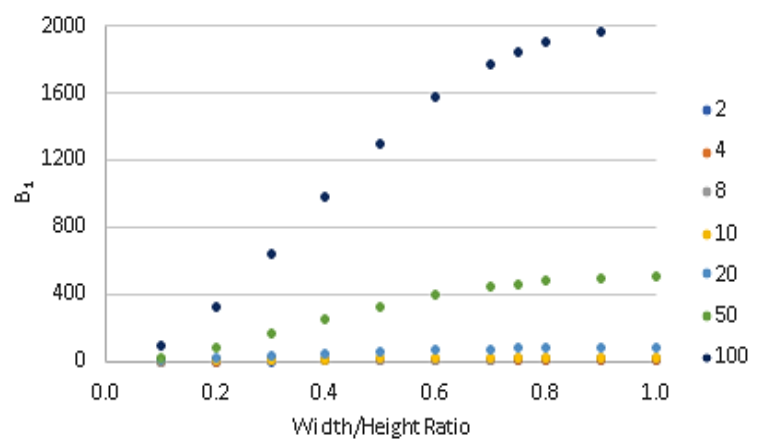

(a)

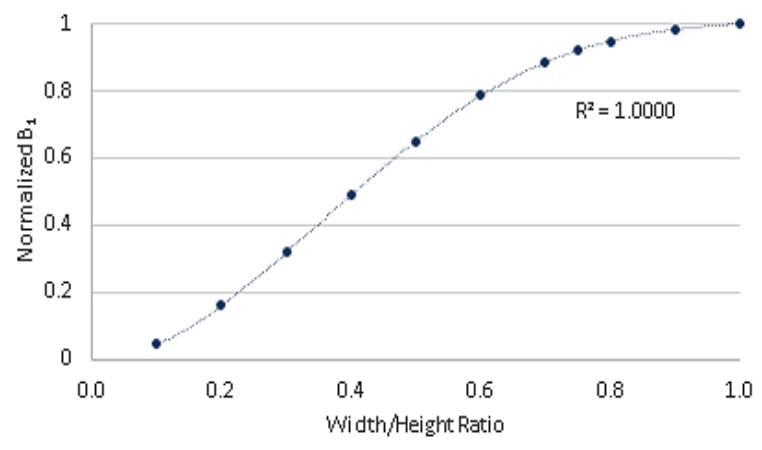

(b)

Figure 4-1. (a) $B_{1}$ versus width/height ( $\left.b / t\right)$ ratio for the cases with different length/height ratios (b) Normalized $B_{1}$ by $B_{1}$ at $(b / t=1.0)$ for all the cases with different width/height ratios

A similar procedure was carried out to determine the slope constant $A_{1}$. The transverse mode and torsional mode were determined using Poisson's ratio ranging from 0.0 to 0.5 in increments of 0.05 . After plotting $\chi_{t}$, the best fit line was used to find $A_{1}$. The coefficient of determination, $R^{2}$, was above 0.999 for all the cases. Table 4-3 shows the calculated value of $A_{1}$ for different specimen dimensions. Like $B_{1}$, the slope, $A_{1}$, increases when the width/height ratio and length/height ratio are enlarged. As the beam gets longer, the value of $A_{1}$ approaches a constant value, indicating that the beam behaves more like a Euler-Bernoulli slender beam. For larger length/height ratios $(L / t>20)$, when compared to $B_{1}$, the variation of $A_{1}$ is very small. Therefore, $\chi_{t}$ approaches a constant value equal to only $B_{1}$.

Table 4-3. The value of $A_{1}$ for different width/height and length/height ratios

Length/height

Width/ height 2 4 8 10 20 50 


\begin{tabular}{llllllll}
\hline 0.100 & 0.011936 & 0.015104 & 0.017019 & 0.017343 & 0.017827 & 0.017974 & 0.017995 \\
0.200 & 0.042568 & 0.054725 & 0.061662 & 0.062837 & 0.064590 & 0.065124 & 0.065203 \\
0.300 & 0.086132 & 0.108994 & 0.122812 & 0.125152 & 0.128642 & 0.129707 & 0.129863 \\
0.400 & 0.132667 & 0.167886 & 0.189171 & 0.192776 & 0.198151 & 0.199792 & 0.200032 \\
0.500 & 0.176157 & 0.222933 & 0.251199 & 0.255986 & 0.263125 & 0.265303 & 0.265622 \\
0.600 & 0.211951 & 0.268255 & 0.302273 & 0.308034 & 0.316624 & 0.319249 & 0.319628 \\
0.700 & 0.237695 & 0.300878 & 0.339043 & 0.345506 & 0.355141 & 0.358082 & 0.358511 \\
0.750 & 0.246657 & 0.312251 & 0.351866 & 0.358573 & 0.368573 & 0.371626 & 0.372071 \\
0.800 & 0.253177 & 0.320540 & 0.361216 & 0.368102 & 0.378369 & 0.381503 & 0.381961 \\
0.900 & 0.259994 & 0.329266 & 0.371066 & 0.378142 & 0.388690 & 0.391909 & 0.392380 \\
1.000 & 0.261149 & 0.330844 & 0.372879 & 0.379992 & 0.390594 & 0.393829 & 0.394303 \\
\hline \hline
\end{tabular}

After normalization by the square section $(b / t=1.0)$, the normalized $A_{1}$ value is plotted in Figure 4-2; the equation below was found from the best fit curve to obtain the normalized value, $\overline{A_{1}}$, for any width/height ratio.

$$
\begin{gathered}
\overline{A_{1}}=3.19490\left(\frac{b}{t}\right)^{4}-8.58348\left(\frac{b}{t}\right)^{3}+6.61445\left(\frac{b}{t}\right)^{2}-0.23720\left(\frac{b}{t}\right) \\
+0.01152 \\
A_{1}=\overline{A_{1}} * A_{1} \text { at }\left(\frac{b}{t}\right)=1.0
\end{gathered}
$$

After calculating $\overline{A_{1}}, A_{1}$ can be found by multiplying by its respective normalization value. For example, $A_{1}$ for a width/height ratio of 0.75 and length/height ratio of 20, can be calculated as follows:

1. Calculate $\overline{A_{1}}$ using Eq. $(31) ;(b / t=0.75)$ to obtain $\overline{A_{1}}=0.94398$

2. Using Table 4-4, determine $A_{1}$ for a square specimen of the same length/height ratio $(L / t$ $=20): A_{1}=0.390594$

3. Multiply the values from Steps 1 and 2 to calculate $A_{1}=0.368712$ 
Therefore, $\quad \chi_{t}=A_{1} v+B_{1}=0.368712 * 0.2+74.7931=74.867, \quad$ and the frequency ratio square can be calculated as $\frac{74.867}{2(0.2+1)}=31.195$ for a beam with $b / t=0.75$ and $L / t=20$.

Table 4-4. Value of $A_{1}$ for a width/height ratio of 1.0

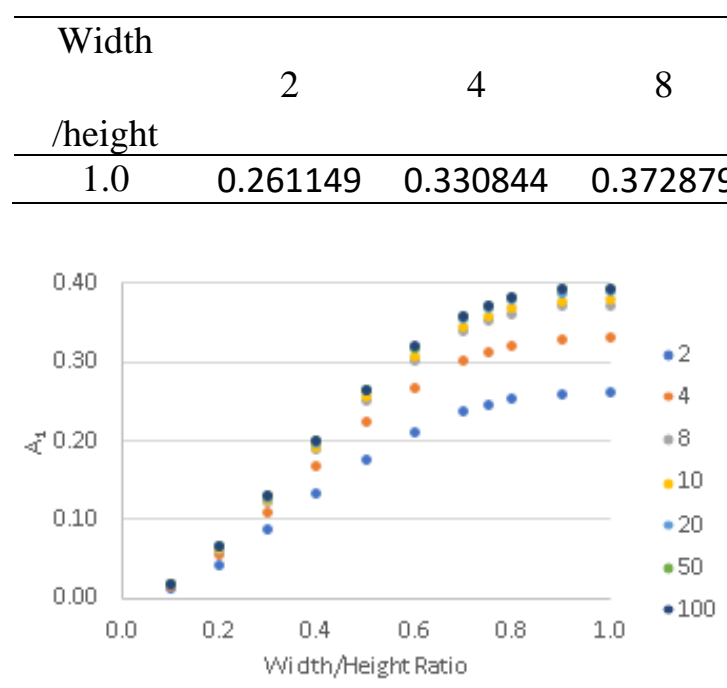

(a)

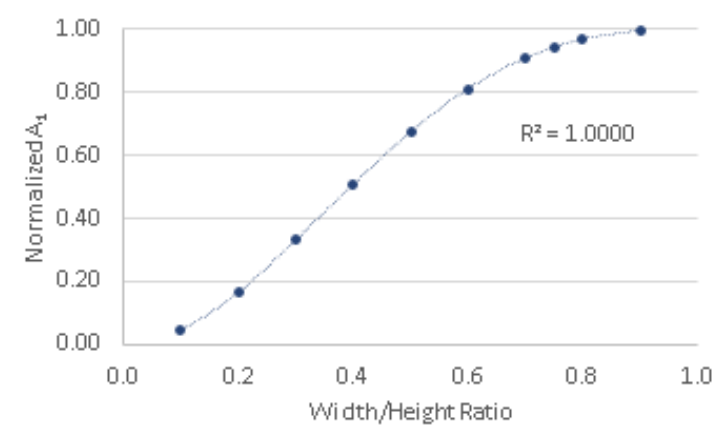

(b)

Figure 4-2. (a) $A_{1}$ versus width/height (b/t) ratio for the cases with different length/height ratios (b) Normalized $A_{1}$ by $A_{1}$ at $(b / t=1.0)$ for all the cases with different width/height ratios

As an example, FEM was performed for a steel prism with an assumed elastic modulus, Poisson's ratio and density of $200 \mathrm{GPa}, 0.3$ and $7750 \mathrm{~kg} \mathrm{~m}^{-3}$, respectively. The ratio between the $1^{\text {st }}$ bending mode and $1^{\text {st }}$ torsional mode was calculated using the resonance frequencies obtained from FEM. Using Eq. (17) with the values of $A_{1}$ and $B_{1}$, obtained from Eq. (29) and Eq. (31), the ratio between the frequencies can be calculated as well. Table 4-5 shows that the first bending mode and the first torsional mode frequencies 
calculated using Eq. (21), Eq. (22) and Eq. (23) compare closely with the FEM results with a maximum difference of $0.11 \%$.

Table 4-5. Steel prism with different length/height ratio

\begin{tabular}{cccccccc}
\hline & \multicolumn{2}{c}{ FEM } & \multicolumn{3}{c}{ Theoretical } \\
\cline { 2 - 7 } Specimen Size & $\begin{array}{c}\text { Bending } \\
\text { Mode } \\
(\mathrm{Hz})\end{array}$ & $\begin{array}{c}\text { Torsional } \\
\text { Mode } \\
(\mathrm{Hz})\end{array}$ & $A_{l}$ & $B_{l}$ & $\begin{array}{c}\text { Bending } \\
\text { Mode } \\
(\mathrm{Hz})\end{array}$ & $\begin{array}{c}\text { Torsional } \\
\text { Mode } \\
(\mathrm{Hz})\end{array}$ \\
\hline $75 \mathrm{~mm} \times 100 \mathrm{~mm} \times 2000 \mathrm{~mm}$ & 127.3 & 682.98 & 0.368712 & 74.79311 & 127.39 & 683.74 \\
$75 \mathrm{~mm} \times 100 \mathrm{~mm} \times 400 \mathrm{~mm}$ & 2699.3 & 3417.9 & 0.312310 & 4.073845 & 2700.22 & 3418.71 \\
\hline
\end{tabular}

The method described above can be used to find $A_{1}$ and $B_{1}$ for any width/height ratio provided that the value of $A_{1}$ and $B_{1}$ are known for a $b / t=1.0$. In Table 4-2 and Table 4-4, the values of $A_{1}$ and $B_{1}$ at $b / t=1.0$ were given for a set of length/height ratios. For those cases that the length/height ratio is not tabulated in Table 4-2 and Table 4-4, a set of equations were developed to calculate $A_{1}$ and $B_{1}$ in terms of the length/height ratio. Eq. (33) and Eq. (34) were developed using the analytical results from Eq. (20) and Eq. (21). The results of $A_{1}$ and $B_{1}$ at $b / t=1.0$ versus the length/height ratio are plotted in Figure 4-3 and Figure 4-4. High order polynomials were chosen to minimize the maximum percent error within $0.1 \%$ from the exact frequency ratio calculated from Eq. (20). Hence, the frequency ratio of the $1^{\text {st }}$ bending mode and the $1^{\text {st }}$ torsional mode for any combination of specimen dimensions can now be estimated. 


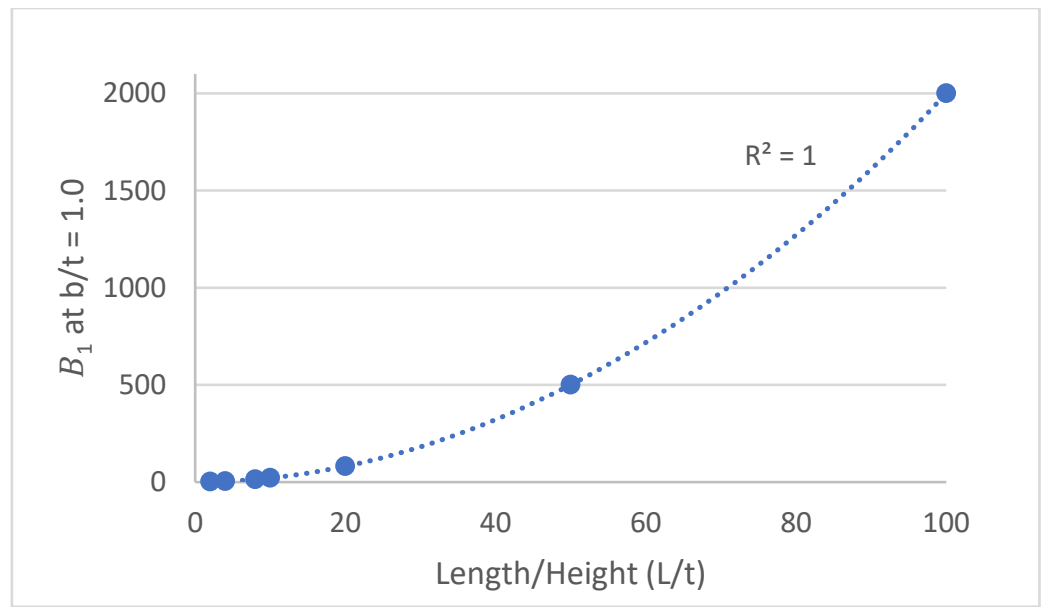

Figure 4-3. Plot of $B_{1}($ at $b / t=1.0)$ versus length/height $(L / t)$ ratio

$$
\begin{aligned}
B_{1}\left(\frac{b}{t}\right. & =1.0)=5.2931 \times 10^{-8}\left(\frac{L}{t}\right)^{5}-9.8630 \times 10^{-6}\left(\frac{L}{t}\right)^{4} \\
& +5.7429 \times 10^{-4}\left(\frac{L}{t}\right)^{3}+0.18707\left(\frac{L}{t}\right)^{2}+0.11725\left(\frac{L}{t}\right) \\
& +0.92607
\end{aligned}
$$

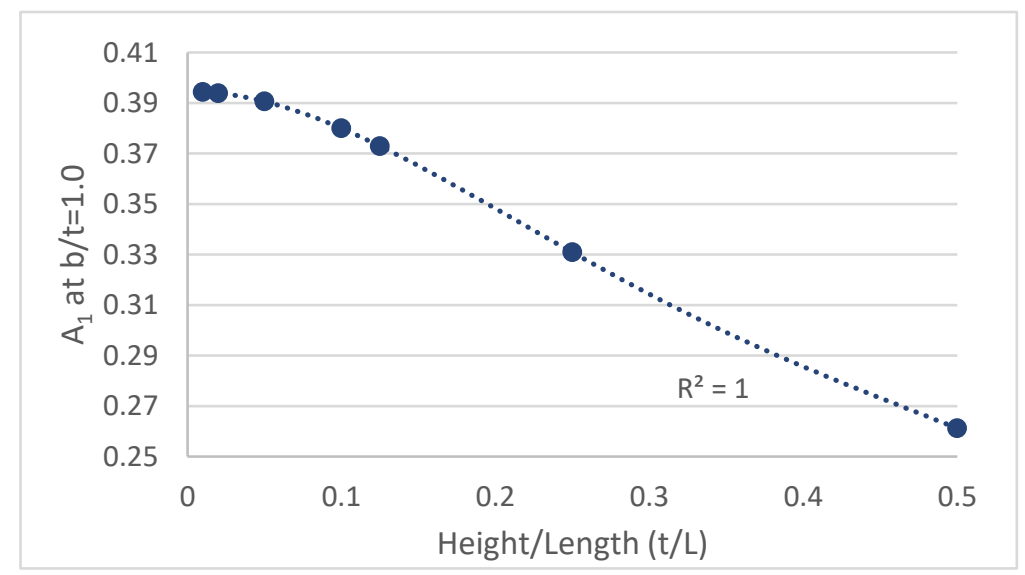

Figure 4-4. Plot of $A_{1}$ (at $b / t=1.0$ ) versus height/length ratio, $(t / L)$ 


$$
\begin{aligned}
A_{1}\left(\frac{b}{t}=\right. & 1.0)=-3.3844\left(\frac{t}{L}\right)^{4}+4.5900\left(\frac{t}{L}\right)^{3}-2.0115\left(\frac{t}{L}\right)^{2} \\
& +0.014948\left(\frac{t}{L}\right)+0.39433
\end{aligned}
$$

To illustrate the usefulness of the above equations, the measured bending frequencies, $n_{1}(\mathrm{~Hz})$ of eighteen steel specimens from the paper by Spinner et.al. are shown in Table 4-6 (Spinner, Reichard, and Tefft 1960). In that paper, each set of specimens were cut from the same stock piece to maintain uniformity of the material properties; the Young's modulus and Poisson's ratio were given as 21,130 MPa and 0.285. The frequencies predicted by the proposed equations are presented in the Table 4-7; it can be seen that the bending frequency predictions of all the specimens are mostly within $0.1 \%$ difference, with a maximum difference of $0.223 \%$. 
Table 4-6. Experimental data from Spinner et.al (1960).

\begin{tabular}{cccccc}
\hline Specimen & Length $(\mathrm{cm})$ & Height $(\mathrm{cm})$ & Width $(\mathrm{cm})$ & Density $\left(\mathrm{g} / \mathrm{cm}^{3}\right)$ & $n_{I}(\mathrm{~Hz})$ \\
II-1 & 15.202 & 3.1496 & 3.1496 & 7.817 & 6411 \\
II-2 & 15.202 & 3.1433 & 2.5405 & 7.819 & 6399 \\
II-3 & 15.202 & 3.1433 & 1.9055 & 7.814 & 6398 \\
II-4 & 15.202 & 3.1433 & 1.5875 & 7.817 & 6400 \\
& & & & & \\
II-5 & 15.202 & 3.1433 & 1.43 & 7.814 & 6397 \\
II-6 & 15.202 & 3.1433 & 1.2708 & 7.816 & 6399 \\
II-7 & 15.202 & 3.1433 & 1.112 & 7.812 & 6399 \\
II-8 & 15.202 & 3.1433 & 0.953 & 7.812 & 6394 \\
& & & & & \\
II-9 & 15.202 & 3.1433 & 0.7943 & 7.813 & 6400 \\
II-10 & 15.202 & 3.1433 & 0.6363 & 7.815 & 6400 \\
II-11 & 15.202 & 3.1433 & 0.4773 & 7.811 & 6400 \\
II-12 & 15.202 & 3.1433 & 0.3172 & 7.814 & 6396 \\
& & & & & \\
II-2a & 7.882 & 3.1433 & 2.5405 & 7.814 & 19203 \\
II-2b & 7.01 & 3.1433 & 2.5405 & 7.817 & 22934 \\
II-3a & 7.546 & 3.1433 & 1.9055 & 7.818 & 20495 \\
II-3b & 7.249 & 3.1433 & 1.9055 & 7.817 & 21789 \\
II-10a & 15.202 & 2.0574 & 0.6363 & 7.816 & 4475 \\
II-10b & 15.202 & 0.6426 & 0.6363 & 7.814 & - \\
\hline
\end{tabular}


Table 4-7. Analytical calculations and comparison with Spinner et.al. experimental data

\begin{tabular}{|c|c|c|c|c|c|c|c|c|c|c|c|c|c|}
\hline \multirow[t]{2}{*}{ Specimen } & \multicolumn{2}{|c|}{ Ratios } & \multirow{2}{*}{$\begin{array}{c}B_{1} \\
(b / t=1.0) \\
\mathrm{Eq}(33)\end{array}$} & \multirow{2}{*}{$\begin{array}{c}A_{1} \\
(b / t=1.0) \\
\mathrm{Eq}(34)\end{array}$} & \multirow{2}{*}{$\begin{array}{c}\overline{B_{1}} \\
\text { Eq (29) }\end{array}$} & \multirow{2}{*}{$\begin{array}{c}B_{1} \\
\mathrm{Eq}(30) \\
\end{array}$} & \multirow{2}{*}{$\begin{array}{c}\overline{A_{1}} \\
\operatorname{Eq}(31)\end{array}$} & \multirow{2}{*}{$\begin{array}{c}A_{1} \\
\operatorname{Eq}(32)\end{array}$} & \multirow[t]{2}{*}{$R$} & \multirow{2}{*}{$\begin{array}{l}n^{\prime \prime}(\mathrm{Hz}) \\
\mathrm{Eq}(23)\end{array}$} & \multirow{2}{*}{$\begin{array}{c}\left(n^{\prime \prime} / n_{1}\right) \\
\mathrm{Eq}(21)\end{array}$} & \multirow[t]{2}{*}{$n_{l}(\mathrm{~Hz})$} & \multirow[t]{2}{*}{$\%$ Difference } \\
\hline & $L / t$ & $b / t$ & & & & & & & & & & & \\
\hline II-1 & 4.827 & 1.000 & 5.909 & 0.346 & 1.000 & 5.909 & 1.000 & 0.346 & 1.183 & 9804.826 & 1.529 & 6412.752 & $0.027 \%$ \\
\hline II-2 & 4.836 & 0.808 & 5.928 & 0.346 & 0.952 & 5.643 & 0.972 & 0.336 & 1.243 & 9564.862 & 1.494 & 6400.907 & $0.030 \%$ \\
\hline II-3 & 4.836 & 0.606 & 5.928 & 0.346 & 0.792 & 4.694 & 0.818 & 0.283 & 1.495 & 8726.009 & 1.363 & 6401.902 & $0.061 \%$ \\
\hline II-4 & 4.836 & 0.505 & 5.928 & 0.346 & 0.658 & 3.898 & 0.681 & 0.235 & 1.800 & 7950.976 & 1.242 & 6400.977 & $0.015 \%$ \\
\hline II-5 & 4.836 & 0.455 & 5.928 & 0.346 & 0.580 & 3.438 & 0.601 & 0.208 & 2.041 & 7467.965 & 1.166 & 6402.290 & $0.083 \%$ \\
\hline II-6 & 4.836 & 0.404 & 5.928 & 0.346 & 0.496 & 2.940 & 0.515 & 0.178 & 2.386 & 6905.851 & 1.079 & 6401.294 & $0.036 \%$ \\
\hline II-7 & 4.836 & 0.354 & 5.928 & 0.346 & 0.409 & 2.427 & 0.425 & 0.147 & 2.891 & 6275.102 & 0.980 & 6402.441 & $0.054 \%$ \\
\hline II- 8 & 4.836 & 0.303 & 5.928 & 0.346 & 0.323 & 1.912 & 0.335 & 0.116 & 3.670 & 5569.300 & 0.870 & 6401.829 & $0.122 \%$ \\
\hline II-9 & 4.836 & 0.253 & 5.928 & 0.346 & 0.239 & 1.417 & 0.248 & 0.086 & 4.953 & 4793.699 & 0.749 & 6401.329 & $0.021 \%$ \\
\hline II-10 & 4.836 & 0.202 & 5.928 & 0.346 & 0.163 & 0.964 & 0.169 & 0.058 & 7.279 & 3953.955 & 0.618 & 6402.143 & $0.033 \%$ \\
\hline II-11 & 4.836 & 0.152 & 5.928 & 0.346 & 0.096 & 0.571 & 0.100 & 0.034 & 12.266 & 3046.702 & 0.475 & 6408.042 & $0.126 \%$ \\
\hline II-12 & 4.836 & 0.101 & 5.928 & 0.346 & 0.045 & 0.265 & 0.046 & 0.016 & 26.483 & 2073.045 & 0.324 & 6401.741 & $0.090 \%$ \\
\hline II- $2 \mathrm{a}$ & 2.508 & 0.808 & 2.405 & 0.286 & 0.952 & 2.289 & 0.972 & 0.278 & 1.243 & 18453.633 & 0.960 & 19223.110 & $0.105 \%$ \\
\hline II-2b & 2.230 & 0.808 & 2.124 & 0.274 & 0.952 & 2.022 & 0.972 & 0.266 & 1.243 & 20745.168 & 0.903 & 22962.887 & $0.126 \%$ \\
\hline II- $3 \mathrm{a}$ & 2.401 & 0.606 & 2.293 & 0.281 & 0.792 & 1.816 & 0.818 & 0.230 & 1.495 & 17574.722 & 0.856 & 20540.628 & $0.223 \%$ \\
\hline II-3b & 2.306 & 0.606 & 2.198 & 0.277 & 0.792 & 1.741 & 0.818 & 0.227 & 1.495 & 18295.949 & 0.838 & 21830.853 & $0.192 \%$ \\
\hline II-10a & 7.389 & 0.309 & 12.209 & 0.370 & 0.333 & 4.064 & 0.346 & 0.128 & 3.556 & 5656.620 & 1.263 & 4478.203 & $0.072 \%$ \\
\hline II- $10 \mathrm{~b}$ & 23.657 & 0.990 & 113.301 & 0.392 & 0.999 & 113.161 & 1.000 & 0.392 & 1.185 & 9800.375 & 6.639 & 1476.203 & - \\
\hline
\end{tabular}




\subsubsection{Rods}

The values of $A_{1}$ and $B_{1}$ for different rod dimensions were found by calculating $\chi_{t}$ for different length/diameter ratios as well as varying Poisson's ratio. The constant $B_{1}$ was found by calculating $\chi_{t}$ when Poisson's ratio is equal to zero. The calculated values for $B_{1}$ are shown in Table 4-8. A similar procedure was carried out to determine $A_{1}$. After plotting $\chi_{t}$, the slope of the best fit line was used to find $A_{1}$. Table 4-8 shows the calculated value of $A_{1}$ for different length/diameter $(L / D)$ ratio.

Table 4-8. The values of $B_{1}$ and $A_{1}$ for different length/diameter ratios

\begin{tabular}{cccccccccc}
\hline & \multicolumn{1}{c}{ Length/diameter $(\boldsymbol{L} / \boldsymbol{D})$} \\
& $\mathbf{2}$ & $\mathbf{3}$ & $\mathbf{4}$ & $\mathbf{5}$ & $\mathbf{8}$ & $\mathbf{1 0}$ & $\mathbf{2 0}$ & $\mathbf{5 0}$ & $\mathbf{1 0 0}$ \\
\hline$B_{1}$ & 2.59893 & 4.25642 & 6.50793 & 9.37206 & 21.7075 & 33.0728 & 127.7261 & 790.2198 & 3156.257 \\
$A_{1}$ & 0.26573 & 0.30686 & 0.33084 & 0.34551 & 0.36556 & 0.37104 & 0.37898 & 0.38135 & 0.38617 \\
\hline
\end{tabular}

As shown in Figure 4-5 and Figure 4-6, polynomials can be used to express the values of $B_{1}$ and $A_{1}$. Although only nine $L / D$ points are shown in Table 4-8, a total of $97 L / D$ data points were used to find the best-fit polynomials. Due to the wide range of $B_{1}$, shown in Figure 4-5, a single polynomial will have a $3 \%$ difference between the estimated values and the theoretical values found using Eq. (20) when $\frac{L}{D}<10$. Therefore, to reduce the difference to less than $0.06 \%$, two polynomials (sixth order) are needed to express $B_{1}$ for two separate intervals, Eq. (35) and Eq. (36). 


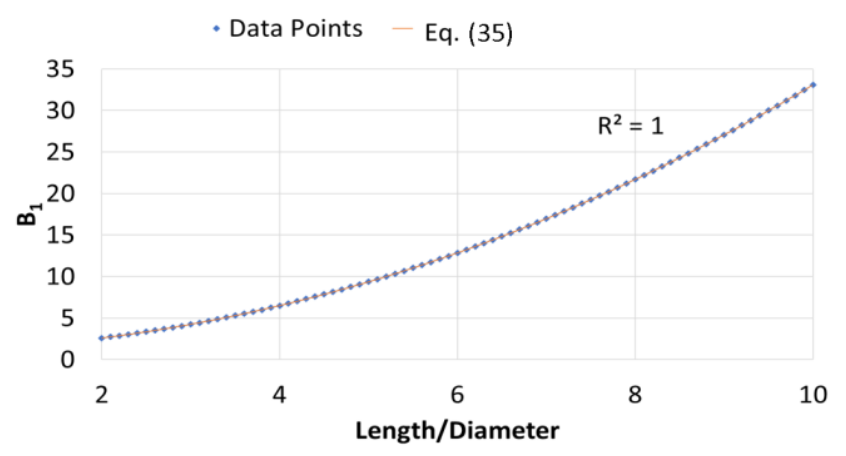

(a)

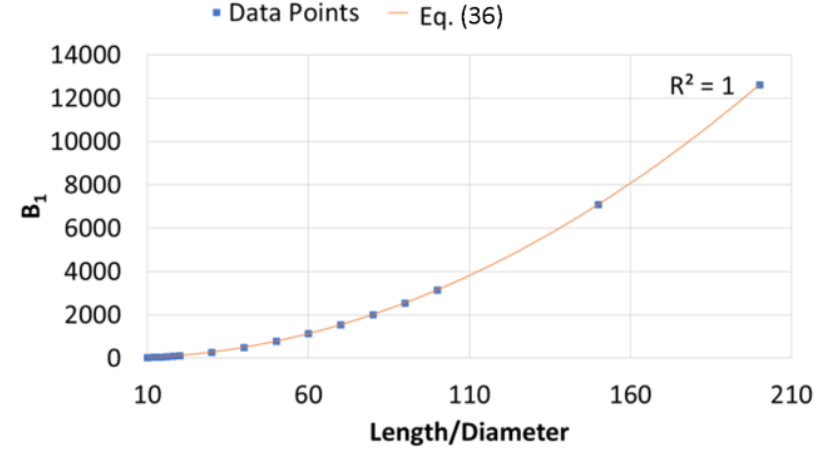

(b)

Figure 4-5. Plot of $\mathrm{B}_{1}$ versus the length/diameter ratio: (a) $\frac{L}{D} \leq 10$ and (b) $\frac{L}{D}>10$

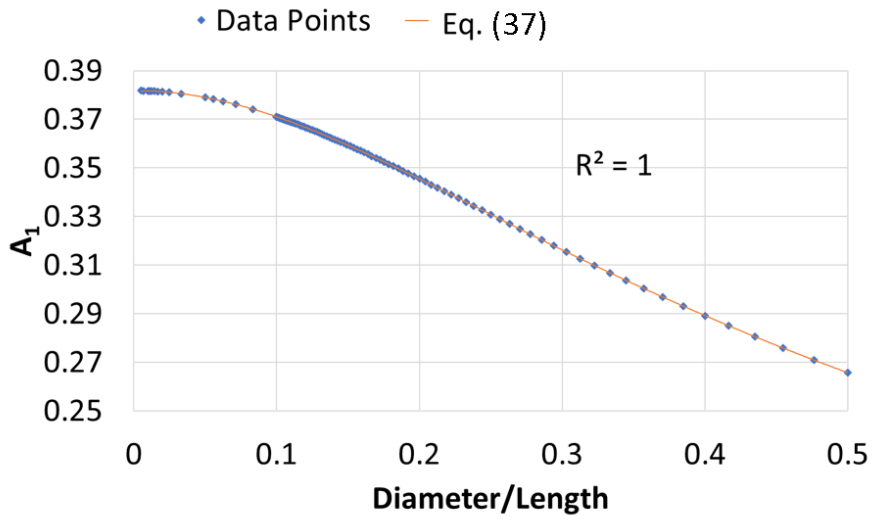

Figure 4-6. Plot of $A_{1}$ versus diameter/length $(D / L)$ ratio

$$
\begin{aligned}
& \text { For } \frac{L}{D} \leq 10 \\
& B_{1}=-2.20790 \cdot 10^{-6}\left(\frac{L}{D}\right)^{6}+9.69895 \cdot 10^{-5}\left(\frac{L}{D}\right)^{5}-1.78941 \cdot 10^{-3}\left(\frac{L}{D}\right)^{4} \\
& +0.0179955\left(\frac{L}{D}\right)^{3}+0.208881\left(\frac{L}{D}\right)^{2}+0.368369\left(\frac{L}{D}\right) \\
& +0.908491
\end{aligned}
$$


For $\frac{L}{D}>10$

$$
\begin{array}{rl}
B_{1}=-2.394 & 73 \cdot 10^{-13}\left(\frac{L}{D}\right)^{6}+1.38944 \cdot 10^{-10}\left(\frac{L}{D}\right)^{5}-3.08859 \cdot 10^{-8}\left(\frac{L}{D}\right)^{4} \\
& +3.34001 \cdot 10^{-6}\left(\frac{L}{D}\right)^{3}+0.315287\left(\frac{L}{D}\right)^{2}+4.89786 \\
& \cdot 10^{-3}\left(\frac{L}{D}\right)+1.49164
\end{array}
$$

Unlike $B_{1}$, only a single polynomial expression is needed for $A_{1}$. Eq. (37) was found from the best fit curve shown in Figure 4-6. Eq. (37) can be used to obtain $A_{1}$ for any diameter/length $(D / L)$ ratio.

$$
\begin{gathered}
A_{1}=9.44922\left(\frac{D}{L}\right)^{6}-13.8392\left(\frac{D}{L}\right)^{5}+5.60087\left(\frac{D}{L}\right)^{4}+1.08665\left(\frac{D}{L}\right)^{3} \\
-1.27914\left(\frac{D}{L}\right)^{2}+5.47273 \cdot 10^{-3}\left(\frac{D}{L}\right)+0.381757
\end{gathered}
$$

\section{$4.3 C_{1}, D_{1}$ and $E_{1}$}

\subsubsection{Rods}

The coefficients $C_{1}, D_{1}$ and $E_{1}$ for different specimen dimensions were found by calculating $\chi_{b}$ for different length/diameter ratios as well as varying Poisson's ratio. It is noted from Eq. (24) that the frequency ratio $\chi_{b}$ is only dependent on the roots of the Timoshenko frequency equation and is independent of the elastic modulus and mass density, therefore, any set of material properties would produce the same values of $C_{1}, D_{1}$ and $E_{1}$. The values of $\chi_{b}$ and its derived $C_{1}, D_{1}$ and $E_{1}$ shown are only applicable to the $1^{\text {st }}$ and $2^{\text {nd }}$ bending mode of a Timoshenko rod with free-free 
boundary conditions. The constant $E_{1}$ was found by calculating $\chi_{b}$ when Poisson's ratio is equal to zero. The calculated values for $E_{1}$ are shown in Table 4-9.

A similar procedure was carried out to determine the coefficients $C_{1}$ and $D_{1}$. The transverse modes were determined using Poisson's ratio ranging from 0.0 to 0.5 in increments of 0.05 . After plotting $\chi_{b}$, the best fit second-order polynomial was used to find $C_{1}$ and $D_{1}$. The coefficient of determination, $R^{2}$, was above 0.999 for all the cases. Table 4-9 shows the calculated values for different specimen dimensions. Unlike $E_{1}$, the coefficients decrease when the length/diameter ratio is enlarged. As the rod gets longer, the value of $C_{1}$ and $D_{1}$ approach zero, indicating that the rod behaves more like a Euler-Bernoulli slender rod. For larger length/diameter ratios $(L / D>20), \chi_{b}$ approaches a constant value equal to only $E_{1}$.

Table 4-9. The values of $C_{1}, D_{1}$ and $E_{1}$ for different length/diameter ratios

\begin{tabular}{cccccccccc}
\hline & & \multicolumn{8}{c}{ Length/diameter $(\boldsymbol{L} / \mathbf{D})$} \\
$\mathbf{C o e f f i c i e n t}$ & $\mathbf{2}$ & $\mathbf{3}$ & $\mathbf{4}$ & $\mathbf{5}$ & $\mathbf{8}$ & $\mathbf{1 0}$ & $\mathbf{2 0}$ & $\mathbf{5 0}$ & $\mathbf{1 0 0}$ \\
\hline$E_{1}$ & 3.69886 & 4.282677 & 5.51093 & 5.99205 & 6.78228 & 7.03545 & 7.44104 & 7.57243 & 7.59195 \\
$D_{1}$ & -0.83478 & -0.60134 & -0.51647 & -0.44455 & -0.27264 & -0.19948 & -0.06117 & -0.01043 & -0.00263 \\
$C_{1}$ & 0.22969 & 0.12914 & 0.10186 & 0.08175 & 0.04227 & 0.02862 & 0.00748 & 0.00120 & 0.0002986 \\
\hline
\end{tabular}

As shown in Figure 4-7, Figure 4-8 and Figure 4-9, the three coefficients can be estimated using polynomial equations, and to increase the accuracy of the proposed method, two intervals are specified for $C_{1}$ and $D_{1}$. A total of $97 L / D$ data points were used to determine the polynomials. The proposed equations can be used to find the coefficients for any $L / D \geq 2$ and allows for the calculation of the elastic constants after knowing the $1^{\text {st }}$ and $2^{\text {nd }}$ bending mode as well as the rod's dimensions. The $6^{\text {th }}$ order polynomials were found to have a maximum percent difference of $0.12 \%$ with the theoretical values. On average the percent difference was $0.01 \%$ indicating that the sixthorder polynomials can be used adequately to estimate the coefficients. 


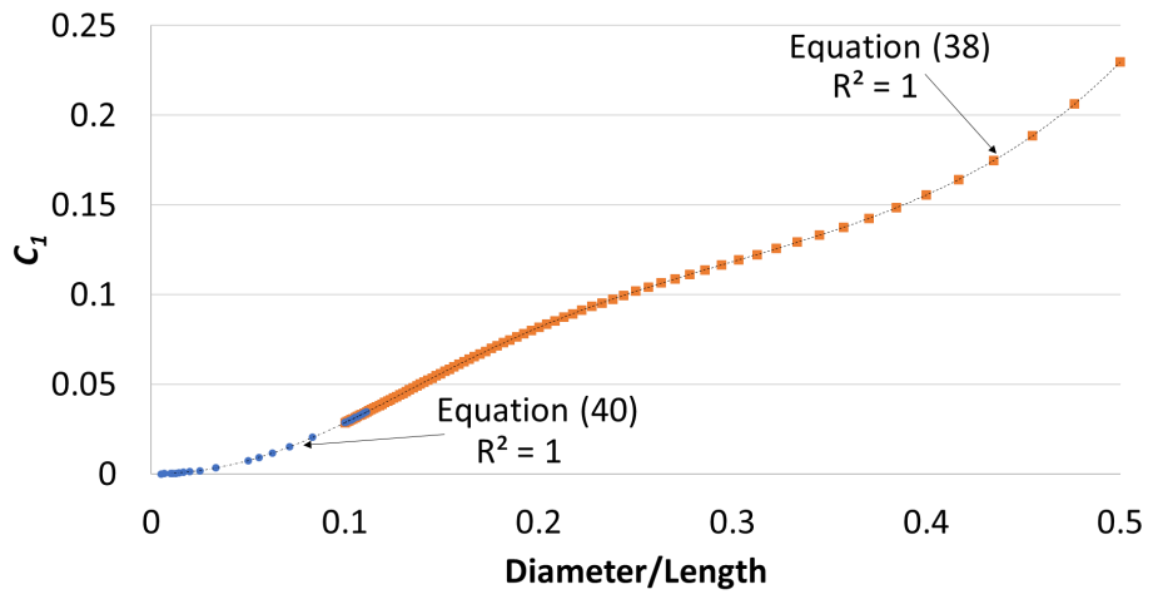

Figure 4-7. Plot of $\mathrm{C}_{1}$ versus the diameter/length $(D / L)$ ratio.

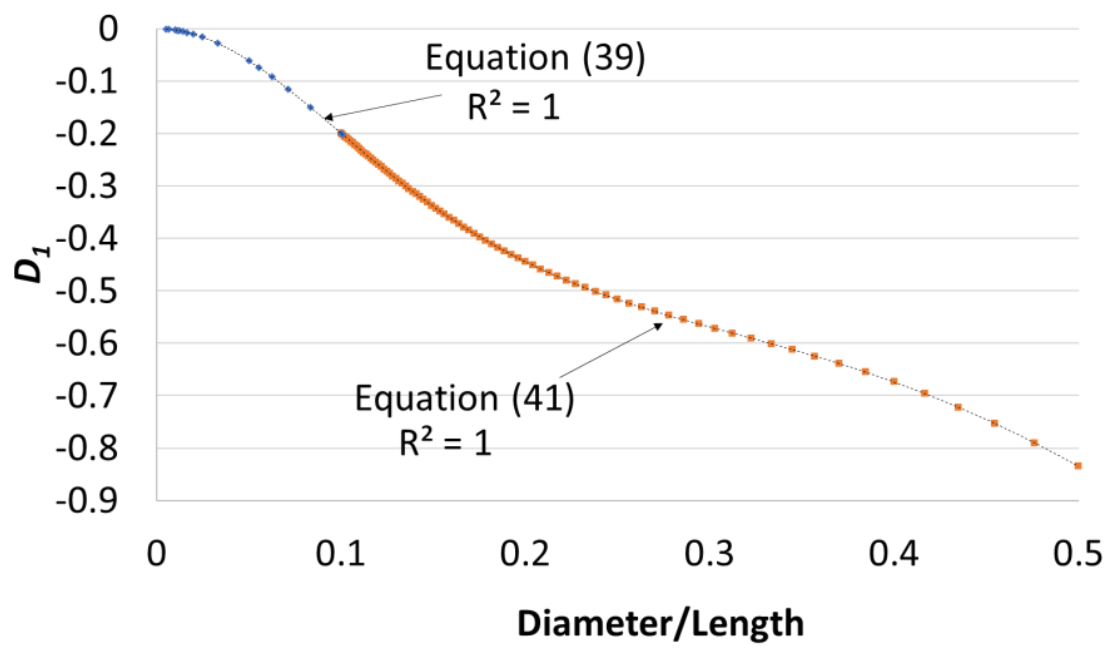

Figure 4-8. Plot of $D_{1}$ versus the diameter/length $(D / L)$ ratio. 


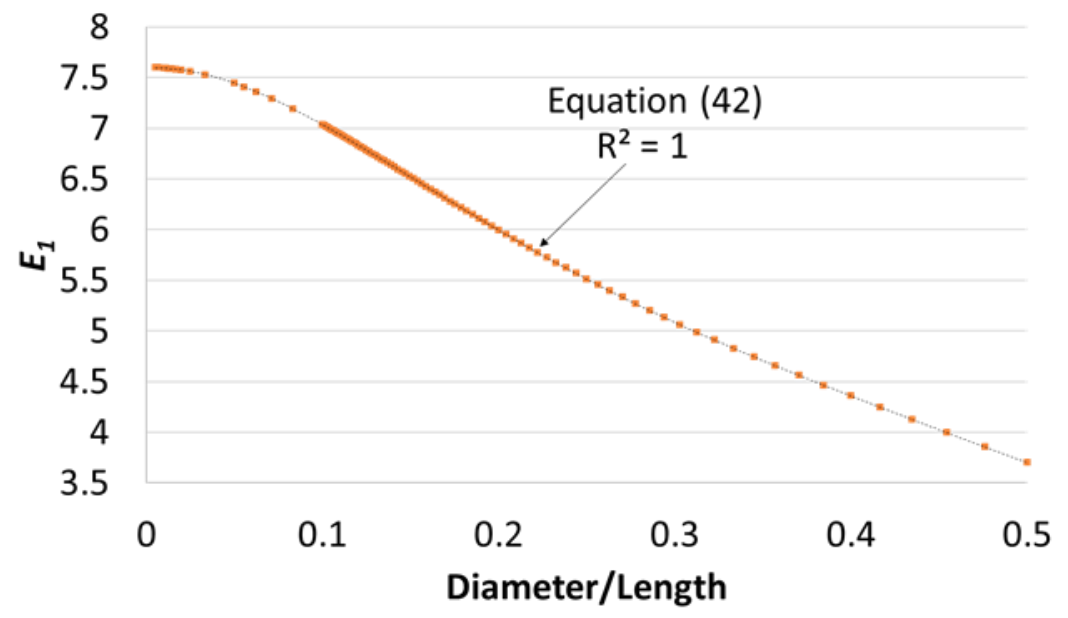

Figure 4-9. Plot of $E_{1}$ versus the diameter/length $(D / L)$ ratio.

For $\frac{L}{D} \leq 10$

$$
\begin{gathered}
C_{1}=112.284\left(\frac{D}{L}\right)^{6}-223.341\left(\frac{D}{L}\right)^{5}+185.884\left(\frac{D}{L}\right)^{4}-77.1737\left(\frac{D}{L}\right)^{3} \\
+15.7309\left(\frac{D}{L}\right)^{2}-0.952765\left(\frac{D}{L}\right)+2.73114 \cdot 10^{-2} \\
D_{1}=-340.388\left(\frac{D}{L}\right)^{6}+717.045\left(\frac{D}{L}\right)^{5}-588.110\left(\frac{D}{L}\right)^{4}+224.277\left(\frac{D}{L}\right)^{3} \\
-35.7879\left(\frac{D}{L}\right)^{2}-0.603707\left(\frac{D}{L}\right)+0.0468
\end{gathered}
$$

For $\frac{L}{D}>10$

$$
\begin{gathered}
C_{1}=2541.87\left(\frac{D}{L}\right)^{6}-920.988\left(\frac{D}{L}\right)^{5}+72.8415\left(\frac{D}{L}\right)^{4}-2.22046\left(\frac{D}{L}\right)^{3} \\
+3.02631\left(\frac{D}{L}\right)^{2}-3.61314 \cdot 10^{-4}\left(\frac{D}{L}\right)+1.08041 \cdot 10^{-6}
\end{gathered}
$$




$$
\begin{aligned}
D_{1}= & 2744.60\left(\frac{D}{L}\right)^{6}-4196.55\left(\frac{D}{L}\right)^{5}+1132.34\left(\frac{D}{L}\right)^{4}-11.5492\left(\frac{D}{L}\right)^{3} \\
& -26.1754\left(\frac{D}{L}\right)^{2}-1.98589 \cdot 10^{-3}\left(\frac{D}{L}\right)+6.00293 \cdot 10^{-6}
\end{aligned}
$$

A single sixth-order polynomial can be used to estimate $E_{1}$. The equation is shown below:

$$
\begin{gathered}
E_{1}=39.7722\left(\frac{D}{L}\right)^{6}+269.519\left(\frac{D}{L}\right)^{5}-530.656\left(\frac{D}{L}\right)^{4}+350.357\left(\frac{D}{L}\right)^{3} \\
-96.4206\left(\frac{D}{L}\right)^{2}+1.08854\left(\frac{D}{L}\right)+7.58933
\end{gathered}
$$

As an example, FEM was performed for a steel rod with an assumed elastic modulus, Poisson's ratio and density of $200 \mathrm{GPa}, 0.3$ and $7750 \mathrm{~kg} \mathrm{~m}^{-3}$, respectively. The values of $A_{1}$ and $B_{1}$ were obtained from Eq. (35) to Eq. (37) while $C_{1}, D_{1}$ and $E_{1}$ were obtained using Eq. (38) to Eq. (42). Table 4-10 shows that the $1^{\text {st }}$ and $2^{\text {nd }}$ bending mode, and the $1^{\text {st }}$ torsional mode

\begin{tabular}{|c|c|c|c|c|c|c|c|c|c|c|c|}
\hline \multirow{3}{*}{$\begin{array}{c}\text { Size } \\
(\mathrm{mm} \times \mathbf{~ m m}) \\
\end{array}$} & \multicolumn{3}{|c|}{ FEM } & \multicolumn{8}{|c|}{ Theoretical } \\
\hline & \multicolumn{2}{|c|}{ Bending $(\mathrm{Hz})$} & \multirow{2}{*}{$\begin{array}{c}\text { Torsional } \\
(\mathbf{H z})\end{array}$} & \multirow{2}{*}{$A_{1}$} & \multirow{2}{*}{$B_{1}$} & \multirow{2}{*}{$\mathbf{C}_{1}$} & \multirow{2}{*}{$\mathbf{D}_{1}$} & \multirow{2}{*}{$\mathbf{E}_{1}$} & \multicolumn{2}{|c|}{ Bending $(\mathrm{Hz})$} & \multirow{2}{*}{$\begin{array}{c}\text { Torsional } \\
(\mathbf{H z})\end{array}$} \\
\hline & $1^{\text {st }}$ & $2^{\text {nd }}$ & & & & & & & $1^{\text {st }}$ & $2^{\text {nd }}$ & \\
\hline $100 \times 2000$ & 112.09 & 305.44 & 784.8 & 0.381786 & 127.7267 & 0.00748 & -0.06116 & 7.4433 & 112.32 & 306.079 & 787.62 \\
\hline $100 \times 400$ & 2468.2 & 5718.0 & 3932.7 & 0.330818 & 6.50796 & 0.10188 & -0.51670 & 5.5142 & 2470.39 & 5723.82 & 3938.11 \\
\hline
\end{tabular}
frequencies calculated using Eq. (22), Eq. (23) and Eq. (28) compare closely with the FEM results with a maximum difference of $0.36 \%$.

Table 4-10. Steel rod with different length/diameter ratio.

\subsubsection{Rectangular Prism}

The coefficients for different $b / t$ and $L / t$ ratios for a rectangular prism are shown in Table 4-11 to Table 4-13. The coefficients were found by evaluating Eq. (34) and fitting the best-fit 
second-order polynomial. Like the rod case, the coefficients are solely dependent on the dimensions of the prism. From the tables as the beam gets slenderer, the value of $C_{1}$ and $D_{1}$ approach zero. Therefore, $\chi_{b}$ becomes a constant equal to only $E_{1}$. It should be noted that $E_{1}$ is only dependent on the length/height ratio unlike the other two coefficients. Similar to the method shown in Section 4.2.1, the coefficients were normalized based on the $b / t=1.0$ values.

Table 4-11. Values of $C_{1}$ for different rectangular prism

\begin{tabular}{cccccccc}
\hline $\begin{array}{c}\text { Width/ } \\
\text { height }\end{array}$ & \multicolumn{7}{c}{ Length/height } \\
& 2 & 4 & 8 & 10 & 20 & 50 & 100 \\
\hline 0.1 & 0.368982 & 0.0883 & 0.027942 & 0.015773 & 0.001645 & $4.98 \mathrm{E}-05$ & $3.23 \mathrm{E}-06$ \\
0.2 & 0.369076 & 0.088384 & 0.027997 & 0.015815 & 0.001659 & $5.25 \mathrm{E}-05$ & $3.89 \mathrm{E}-06$ \\
0.3 & 0.369468 & 0.088734 & 0.028226 & 0.015994 & 0.001721 & $6.34 \mathrm{E}-05$ & $6.68 \mathrm{E}-06$ \\
0.4 & 0.370479 & 0.089639 & 0.028817 & 0.016454 & 0.00188 & $9.17 \mathrm{E}-05$ & $1.39 \mathrm{E}-05$ \\
0.5 & 0.372523 & 0.091465 & 0.030008 & 0.017382 & 0.0022 & 0.000149 & $2.83 \mathrm{E}-05$ \\
0.6 & 0.376077 & 0.094636 & 0.032077 & 0.018993 & 0.002756 & 0.000248 & $5.35 \mathrm{E}-05$ \\
0.7 & 0.381673 & 0.099614 & 0.035322 & 0.021521 & 0.003627 & 0.000403 & $9.29 \mathrm{E}-05$ \\
0.75 & 0.385412 & 0.102931 & 0.037483 & 0.023203 & 0.004207 & 0.000506 & 0.000119 \\
0.8 & 0.389876 & 0.106881 & 0.040055 & 0.025206 & 0.004897 & 0.000629 & 0.00015 \\
0.9 & 0.401277 & 0.116923 & 0.046586 & 0.030289 & 0.006648 & 0.00094 & 0.000229 \\
1 & 0.416492 & 0.130217 & 0.055217 & 0.037004 & 0.008959 & 0.001351 & 0.000334 \\
\hline
\end{tabular}

Table 4-12. Values of $D_{1}$ for different rectangular prisms

\begin{tabular}{cccccccc}
\hline $\begin{array}{c}\text { Width/ } \\
\text { height }\end{array}$ & \multicolumn{7}{c}{ Length/height } \\
& 2 & 4 & 8 & 10 & 20 & 50 & 100 \\
\hline 0.1 & -1.15596 & -0.67323 & -0.39308 & -0.29698 & -0.09656 & -0.01681 & -0.00426 \\
0.2 & -1.15593 & -0.67321 & -0.39307 & -0.29697 & -0.09656 & -0.01681 & -0.00426 \\
0.3 & -1.1558 & -0.67315 & -0.39304 & -0.29695 & -0.09655 & -0.01681 & -0.00426 \\
0.4 & -1.15548 & -0.673 & -0.39296 & -0.29689 & -0.09653 & -0.01681 & -0.00425
\end{tabular}




\begin{tabular}{cccccccc}
0.5 & -1.15483 & -0.6727 & -0.3928 & -0.29677 & -0.0965 & -0.0168 & -0.00425 \\
0.6 & -1.15371 & -0.67218 & -0.39253 & -0.29657 & -0.09644 & -0.01679 & -0.00425 \\
0.7 & -1.15195 & -0.67136 & -0.3921 & -0.29625 & -0.09634 & -0.01677 & -0.00425 \\
0.75 & -1.15078 & -0.67082 & -0.39181 & -0.29604 & -0.09627 & -0.01676 & -0.00424 \\
0.8 & -1.14939 & -0.67018 & -0.39147 & -0.29579 & -0.0962 & -0.01675 & -0.00424 \\
0.9 & -1.14589 & -0.66854 & -0.3906 & -0.29516 & -0.096 & -0.01672 & -0.00423 \\
1 & -1.1413 & -0.6664 & -0.38946 & -0.29432 & -0.09575 & -0.01667 & -0.00422 \\
\hline
\end{tabular}

Table 4-13. Values of $E_{1}$ for different rectangular prisms

\begin{tabular}{|c|c|c|c|c|c|c|c|}
\hline \multirow{2}{*}{$\begin{array}{l}\text { Width/ } \\
\text { height }\end{array}$} & \multicolumn{7}{|c|}{ Length/height } \\
\hline & 2 & 4 & 8 & 10 & 20 & 50 & 100 \\
\hline 0.1 & 3.151485 & 5.153886 & 6.564285 & 6.871066 & 7.3881 & 7.5633 & 7.5896 \\
\hline 0.2 & 3.151485 & 5.153886 & 6.564285 & 6.871066 & 7.3881 & 7.5633 & 7.5896 \\
\hline 0.3 & 3.151485 & 5.153886 & 6.564285 & 6.871066 & 7.3881 & 7.5633 & 7.5896 \\
\hline 0.4 & 3.151485 & 5.153886 & 6.564285 & 6.871066 & 7.3881 & 7.5633 & 7.5896 \\
\hline 0.5 & 3.151485 & 5.153886 & 6.564285 & 6.871066 & 7.3881 & 7.5633 & 7.5896 \\
\hline 0.6 & 3.151485 & 5.153886 & 6.564285 & 6.871066 & 7.3881 & 7.5633 & 7.5896 \\
\hline 0.7 & 3.151485 & 5.153886 & 6.564285 & 6.871066 & 7.3881 & 7.5633 & 7.5896 \\
\hline 0.75 & 3.151485 & 5.153886 & 6.564285 & 6.871066 & 7.3881 & 7.5633 & 7.5896 \\
\hline 0.8 & 3.151485 & 5.153886 & 6.564285 & 6.871066 & 7.3881 & 7.5633 & 7.5896 \\
\hline 0.9 & 3.151485 & 5.153886 & 6.564285 & 6.871066 & 7.3881 & 7.5633 & 7.5896 \\
\hline 1 & 3.151485 & 5.153886 & 6.564285 & 6.871066 & 7.3881 & 7.5633 & 7.5896 \\
\hline
\end{tabular}

The normalized values were plotted in Figure 4-10 to Figure 4-11. Unlike $A_{1}$ and $B_{1}$, no clear trend exists for $C_{1}$ and $D_{1}$. Therefore, empirical equation cannot be formulated. However, the coefficients can be found for any specimen following the steps below:

1. Measure the specimen dimensions.

2. Assume a dynamic elastic modulus (Note: any combination of elastic constants would produce the same values for $C_{1}, D_{1}$ and $E_{1}$ ). 
3. Solve the Timoshenko frequency equation and determine the values of $\gamma_{1}$ and $\gamma_{2}$ for different Poisson's ratio (preferable in intervals of 0.05 ).

4. Calculate $\chi_{b}$ and plot it versus its respective Poisson's ratio.

5. Find the best-fit second order polynomial using $\chi_{b}$ at $v=0$ as the y-intercept.

6. The coefficients of the second-order polynomial are $C_{1}, D_{1}$ and $E_{1}$.

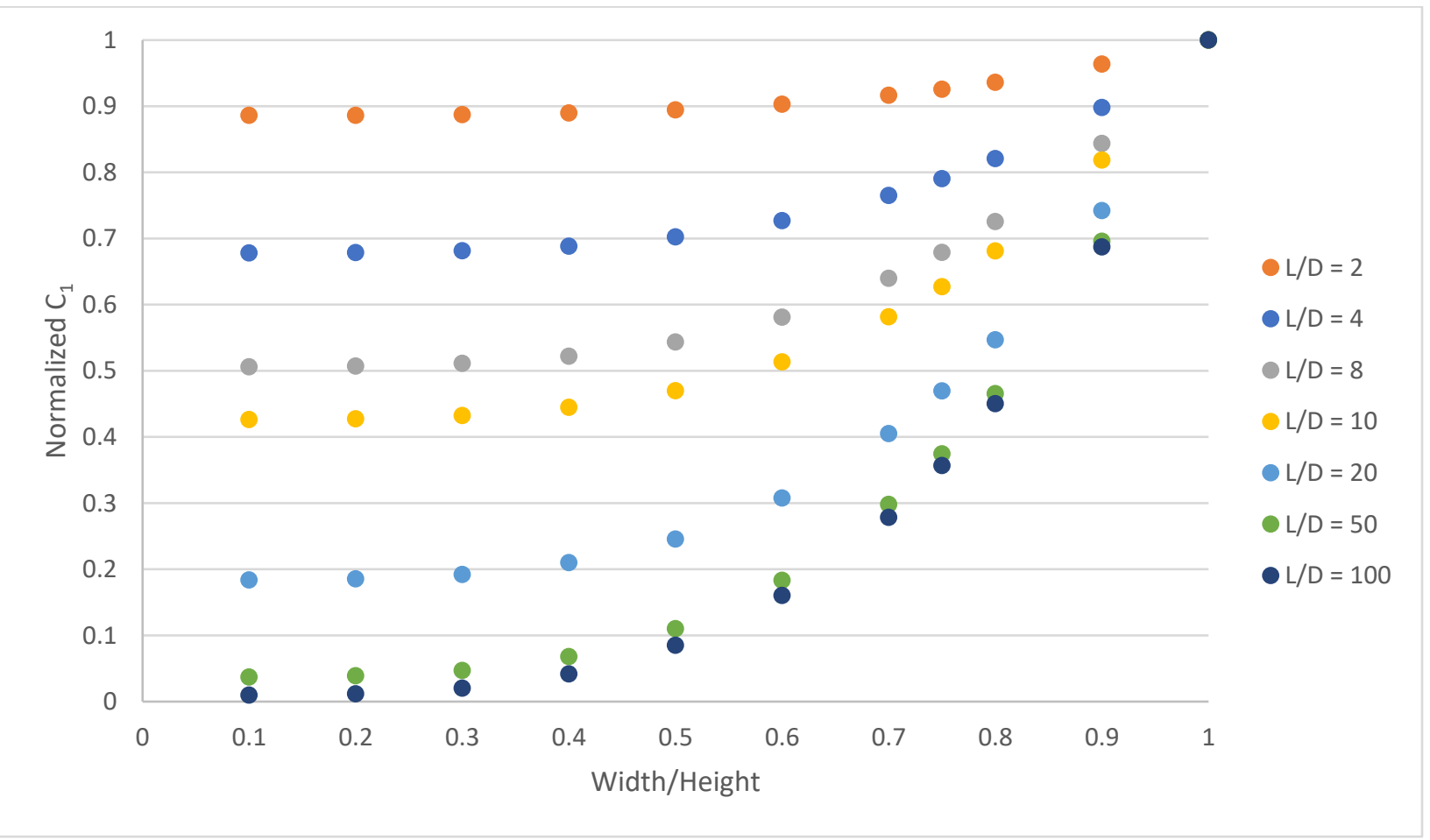

Figure 4-10. Normalized $C_{1}$ for rectangular prisms 


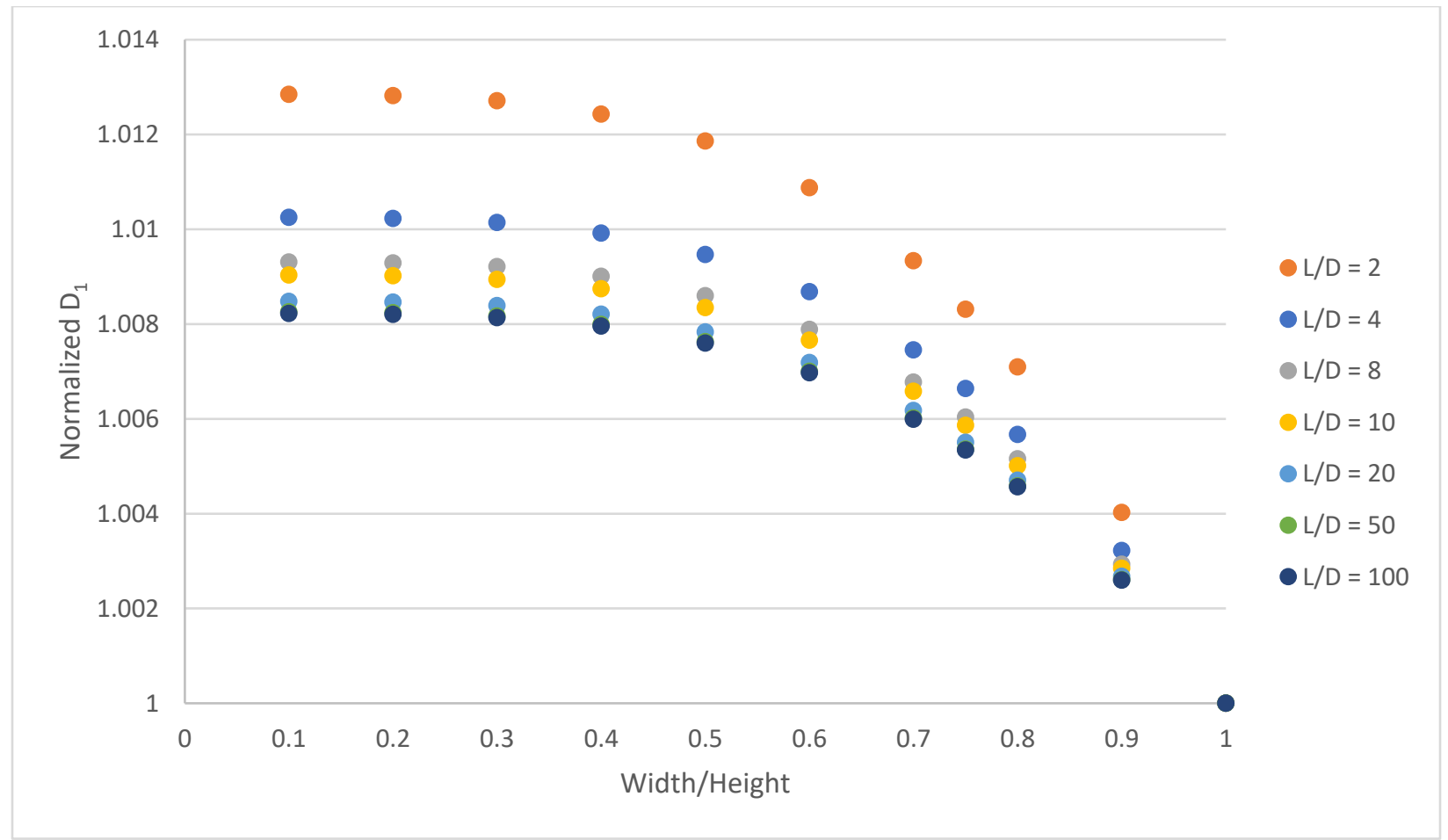

Figure 4-11. Normalized $D_{1}$ for rectangular prism

\subsection{Summary}

In this chapter empirical equations were presented for the coefficients $A_{1}, B_{1}, C_{1}, D_{1}$ and $E_{1}$. It was found that they were independent of the elastic modulus and density and therefore any set would produce the same values. Additionally, the equations presented were non-dimensionalized based on the width/height, length/height and length/diameter ratios. Therefore, the coefficient could be found for any rectangular or circular Timoshenko beam. However, for the rectangular prism empirical equations for $C_{1}, D_{1}$ and $E_{1}$ could not be found. Nevertheless, these coefficients can be determined based solely from the dimensions of the rectangular prism before conducting the experimental tests. It was found that the empirical equations could be used to verify the bending and torsional modes of a steel beam with a maximum 
difference of $0.36 \%$. Two separate methods were proposed, Method 1 uses $\chi_{t}$ while Method 2 employs $\chi_{b}$. First, the dimensions and mass of the specimen must be measured. Next, the required coefficients should be determined based on the chosen method. Then, using the measured resonance frequencies, the Poisson's ratio and the elastic modulus can be calculated. 


\section{Chapter 5 Experiments}

\subsection{Introduction}

The methods presented in Chapter 3 were used to measure the elastic modulus and Poisson's ratio of three rectangular prisms and rods. In this chapter the experimental setup will be explained in detail. First, an overview of the testing will be given followed by an explanation of the experimental data. This chapter also discusses the results of the experimental program.

\subsection{Experimental Program}

Three concrete mix designs used to produce the prism specimens for the experiments can be found in Table 5-1. The measured air content and slump can be found in

Table 5-2. The concrete specimens were moisture-cured in a $23{ }^{\circ} \mathrm{C}$ water tank concurrently to ensure equivalent maturity of the samples. The size of the concrete prism specimen was $75 \mathrm{~mm} \mathrm{x}$ $100 \mathrm{~mm}$ x $400 \mathrm{~mm}$. Three concrete prism specimens were cast for each mix design.

Table 5-1. Mix designs

\begin{tabular}{cccc}
\hline & \multicolumn{3}{c}{ Unit Weight $\left(\mathrm{kg} \mathrm{m}^{-3}\right)$} \\
\cline { 2 - 4 } Material & $50 \%$ Slag & $30 \%$ Fly Ash & OPC \\
\hline Cement & 151 & 202 & 335 \\
Slag & 151 & - & - \\
Fly Ash & - & 100 & - \\
Sand & 809 & 807 & 845 \\
\#57 Aggregate & 1065 & - & 969 \\
\#67 Aggregate & - & 1056 & - \\
Water & 128 & 128 & 139 \\
W/Cem Ratio & 0.42 & 0.42 & 0.42 \\
\hline
\end{tabular}


Table 5-2. Fresh properties for concrete batches

\begin{tabular}{cccc}
\hline Concrete Type & Air Content $(\%)$ & Slump $(\mathrm{mm})$ & Density $\left(\mathrm{kg} \mathrm{m}^{-3}\right)$ \\
\hline 50\% Slag & $4.3 \%$ & 170 & 2370 \\
$30 \%$ Fly ash & $7.6 \%$ & 130 & 2453 \\
OPC & $11.0 \%$ & 210 & 2433 \\
\hline
\end{tabular}

The dynamic modulus of elasticity was measured using the impact resonance frequency test. Figure 5-1 shows the instrument used in the experiment. The supports were placed at the nodal locations to allow free vibration in the fundamental transverse mode with free-free boundary condition. The accelerometer was attached to the specimen centered at $40 \mathrm{~mm}$ from the edge of the specimen using a hot glue adhesive and the impact point was located at the center of the top face of the prism. For each test, the acceleration time history was plotted on a LabView waveform analyzer. Using fast Fourier transform (FFT) the time domain was converted to the frequency domain.

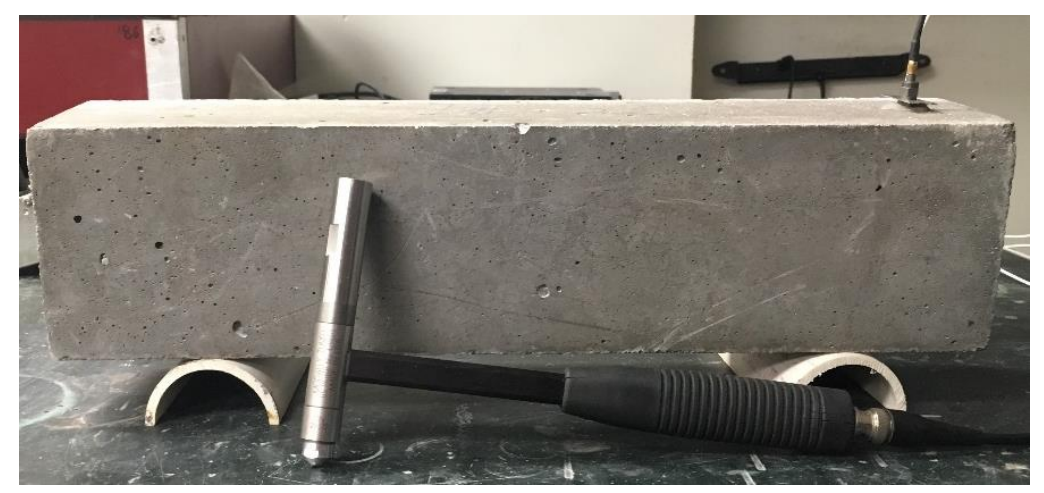

Figure 5-1. Impact hammer, accelerometer, and specimen

The torsional frequency was also tested on the concrete prisms. The support was placed at the center of the specimen which corresponds to the nodal point of the specimen. Similar to the 
transverse frequency testing the accelerometer was place with hot glue adhesive $15 \mathrm{~mm}$ from the top edge on the side surface as shown in Figure 5-2.

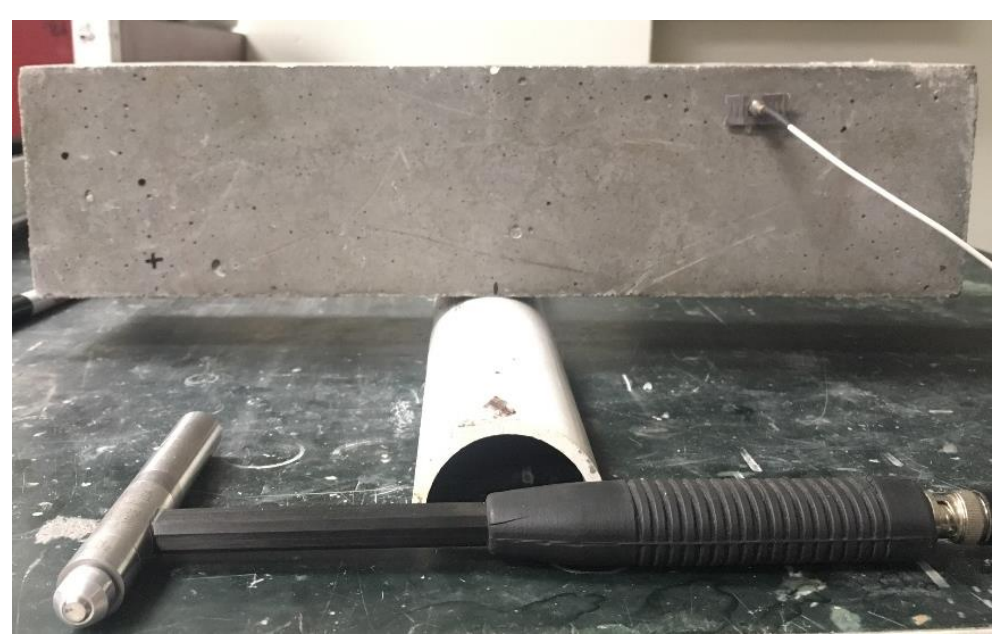

Figure 5-2. Typical setup of torsional mode testing

An aluminum, steel and concrete rod with different length/diameter ratio were experimentally tested to validate the proposed methods. The density and specimen dimensions can be found in Table 5-3.

Table 5-3. Material properties of rods.

\begin{tabular}{cccc}
\hline \multirow{2}{*}{ Material } & \multicolumn{3}{c}{ Properties } \\
\cline { 2 - 4 } & Diameter $(\mathbf{m m})$ & Length $(\mathbf{m m})$ & Density $\left(\mathbf{k g ~ m}^{\mathbf{3}}\right)$ \\
\hline Aluminum & 63.50 & 736.60 & 2780.56 \\
Steel & 46.83 & 279.4 & 8143.13 \\
Concrete & 99.63 & 622.30 & 2288.75 \\
\hline
\end{tabular}

The impact resonance frequency method was used to measure the fundamental transverse and torsional modes. The rods were suspended with soft flexible rubber tubing placed at 
approximately $0.15 \mathrm{~L}$ to allow free vibration in the fundamental transverse and torsional mode as shown in Figure 5-3. The accelerometer was attached to the specimen centered at $0.55 \mathrm{~L}$ from the edge of the specimen using a hot glue adhesive. The torsional frequency was also tested for each rod. The supports were kept at the same location as the transverse mode experiment. The accelerometer was placed with hot glue adhesive on a rigid metal tab which was located $0.223 \mathrm{~L}$ from the edge of the specimen. A tangential impact was made using another metal tab located $0.13 L$ from the other edge. A schematic of the torsional mode testing can be found in ASTM C215. For each test, the acceleration time history was plotted on a LabView waveform analyzer. Using fast Fourier transform (FFT) the time domain was converted to the frequency domain.

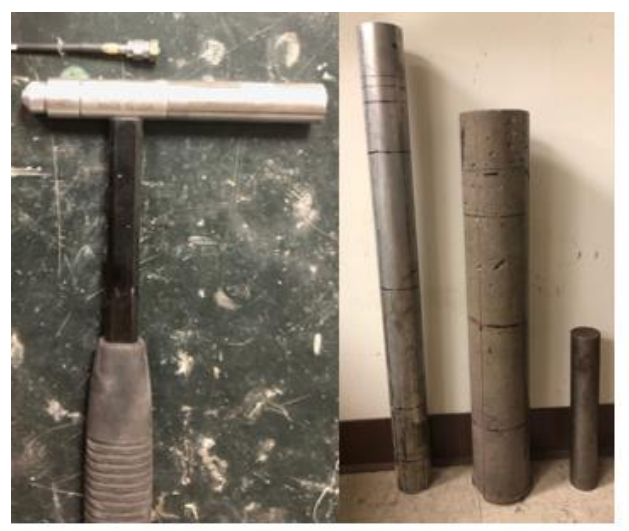

(a)

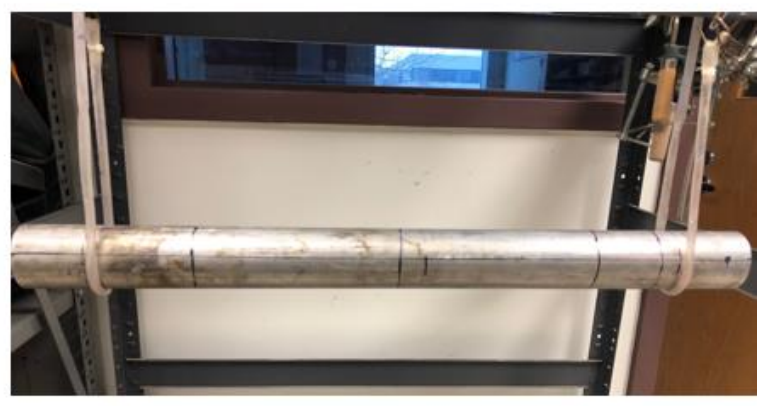

(b)

Figure 5-3. Picture of experiment (a) Impact hammer, accelerometer, and specimens (b) Experimental set-up.

\subsection{Rectangular Prism}

Typical acceleration time histories for the impact and response before and after performing the FFT are shown in Figure 5-4 and Figure 5-5. The excitation frequency range for the transverse and torsional impact is approximately $4,500 \mathrm{~Hz}$. To find the peak frequency, the frequency 
response function, which is the ratio between the output response and the input excitation force in the frequency domain, was calculated (Chen and Kiriakidis 2000). An example of the peak amplitude is shown in Figure 5-6. As the concrete matures the resonance frequency shifts towards the right due to its gain in stiffness; the specimens shown below were tested at an age of about 12 months. Based on Figure 5-6, the 50\% slag mix achieves a higher stiffness than both the OPC and fly ash mix designs.

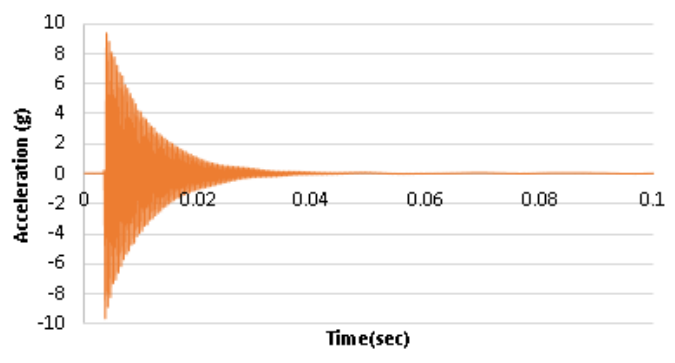

(a)

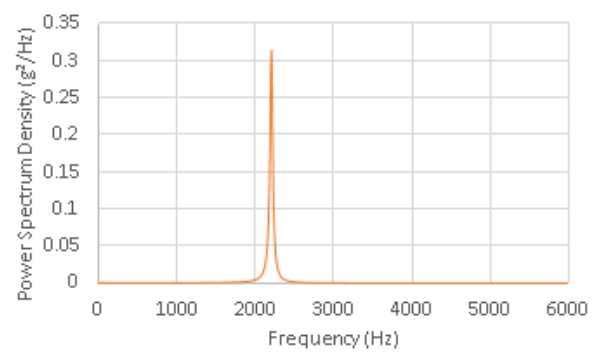

(b)

Figure 5-4. (a) Typical acceleration time history and (b) Typical response power spectrum (transverse mode)

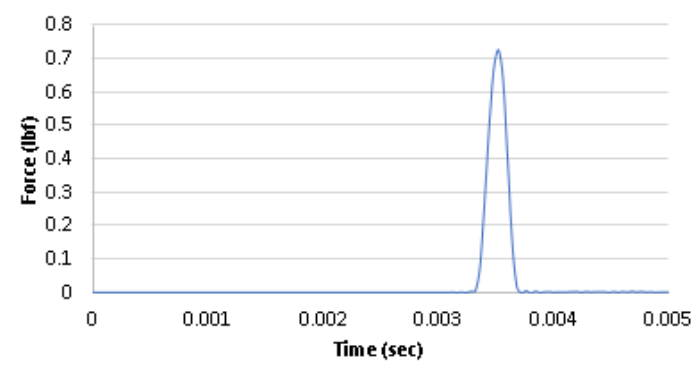

(a)

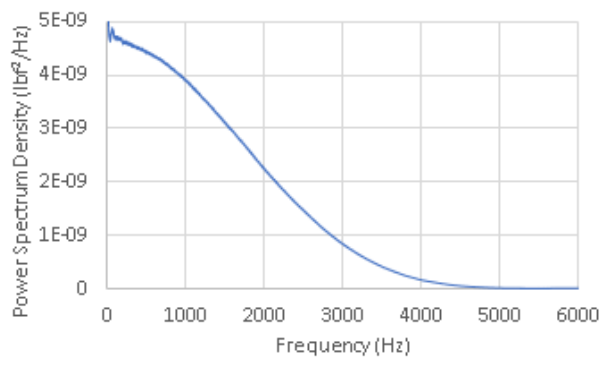

(b)

Figure 5-5. (a) Typical impact loading time history and (b) Typical impact power spectrum (transverse mode) 


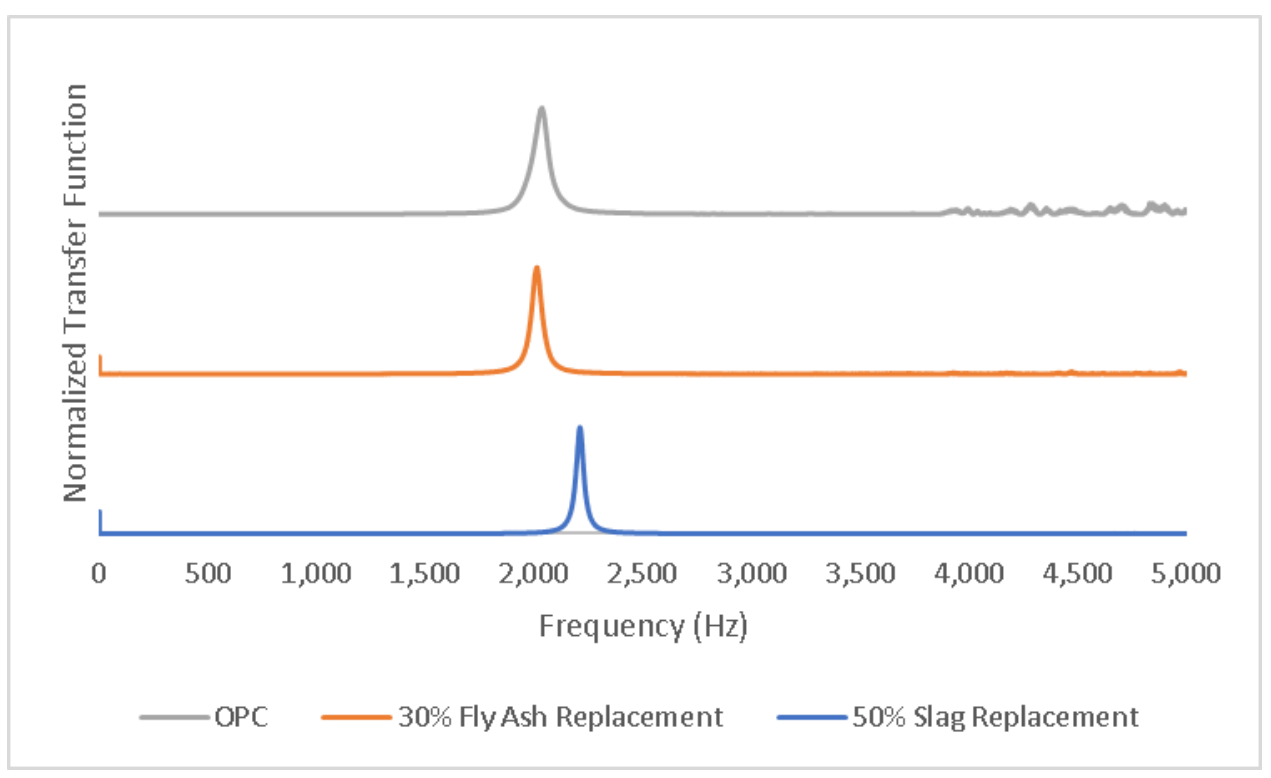

Figure 5-6. Example of amplitude vs. frequency (transverse mode)

Similarly, Figure 5-7, Figure 5-8 and Figure 5-9, present the typical acceleration time histories and the frequency response function for the torsional mode. A clear peak can be seen in all the specimens. Likewise, the $50 \%$ slag replacement mix shows a higher torsional frequency than the two other mix designs.

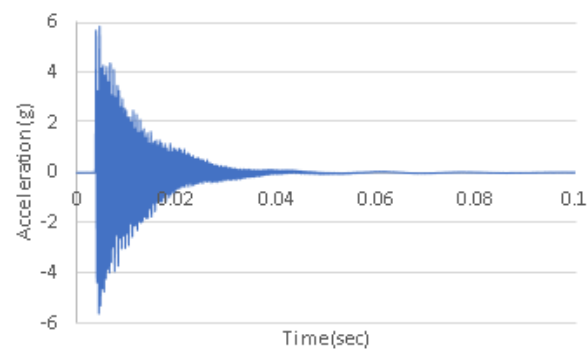

(a)

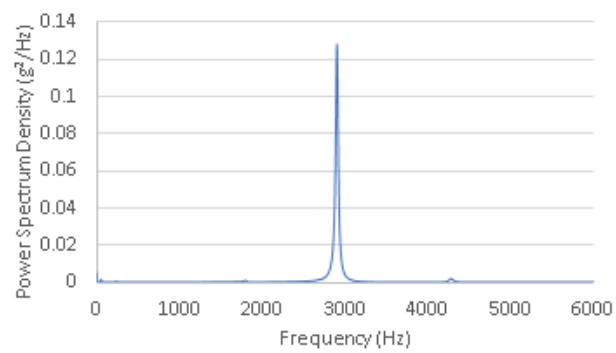

(b)

Figure 5-7. (a) Typical acceleration time history and (b) Typical response power spectrum density (torsional mode) 


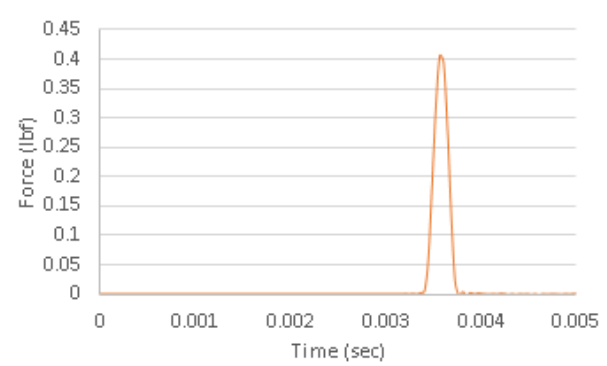

(a)

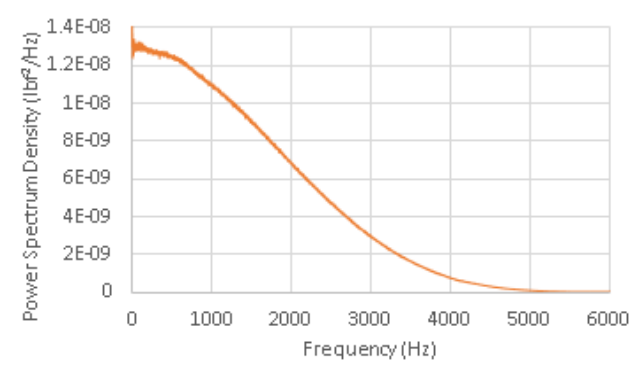

(b)

Figure 5-8. (a) Typical impact loading time history and (b) Typical impact power spectrum (torsional mode)

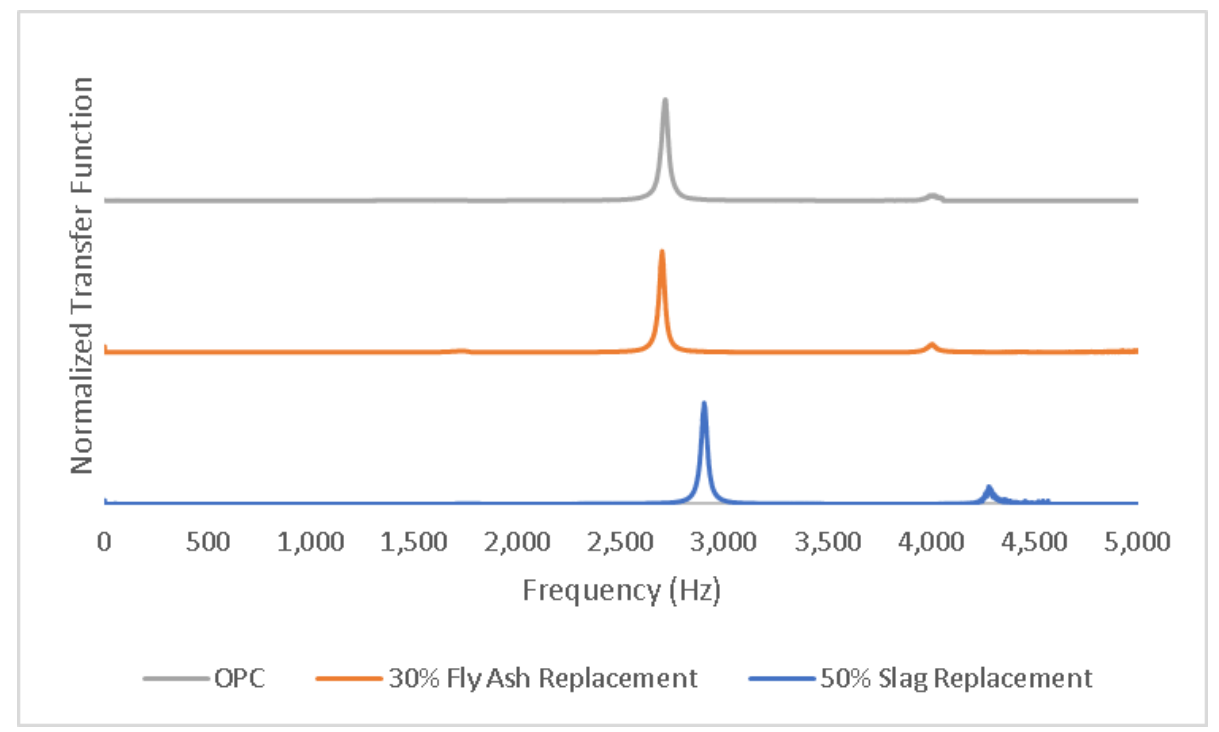

Figure 5-9. Example of amplitude vs. frequency (torsional mode)

Table 5-4 presents the average measured frequencies for the fundamental transverse and torsional frequencies of three typical specimens. The average value was determined from at least four tests. The sampling frequency for both impact force and acceleration response was $25.6 \mathrm{kHz}$, and the resolution of the measured frequencies was $0.25 \mathrm{~Hz}$. Due to the placement of the 
accelerometer, the second bending mode was not measured. Therefore, only Method 1 could be used on the rectangular prism.

The values given for $A_{1}$ and $B_{1}$ can be obtained for the prism specimen with a width/height ratio of 0.75 and a length/height ratio of 4 . In this case for a $75 \mathrm{~mm}$ x $100 \mathrm{~mm}$ x $400 \mathrm{~mm}$ prism specimen, the value of $A_{1}$ and $B_{1}$ are 0.312251 and 4.07392, respectively. Using Eq. (22), the Poisson's ratio for the three different mix designs was calculated and shown in Table 5-4. The calculated values for the dynamic elastic modulus using Eq. (23), are also shown in Table 5-4. As expected, the $50 \%$ slag replacement mix design had the largest elastic modulus. Since the measured natural frequencies had a resolution of $0.25 \mathrm{~Hz}$; the resolution of the calculated Poisson's ratio and the elastic modulus are approximately 0.0005 and $1.5 \mathrm{MPa}$.

Table 5-4.Calculated properties of three different mix designs

\begin{tabular}{ccccccccc}
\hline \multirow{3}{*}{ Mix Design } & Transverse & Torsional & \multicolumn{2}{c}{$v$} & \multicolumn{2}{c}{ Shape Factor $(k)$} & \multicolumn{2}{c}{$E(\mathrm{MPa})$} \\
\cline { 4 - 8 } & $\begin{array}{c}\text { Frequency } \\
(\mathrm{Hz})\end{array}$ & $\begin{array}{c}\text { Frequency } \\
(\mathrm{Hz})\end{array}$ & $\begin{array}{c}\text { Theoretical } \\
\text { Method }\end{array}$ & $\begin{array}{c}\text { ASTM } \\
\text { C215 }\end{array}$ & $\begin{array}{c}\text { Theoretical } \\
\text { Method }\end{array}$ & $\begin{array}{c}\text { ASTM } \\
\text { C215 }\end{array}$ & $\begin{array}{c}\text { Theoretical } \\
\text { Method }\end{array}$ & $\begin{array}{c}\text { ASTM } \\
\text { C215 }\end{array}$ \\
\hline 50\% Slag & $2,211.69 \pm 0.43$ & $2,903.59 \pm 0.71$ & 0.2000 & 0.2033 & 0.8581 & 0.889 & 42,150 & 42,267 \\
30\% Fly Ash & $2,012.51 \pm 0.33$ & $2,699.67 \pm 0.82$ & 0.1445 & 0.1460 & 0.8518 & 0.889 & 34,468 & 34,513 \\
OPC & $2,038.40 \pm 1.07$ & $2,714.89 \pm 0.94$ & 0.1627 & 0.1645 & 0.8539 & 0.889 & 34,486 & 34,541
\end{tabular}

\subsection{Rods}

Typical acceleration time histories for the impact and response before and after performing the FFT are shown in Figure 5-10 and Figure 5-11. The excitation frequency range for the transverse and torsional impact is approximately 5,000 Hz. To find the peak frequency, the frequency response function, which is the ratio between the output response and the input excitation force in 
the frequency domain, was calculated (Chen Hung-Liang "Roger" and Kiriakidis Alejandro C. 2000). Four peaks can be seen in the output response; these peaks correspond to the first four fundamental bending modes. In this study, only the $1^{\text {st }}$ and $2^{\text {nd }}$ bending mode were analyzed however the $3^{\text {rd }}$ and $4^{\text {th }}$ bending modes could be used as verification of the measured elastic constants.

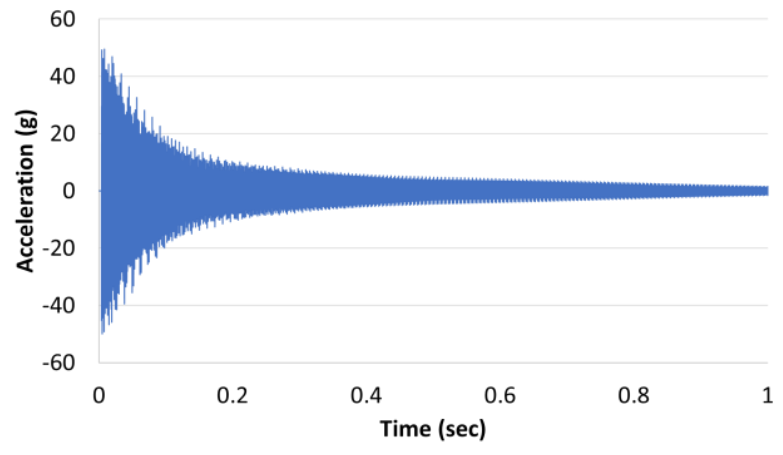

(a)

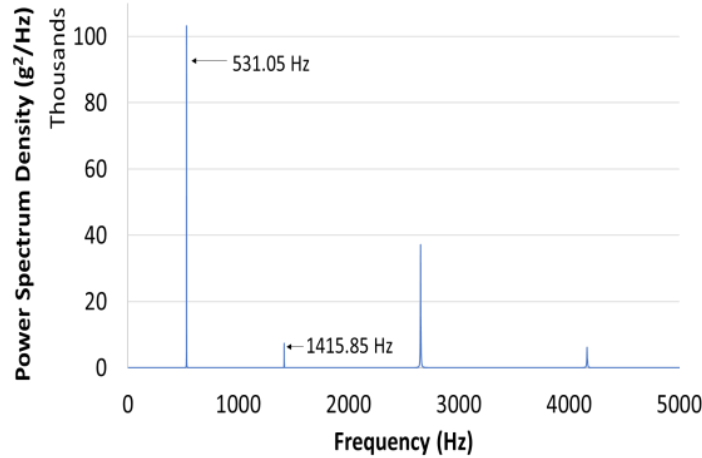

(b)

Figure 5-10. (a) Typical acceleration time history and (b) Typical response power spectrum (Transverse Mode).

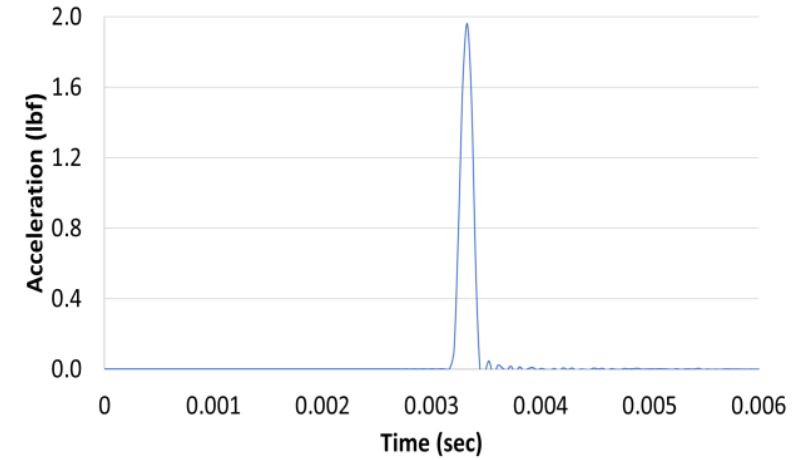

(a)

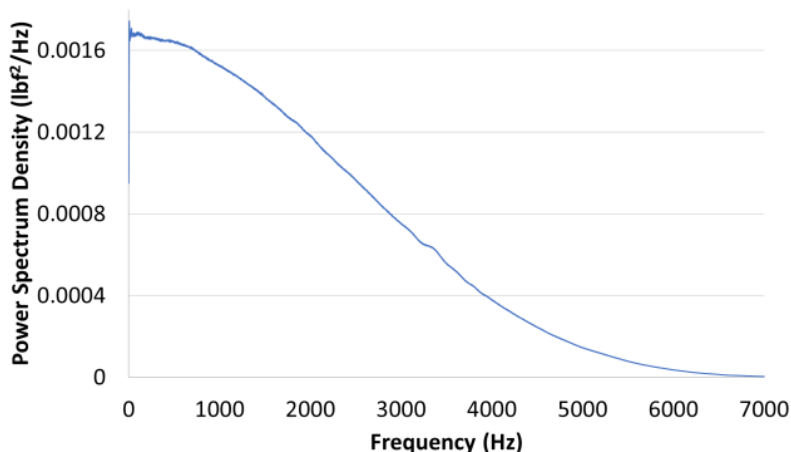

(b)

Figure 5-11. (a) Typical impact loading time history and (b) Typical impact power spectrum (Transverse Mode). 
Similarly, Figure 5-12 and Figure 5-13, present the typical acceleration time histories and the frequency response function for the torsional mode. A clear peak can be seen in all the specimens

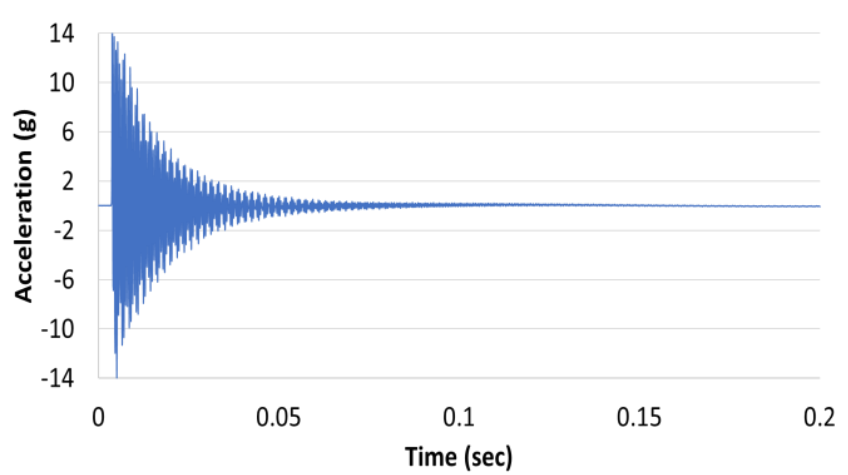

(a)

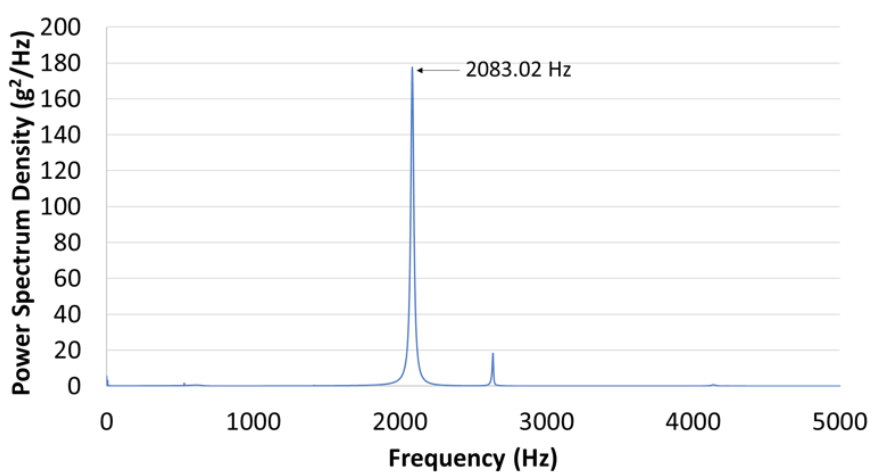

(b)

Figure 5-12. (a) Typical acceleration time history and (b) Typical response power spectrum density (Torsional Mode).

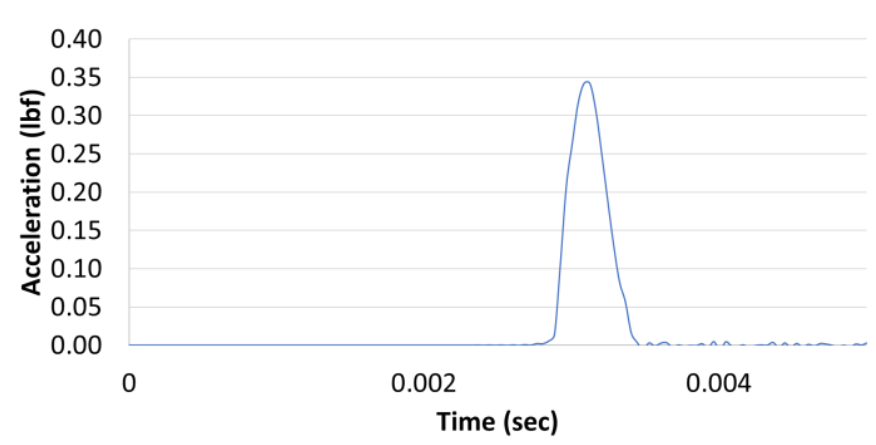

(a)

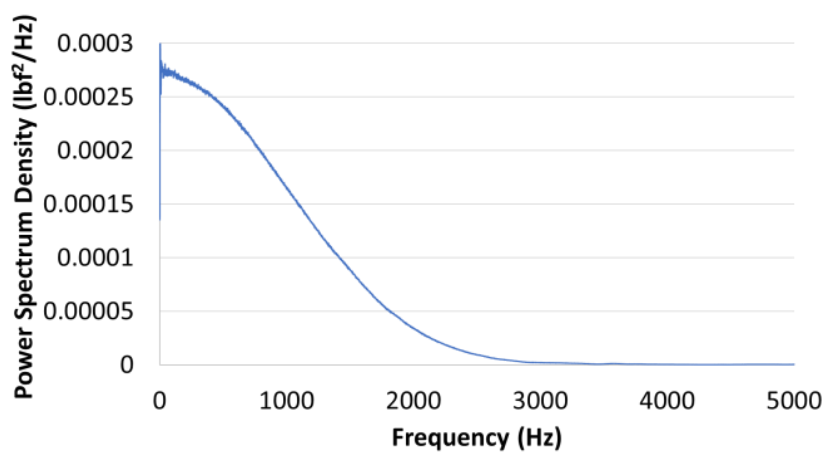

(b)

Figure 5-13. (a) Typical impact loading time history and (b) Typical impact power spectrum (Torsional Mode). 
Table 5-5 presents the average measured frequencies for the fundamental transverse and torsional frequencies of the three rods. The average value was determined from at least four tests. The values for $A_{1}, B_{1}, C_{1} D_{1}$ and $E_{1}$ can be obtained for each rod specimen using their respective $L / D$ ratio. Using Eq. (22) and Eq. (27), the Poisson's ratio for the three rods was calculated and shown in Table 5-5. The calculated values for the dynamic elastic modulus using Eq. (23) and Eq. (28), are also shown in Table 5-5. Table 5-5 shows a comparison between Method 1 and Method 2. Method 1 uses $\chi_{t}$ to calculate Poisson's ratio and elastic modulus. As expected, Method 2, which uses the $1^{\text {st }}$ and $2^{\text {nd }}$ bending modes, produces more reasonable elastic constants. This is mainly due to the inaccuracy of the experimental torsional mode frequency. Note, the largest difference occurs in the Poisson's ratio while the elastic modulus for both methods are almost identical.

Table 5-5. Calculated properties of an aluminum, steel and concrete rod.

\begin{tabular}{|c|c|c|c|c|c|c|c|}
\hline \multirow[b]{2}{*}{ Rod } & \multicolumn{2}{|c|}{ Transverse Frequency } & \multirow{2}{*}{$\begin{array}{c}\text { Torsional } \\
\text { Frequency } \\
(\mathrm{Hz})\end{array}$} & \multicolumn{2}{|c|}{$v$} & \multicolumn{2}{|c|}{ E (GPa) } \\
\hline & $1^{\text {st }}$ & $2^{\text {nd }}$ & & Method 1 & Method 2 & Method 1 & Method 2 \\
\hline Aluminum & $531.05 \pm 0.03$ & $1415.85 \pm 0.07$ & $2,083.02 \pm 0.45$ & 0.434 & 0.364 & 75.12 & 75.08 \\
\hline Steel & $2589.83 \pm 0.33$ & $6460.95 \pm 0.43$ & $5686.97 \pm 0.87$ & 0.332 & 0.300 & 219.10 & 218.91 \\
\hline Concrete & $847.02 \pm 0.20$ & $2130.61 \pm 0.43$ & $1972.06 \pm 0.77$ & 0.283 & 0.241 & 35.38 & 35.35 \\
\hline
\end{tabular}




\section{Chapter 6 Discussion and Conclusion}

\subsection{Introduction}

In this chapter, the results from the experimental program are discussed in depth. A comparison between ASTM C215 and Method 1 for the rectangular prism is made. Additionally, a sensitive analysis is conducted for Method 1 and Method 2 for the rod specimens. Finally, in the last section of the chapter future work is recommended.

\subsection{Discussion}

The frequency ratio between the $1^{\text {st }}$ torsional mode and the $1^{\text {st }}$ bending mode, $\chi_{t}$, was found to be linearly proportional to the Poisson's ratio with a slope, $A_{1}$, and a y-intercept, $B_{1}$, whereas the frequency ratio between the first two bending modes, $\chi_{b}$, was slightly parabolic with coefficients $C_{1}, D_{1}$, and $E_{1}$. It was found that the constants $A_{1}, B_{1}, C_{1}, D_{1}$, and $E_{1}$ depend only on the dimensions of the specimen and can be tabulated for different specimen sizes. Values for $A_{1}$, $B_{1}, C_{1}, D_{1}$, and $E_{1}$ at different length/diameter ratios were found, allowing the use for any rod dimensions. As the length/diameter ratio increased, the value of $A_{1}$ could be ignored and $\chi_{t}$ approached to a constant. In other words, $\chi_{t}$ is independent of Poisson's ratio at very large length/diameter ratios. Likewise, as the length/diameter increases, the values of $C_{1}$ and $D_{1}$ approach to zero, and $\chi_{b}$ approaches a constant value of 7.598. Equations for the elastic modulus, $E$, and Poisson's ratio, $v$, were proposed in this paper using the tabulated values of $A_{1}, B_{1}, C_{1}, D_{1}$, and $E_{1}$, allowing for a quick calculation of both $E$ and $v$. The proposed methods do not require any iterations to solve for the material constants. Results show that, using the equations 
proposed in this study, the Young's modulus and Poisson's ratio of a rod can be determined from the measured frequency ratio quickly and efficiently.

\subsubsection{Comparison Between ASTM and Exact Solution}

Through an iterative process the elastic modulus and Poisson's ratio can be calculated using ASTM C215. Iterations are necessary because the correction factor found in ASTM C215, T, must be found using an assumed Poisson's ratio. After which, Poisson's ratio can be calculated using the relationship between the elastic modulus and shear modulus. Both the elastic modulus and shear modulus can be calculated using the experimental resonance frequencies. The calculated Poisson's ratio can then be compared to the assumed value used to find the correction factor, $T$. Subsequently, $T$ is recalculated using the calculated Poisson's ratio until the calculated and assumed values for Poisson's ratio converge. Typically, convergence is achieved after five iterations. Following the ASTM process, the elastic modulus and Poisson's ratio were calculated for the three different mix designs and the results are shown in Table 5-4. Table 5-4 shows the comparison between the ASTM method results and the elastic modulus and Poisson's ratio obtained using the equations proposed by this paper. Both methods produce similar values, however, ASTM C215 method requires iterations and is based on an assumed constant shape factor, $k^{\prime}=8 / 9$. In fact, $k^{\prime}$ as shown in Eq. (6) and Eq. (7) is not a constant, and in the frequency equation $k^{\prime}$ is needed to calculate the roots. The shape factor for the different mix designs is also shown in Table 5-4. There is a slight variation for the shape factor since the mix designs have different Poisson's ratio. 


\subsubsection{Sensitivity Analysis}

In this study, the diameter and length of the specimens were measured with a resolution of $0.01 \mathrm{~mm}$, while the mass had a resolution of $0.01 \mathrm{~kg}$. A sensitivity analysis of the proposed methods was conducted using the experimental resolution. The experimental frequencies were measured with a resolution of $0.25 \mathrm{~Hz}$, which was achieved using a signal processing technique. It was found that Poisson's ratio and the elastic modulus had a maximum deviation of $0.3 \pm 0.001$ and $218.91 \pm 0.2 \mathrm{GPa}$, respectively, when changing the diameter or length by $0.01 \mathrm{~mm}$. Therefore, it is recommended to at least have a resolution of $0.1 \mathrm{~mm}$ in order to achieve an accuracy of Poisson's ratio with \pm 0.01 deviation. It was also found that a mass change of $0.01 \mathrm{~kg}$ can influence the elastic modulus by $\pm 0.5 \mathrm{GPa}$. Furthermore, if only a $0.25 \mathrm{~Hz}$ frequency resolution is obtainable, the estimated Poisson's ratio can have a large deviation of \pm 0.05 when a specimen has a large $L / D$ like the aluminum specimen $(L / D=11.6)$. This is because, as shown in Figure 3-7 and Table 3-5, Poisson's ratio is not sensitive to the change of the bending frequency ratio $\chi_{b}$ when $L / D$ becomes large. During the experiment, the concrete and steel rods both showed high accuracy in the measurement of Poisson's ratio using the bending modes as displayed in Table 6-1. However, since the aluminum rod has an $L / D=11.6$, a frequency resolution of $\pm 0.05 \mathrm{~Hz}$ was used to reduce the Poisson's ratio deviation to \pm 0.009 . For an accurate measurement of the Poisson's ratio, it is recommended that an $L / D \cong 6$ be used when using $\chi_{\boldsymbol{b}}$.

Table 6-1.Sensitivity analysis of the aluminum, steel, and concrete specimens.

\begin{tabular}{cccccccc}
\hline \multirow{2}{*}{$\begin{array}{l}\text { Measured } \\
\text { Properties }\end{array}$} & \multirow{2}{*}{ Method } & \multicolumn{2}{c}{ Aluminum } & \multicolumn{2}{c}{ Steel } & \multicolumn{2}{c}{ Concrete } \\
\cline { 2 - 9 } & & $E \mathbf{( G P a )}$ & $\boldsymbol{V}$ & $\boldsymbol{E}(\mathrm{GPa})$ & $\boldsymbol{v}$ & $\boldsymbol{E} \mathbf{( G P a )}$ & $\boldsymbol{v}$ \\
\hline Mass & 1 & $75.12 \pm 0.1$ & - & $219.10 \pm 0.5$ & - & $35.38 \pm 0.03$ & - \\
$( \pm 0.01 \mathrm{~kg})$ & 2 & $75.08 \pm 0.1$ & - & $218.91 \pm 0.5$ & - & $35.35 \pm 0.03$ & - \\
\hline$L$ & 1 & $75.12 \pm 0.003$ & $0.434 \pm 0.00004$ & $219.10 \pm 0.02$ & $0.332 \pm 0.00009$ & $35.38 \pm 0.002$ & $0.283 \pm 0.00004$ \\
$( \pm 0.01 \mathrm{~mm})$ & 2 & $75.08 \pm 0.003$ & $0.364 \pm 0.00008$ & $218.91 \pm 0.02$ & $0.300 \pm 0.0002$ & $35.35 \pm 0.002$ & $0.241 \pm 0.00009$ \\
\hline & 1 & $75.12 \pm 0.05$ & $0.434 \pm 0.0004$ & $219.10 \pm 0.2$ & $0.332 \pm 0.0005$ & $35.38 \pm 0.001$ & $0.283 \pm 0.0002$ \\
\hline
\end{tabular}




\begin{tabular}{cccccccc}
\hline $\begin{array}{c}D \\
( \pm 0.01 \mathrm{~mm})\end{array}$ & 2 & $75.08 \pm 0.05$ & $0.364 \pm 0.0009$ & $218.91 \pm 0.2$ & $0.300 \pm 0.001$ & $35.35 \pm 0.001$ & $0.241 \pm 0.0005$ \\
\hline$n_{1}$ & 1 & $75.12 \pm 0.07$ & $0.434 \pm 0.001$ & $219.10 \pm 0.04$ & $0.332 \pm 0.0003$ & $35.38 \pm 0.02$ & $0.283 \pm 0.0008$ \\
$( \pm 0.25 \mathrm{~Hz})$ & 2 & $75.08 \pm 0.1^{*}$ & $0.364 \pm 0.05 *$ & $218.91 \pm 0.06$ & $0.300 \pm 0.004$ & $35.35 \pm 0.03$ & $0.241 \pm 0.01$ \\
\hline$n_{2}$ & 1 & - & - & - & - & - & - \\
$( \pm 0.25 \mathrm{~Hz})$ & 2 & $75.08 \pm 0.01 * *$ & $0.364 \pm 0.02 * *$ & $218.91 \pm 0.008$ & $0.300 \pm 0.001$ & $35.35 \pm 0.004$ & $0.241 \pm 0.004$ \\
\hline$n^{\prime \prime}$ & 1 & $75.12 \pm 0.07$ & $0.434 \pm 0.001$ & $219.10 \pm 0.001$ & $0.332 \pm 0.0001$ & $35.38 \pm 0.0003$ & $0.283 \pm 0.0003$ \\
$( \pm 0.25 \mathrm{~Hz})$ & 2 & - & - & - & - & - & - \\
\hline$*$ For a frequency resolution of $\pm 0.05 \mathrm{~Hz}$ for $n 1, E=75.08 \pm 0.02 \mathrm{GPa}$ and $v=0.364 \pm 0.009$. &
\end{tabular}

\subsection{Conclusion}

This thesis presents a method to calculate the Poisson's ratio and dynamic elastic modulus using experimentally measured transverse and torsional modes. The method is based on the exact solution to the frequency equation for a Timoshenko beam. Finite element method using an ABAQUS program was shown to match with less than $0.15 \%$ with the exact solution for both the transverse and torsional mode. The frequency ratio, $\chi$, was found to be linearly proportional to the Poisson's ratio with a slope, $A_{1}$, and a y-intercept, $B_{1}$. It was found that the constants $A_{1}$ and $B_{1}$ depend only on the dimensions of the specimen and can be tabulated for different specimen sizes. Values for $A_{1}$ and $B_{1}$ at different width/height and length/height ratios were found allowing the use of different specimen geometries. As the length/height ratio increases, the value of $A_{1}$ could be ignored and $\chi$ approached a constant, and in other words, $\chi_{t}$ is independent from Poisson's ratio at very large length/height ratios. An equation for the elastic modulus, $E$, and Poisson's ratio, $v$, was proposed in this paper using the tabulated values of $A_{1}$ and $B_{1}$ allowing for a quick calculation of both $E$ and $v$. Unlike ASTM C215, the proposed method does not require any iterations to solve for the material constants. The proposed equations can be used to calculate the frequency ratio of rectangular prisms with different dimension sizes and was used to predict the measured bending frequencies from seventeen steel specimens with different length/height and width/height ratios. 
The results show the differences between the prediction and the measured bending frequencies of all the specimens are mostly within $0.1 \%$, with a maximum difference of $0.223 \%$.

The frequency ratio between the $1^{\text {st }}$ bending mode and the $1^{\text {st }}$ torsional mode or the frequency ratio between the $1^{\text {st }}$ bending mode and the $2^{\text {nd }}$ bending mode for any rod with a lengthto-diameter ratio of $L / D \geq 2$ can be directly estimated using the proposed equations. The proposed method does not require any iterations to solve for the material constants and can be used to calculate the elastic constants of rods with different dimension sizes. The proposed equations were used to verify the elastic constants of a steel rod with less than $0.36 \%$ error percentage, and the equations were also used to measure elastic constants of three rods with different material properties (aluminum, steel, and concrete) using simple impact vibration. It was found that the torsional mode is more difficult to excite and not as reliable as the bending modes, whereas a more accurate measurement can always be obtained from using the $1^{\text {st }}$ and $2^{\text {nd }}$ bending modes which were measured simultaneously.

\subsection{Future Work}

This study focused exclusively on the free-free vibration of rectangular prisms and rods. In some cases, it may not be possible to excite the free-free transverse and torsional modes. Therefore, to have a wider range of implementation other boundary conditions should be investigated. Similarly, other cross-section can be investigated however prisms and rods are the most common specimens. Although not stated explicitly, this method can be used to estimate the bending and torsional mode with given specimen dimensions and elastic constants. Therefore, it may be used to estimate the free-free vibration of reinforced concrete beams. However, more work should be done to verify its applicability. 


\section{REFERENCES}

Alfano, Marco, and Leonardo Pagnotta. 2007. "A Non-Destructive Technique for the Elastic Characterization of Thin Isotropic Plates.” NDT \& E International 40 (2): 112-20. https://doi.org/10.1016/j.ndteint.2006.10.002.

Augustyn, Elzbieta, and Marek Kozien. 2015. "Possibility of Existence of Torsional Vibrations of Beams in Low Frequency Range." Technical Transactions Mechanics. https://doi.org/10.4467/2353737XCT.15.170.4375.

Chavhan, P, and M Vyawahare. 2015. "Correlation of Static and Dynamic Modulus of Elasticity for Different SCC Mixes." International Journal on Recent and Innovation Trends in Computing and Communication.

Chen Hung-Liang "Roger," and Kiriakidis Alejandro C. 2000. "Stiffness Evaluation and Damage Detection of Ceramic Candle Filters." Journal of Engineering Mechanics 126 (3): 30819. https://doi.org/10.1061/(ASCE)0733-9399(2000)126:3(308).

Chen, Hung-Liang (Roger), and Alejandro C. Kiriakidis. 2005. "Nondestructive Evaluation of Ceramic Candle Filter with Various Boundary Conditions." Journal of Nondestructive Evaluation 24 (2): 67-81. https://doi.org/10.1007/s10921-005-3483-z.

Cowper, G. R. 1966. "The Shear Coefficient in Timoshenko's Beam Theory." Journal of Applied Mechanics 33 (2): 335-40. https://doi.org/10.1115/1.3625046.

Gladwell, G.M.L., and D.K. Vijay. 1975. "Natural Frequencies of Free Finite-Length Circular Cylinders." Journal of Sound and Vibration 42 (3): 387-97. https://doi.org/10.1016/0022-460X(75)90252-7.

Goens E. 1931. "Uber Die Bestimmung Des Elastizitätsmoduls von Stäben Mit Hilfe von Biegungsschwingungen.” Annalen Der Physik 403 (6): 649.

Gucunski, N., N.R.C.T.R. Board, and S.S.H.R. Program. 2013. Nondestructive Testing to Identify Concrete Bridge Deck Deterioration. SHRP 2 Report. Transportation Research Board. https://books.google.com/books?id=yGWL7O705FwC.

Huang, T. C. 1961. "The Effect of Rotatory Inertia and of Shear Deformation on the Frequency and Normal Mode Equations of Uniform Beams With Simple End Conditions." Journal of Applied Mechanics 28 (4): 579-84. https://doi.org/10.1115/1.3641787.

Hutchinson, J. R. 2000. "Shear Coefficients for Timoshenko Beam Theory." Journal of Applied Mechanics 68 (1): 87-92. https://doi.org/10.1115/1.1349417.

John S. Popovics. 2008. "CRC \#43: A STUDY OF STATIC AND DYNAMIC MODULUS OF ELASTICITY OFCONCRETE." CRC, October.

Kolluru, S., J. Popovics, and S. Shah. 2000. "Determining Elastic Properties of Concrete Using Vibrational Resonance Frequencies of Standard Test Cylinders." Determining Elastic Properties of Concrete Using Vibrational Resonance Frequencies of Standard Test Cylinders.

Lee, Byung Jae, Seong-Hoon Kee, Taekeun Oh, and Yun-Yong Kim. 2015. "Effect of Cylinder Size on the Modulus of Elasticity and Compressive Strength of Concrete from Static and Dynamic Tests." Advances in Materials Science and Engineering 2015: 12. 2017. "Evaluating the Dynamic Elastic Modulus of Concrete Using Shear-Wave Velocity Measurements." Advances in Materials Science and Engineering 2017: 13. 
Logan, Trifone. 2017. "A Study of the Correlation between Static and Dynamic Modulus of Elasticity on Different Concrete Mixes." West Virginia University.

Lydon, F.D., and R.V. Balendran. 1986. "Some Observations on Elastic Properties of Plain Concrete." Cement and Concrete Research 16 (3): 314-24. https://doi.org/10.1016/00088846(86)90106-7.

Medina, R., and A. Bayón. 2010. "Elastic Constants of a Plate from Impact-Echo Resonance and Rayleigh Wave Velocity." Journal of Sound and Vibration 329 (11): 2114-26. https://doi.org/10.1016/j.jsv.2009.12.026.

Nieves, F. J., F. Gascón, and A. Bayón. 1998. "Estimation of the Elastic Constants of a Cylinder with a Length Equal to Its Diameter." The Journal of the Acoustical Society of America 104 (1): 176-80. https://doi.org/10.1121/1.423266.

Pickett, Gerald. 1945. Equations for Computing Elastic Constants from Flexural and Torsional Resonant Frequencies of Vibration of Prisms and Cylinders. Chicago: [Portland Cement Association].

Powers, T.C. 1938. "Measuring Young's Modulus of Elasticity by Means of Sonic Vibrations." American Society for Testing and Materials, no. Part III: 460.

Spinner, S., T. W. Reichard, and W. E. Tefft. 1960. "A Comparison of Experimental and Theoretical Relations between Young's Modulus and the Flexural and Longitudinal Resonance Frequencies of Uniform Bars." Journal of Research of the National Bureau of Standards Section A: Physics and Chemistry 64A (2): 147. https://doi.org/10.6028/jres.064A.014.

"Standard Test Method for Fundamental Transverse, Longitudinal, and Torsional Resonant Frequencies of Concrete Specimens." 2014. ASTM C215-14. West Conshohoken, Pa: ASTM International.

Timoshenko, S. 1937. Vibration Problems in Engineering. 2nd ed. Read Books.

Vet, Maarten. 1962. "Torsional Vibration of Beams Having Rectangular Cross Sections." The Journal of the Acoustical Society of America 34 (10): 1570-75. https://doi.org/10.1121/1.1909051.

Wang, Jin-Jun, Ta-Peng Chang, Bo Chen, and Helsin Wang. 2012. Determination of Poisson's Ratio of Solid Circular Rods by Impact-Echo Method. Vol. 331. https://doi.org/10.1016/j.jsv.2011.10.030.

Weiss, J. 2006. “Chapter 19: Elastic Properties, Creep, and Relaxation.” In Chapter 19: Elastic Properties, Creep, and Relaxation.

Y1ldırım, Hasan, and Ozkan Sengul. 2011. "Modulus of Elasticity of Substandard and Normal Concretes." Construction and Building Materials 25 (4): 1645-52. https://doi.org/10.1016/j.conbuildmat.2010.10.009.

Zhou, Yong, Jie Gao, Zhihui Sun, and Wenjun Qu. 2015. “A Fundamental Study on Compressive Strength, Static and Dynamic Elastic Moduli of Young Concrete." Construction and Building Materials 98 (Supplement C): 137-45. https://doi.org/10.1016/j.conbuildmat.2015.08.110. 


\section{VITA}

Guadalupe Leon was born in Martinsburg, WV on July 4, 1993. After graduating from Hedgesville high school in 2011, he continued his education at West Virginia University and obtained a degree in Civil and Environmental Engineering. Upon receiving a B.S. in Civil Engineering in the spring of 2015, he began graduate school at West Virginia University under the guidance of Dr. Roger Chen. In the fall of 2016, he was accepted into the Ph.D. program at West Virginia University. The following peer-reviewed articles were published from his Master's thesis.

Chen, H.-L.R.; Leon, G. Direct Determination of Dynamic Elastic Modulus and Poisson's Ratio of Rectangular Timoshenko Prisms. Journal of Engineering Mechanics 2019, 145(9), p. 04019071.

Leon, G.; Chen, H.-L.R. Direct Determination of Dynamic Elastic Modulus and Poisson's Ratio of Timoshenko Rods. Vibration 2019, 2, 157-173. 